\title{
Post Trauma
}

\section{: Memory as a Catalyst}

An inquiry into architectural drawing and [re]presentation; exploring decaying architectural ruins as memory-scapes.

A thesis by Ben Wade.

A 120 point thesis

submitted to the Victoria University of Wellington, in partial fulfillment of the requirements for the degree, Master of Architecture (Professional)

Victoria University of Wellington 


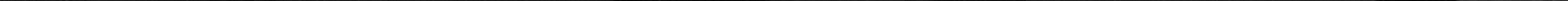




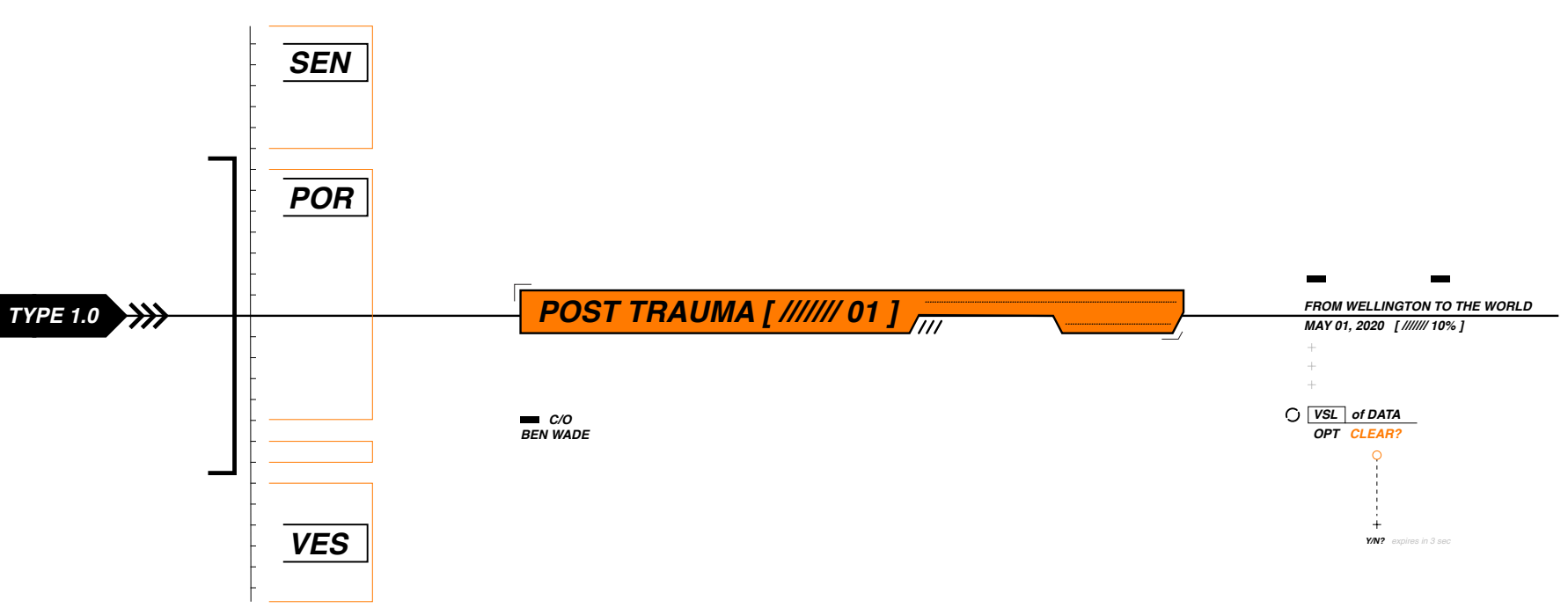

$\underset{\text { / pro-logue / }}{\text { prologue* }}$

a separate introductory section of a literary, or visual woun a separate introductory section of a literary, or visual work
from greek; prologos 


\section{Abstract}

"Buildings, landscapes and materials serve as poignant reminders of our personal and collective heritage and history. Sites become palimpsests upon which layers of memory are recorder through time... Buildings act as witnesses of the past" (Berger, 2013.

Upon visiting the Tory Channel this past summer, my reality was infused with imagination when stumbling upon the Perano Whaling station. An erased architectural artefact - a landscape experiencing scarring from human and environmental interaction. The catalyst for this thesis was born from this experience. Visiting the Station, there was an aura of historical relevance, and a scarring conversion to architectural ruins, but, my memory of such erasure lacked. The collective yea be consumed with restoring effaced artefacts like Peran be consumed with restoring effaced artefacts like Perano to ther former countless whales from the channel. This design-led thesis does not conform to such principals. Rather than ignoring or removing these scars, this thesis aims to reimagine them through a contemporary architectural premise that acts as a pedagogical premise for future generations to dwell.

Allegorical constructs explored through architecture can be witnessed as the despair and ruination of a loss; the anamnesis of Perano. Allegory will be integrated in this design-led research as a structural framework to investigate collective memories at Perano Whaling Station. This will collective memories at Perano Whaling Station. This will Progressive inquiry into the [re]interpretation of architectural Progressive inquiry into the [re]interpretation of architectur
drawing as a medium will expose speculative design outcomes to [re]imagine Perano - inviting a dizzying array of interpretations. This thesis proposes through an author's design-led investigation, how traumatic experiential memories, and [re]presentation of forgotten and scarred landscapes in New Zealand's robust history, can be enabled through speculative architectural interventions.
This thesis aims to precede a design-led approach interrogating the language of speculative drawing and representation as mediums to make an expression that renders and reflects upon traumatic memories. The process of research 'for' design and research 'through' design will be adopted. This process is defined as allowing for "selfscrutiny, done with caution and thoroughness, then, what is revealed and understood can be incrementally assembled into knowledge within the discipline" (Downton, 2013). This thesis proposes integration of theoretical arguments This thesis proposes integration of theoretical arguments
from Tim Edensor and Andreas Huyssen, which place ruins as investigative modes to create narratives exploring a process of on-going erasure. Mnemonic relationships are explored as a repository of scarred ruins, critiqued through the ambiguities and layers of working to make meaningful expressions.

This process aims to create composed architectural interventions as repositories of fragmentations found in the landscape - forced to engage conflicting narrative formats that represent erasure. This will engage and further formats that represent erasure. This will engage and further Virgil Abloh's 'Purist' and 'Tourist' constructs through an author's design-led thesis. This process expands on potential readings and misreadings of the work, but, invites reflections as an emotive process to enhance awareness of the site and it's traumatic history - furthering our understanding of the role [re]presentational drawings play on our interpretations of a traumatised landscape, explored through multifaceted speculative architectural investigations. 
As I have progressed through the past four years of study at the Wellington Faculty of Architecture and Design Innovation (Te Wāhanga Waihanga-Hoahoa), drawing and the search for existential meaning has become an intangible detail within the discourse. A fascination with drawing as a representation technique has always existed. Thus, exploring the creation of an architectural language to represent on-going erasure as a story-telling mechanism acts as a catalyst for this exploration. Embedded in soliloquy, the question was asked: exploration. Embedded in soliloquy, the question was asked become evocative memory repositories?

Visiting the Marlborough Sounds in the summer of 2020 spawned a collection of erased memories - I struggled to grasp the scarred landscape. Perano Whaling Station, settled in Fishing Bay (Whekenui), Tory Channel, exists as the site for this investigation. Originally carved into the cliffs with hand tools, machinery was later installed, being usefully occupied from 1911, processing its last whale on December 21st, 1964 (Grady, 1982, p.22) Images still crisp, still evocative, played Grady, 1982, p.22). Images: in my mind over summer - yet despite my dis traumatic happenings, this thesis was born.

Shards of light penetrated the rusted machinery and

structural ruins upon initial site immersion - 'scars aligned' The brisk sea-shore air slowly erodes the architecture as vapour escapes my mouth as I exhale. It was at this precise moment... An existential search for memories encapsulated within a scarred architectural context in desperate need for a new re-contextualised identity. My physiological state yearned to connect these physical (ruins) with the mental (memories) to thus inform these erased spaces as physical memories to which viewers, both 'Purists', as an entity that embodies all language paradigms, or 'Tourists', whom sample without attachments or restrictions, can reflect upon past traumas.

It was not until excavation into the history of these decaying scars that my introspect engaged in these collective memories. To reflect and converge on this erasure, it seemed essential to engage in the unknown. Relative narrative stories unock the potential imaginations as a means to inner work the speculative erasure as an expreans to inner work the speculative erasure as an expression. This thesis then does not set out to solve or reclaim architectur ruins, but, to use scarred erasure as material to speculat transformations as architectural interventions make an expression that unlocks memories suppressed by these scars.

An excerpt from Denis Diderot's 'Le Salonde 1767' encapsulated initial feelings of Perano; "If the site of a ruin seems perilous, I shudder. If I feel safe and secure there, I'm freer, more alone, more myself, closer to myself" (Diderot, 2011, p. 22).

[End of Preface] 
Acknowledgments

A 120 point thesis submitted to the school of Architecture and Design at Victoria University of Wellington, in partial fulfillment of the

requirements for the degree, Master of Architecture (Professional)

I would first of all like to thank my Supervisor, Daniele Abreu e Lima, for her unwavering guidance, relentless

determination and incredible engagement throughout my

hunt for exploring scarred landscapes. Your enthusiasm and support throughout has been immense, and I can not thank you enough.

To my parents, Stuart and Penny, thank you for being supportive through the tougher times, when it mattered most. You have been selfless the past five years of study, and words simply cannot thank you enough.

To my friends and flatmates who encouraged me to expose my creative outputs, thank you for your continual support and ability to ground me when necessary. At times I am sure this was not easy, but I thank you all.

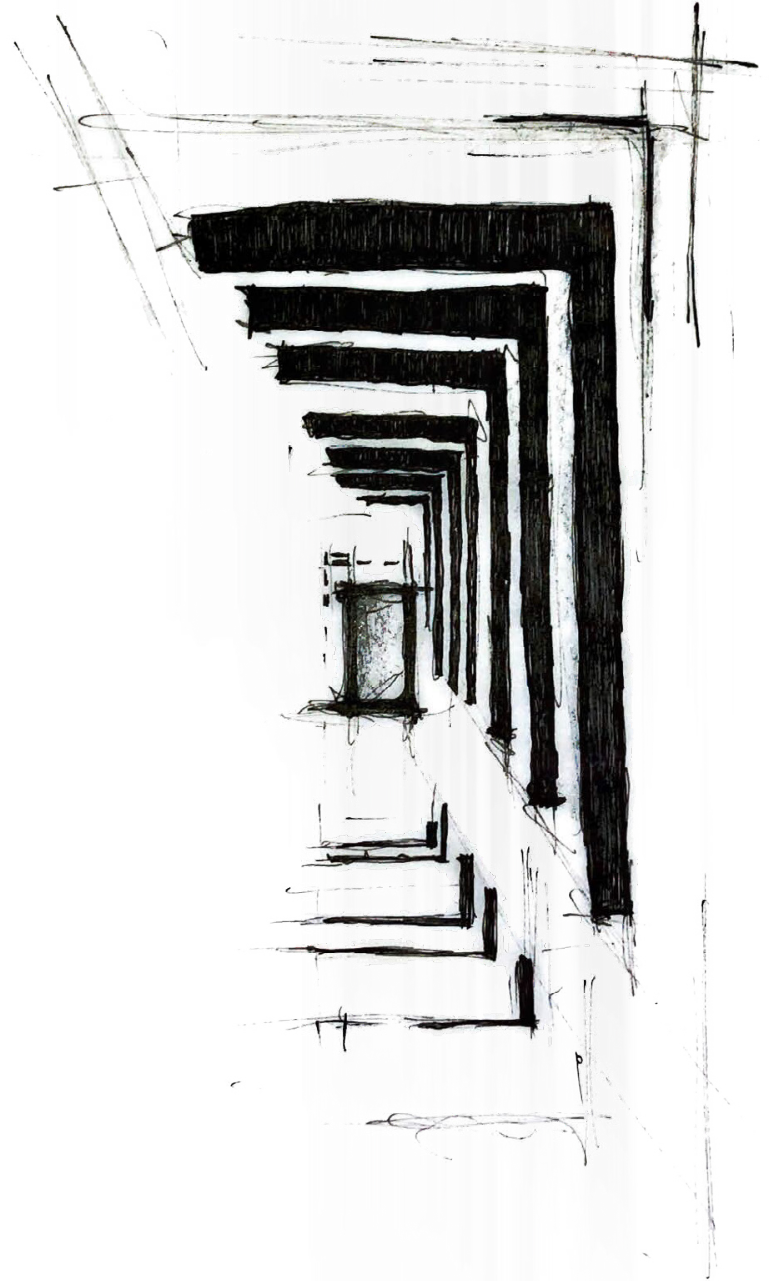

Figure 4: 'Into the Ruin', (2020), Sketch by Author 
At the cry of 'There she blows'

gangs of whalers took to the waters.

Whale oil, baleen, ambergris and bone were valuable,

but many men hunted whales for the thrill of the chase.

Whaling was dangerous - harpooned whales thrashed and rolled, damaging boats or pulling them under

$[\ldots]$

It was a dangerous game, there's no doubt about that..

But, very exciting on the other hand + 


\section{Post Trauma}

For me, as the author of this speculative investigation, it lies within

y own inner workings to treat these ruins and

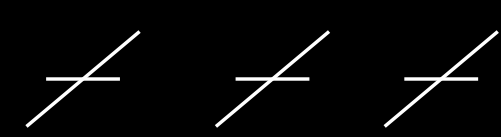




\section{Part One}

[ Allegory in Architecture: Validating a Method ]

Research Objective 1: to explore how fictional narrative can

incorporate storytelling to form a critical framework that invites

narrative based architectural interventions to [re]interpret

architectural drawing and [re]present an ongoing process of erasure.

an allegorical narrative usually intended to convey a moral

from greek; apologos 
Abstract $\quad \cdots \cdots$

Preface $\quad \ldots \ldots \ldots$ vii.

Part One: Trauma: [ Beginnings ] …_............ 18

A Forgotten Ruin

Forging a Ruinenlust

Problem Statement

Research Proposition

Research Question

Research Aims and Objectives

Design-Led Methodology

Thesis Scope

Thesis Structure

\section{Allegory on Architecture: Validating a Method}

Introduction: Apologue

Allegory as Critical Method

Constructing a Narrative

\section{Literature and Project Reviews}

Alfredo Thiermann Riesco - Artifact $N^{\circ} 1$

Antoine Picon - From Ruin to Rust

Laura Allen - Retreating Village

Renzo Piano + Aldo Rossi - Architecture of the City

Warren and Mahoney - Memorial Bridge

Bryan Cantley - Form:uLA (Dirty Geometries +

Mechanical Imperfections)
Part Two: Preliminary Design Experiments

Site Introduction

Site Cartography

Installation

Speculative Cartography

Theatrical Observation

Part Three: Design Experiments [Speculative Drawing]

Preliminary Design Research

Drawing Methodology

Design Experiments

Developed Design [Outcomes]

The Gateway

The Vessel

The Sentinel

Conclusions \& Critical Reflections

Concluding Comments

Works Cited

List of Figures 


\section{A Forgotten Ruin}

The term 'ruin' has a nuanced meaning; and can refer to both the object in destruction and process of decay (Scho"nle, 2010, p. 6).

Nowadays, a rise of software capabilities and tools help mprove architectural processing and visualisations, a fall in analogue techniques created a void. Despite new technologies, the hand drawing still possesses an evocative starting point for design and [re]presentation; something irreplaceable. The ruin is one of the most enduring and complex representational machines in architecture, and contemporary attitudes are inevitably modulated with engagement. The ruin is emblematic of 'a sundered past' (Dillon, 2006).

With our physical architectural realm diminishing in

representation of the hand drawing, the drawing - like the ruin - is multivalent, open to interpretations. Thus, ignited this thesis to call for the [re]interpretation of drawing as a visual language to represent the collective memory of erasure; as well as new architectural readings. Inquiry into forgotten spaces highlighted how ruined sites encourage a sensual and imaginative engagement with past erasure. Tim Edensor's, 'The Ghost's of Industrial Ruins: Ordering and Disordering Memory in Excessive Space' enacts the body Disordering Memory in Excessive Space' enacts the body as a vessel for sensual engagement and idealised narratives (Edensor, 2005)

This design-led research investigation employs the notion that ruins serve as emblematic sites to re-examine and recast our relationship with the past, and our understandings of temporality. "Ruins foreground the value of inarticulacy, for disparate fragments, juxtapositions, traces, involuntary memories, uncanny impressions, and peculiar atmospheres cannot be woven into an eloquent narrative. Stories can on be contingently assembled out of a jumble of disconnected things, occurrences, and sensations" (Edensor, 2005, p. 840).

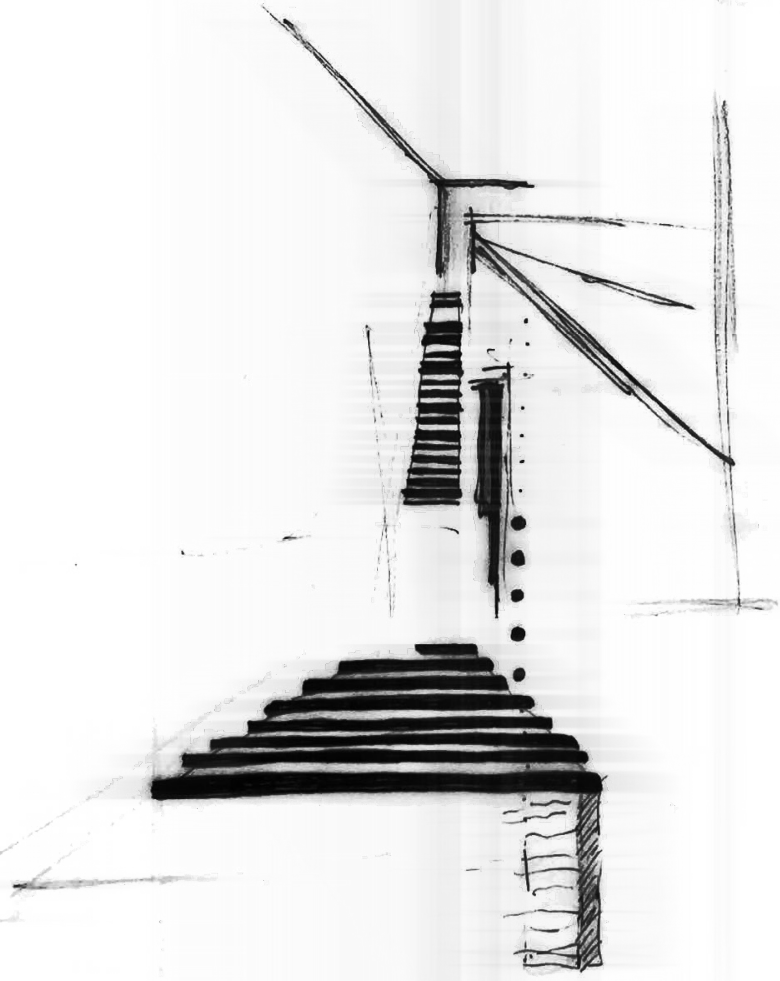




\section{( II )}

Forging a Ruin[lust]

Entering into multi-hyphenate Virgil Abloh's (b. 1990) multidisciplinary retrospective "Figures of Speech", first exhibited at the Museum of Contemporary Art, he encapsulates an enigmatic provocation; the idea of 'Purist vs. Tourist'. Virgil notes, "This twenty-year survey shows how I am constantly looking for a way to transform myself from consumer to producer, navigating a path between 'Purist' and 'Tourist', between the literal and the figurative" (Darling, 2019). According to the exhibitors designer

Samir Bantal, director of AMO, the design research studio of OMA, the dichotomy enacts Abloh's split person stud o and serves to welcome all audiences to participonality and serves to welcome all audiences to participate and engage in the cultural flashpoint (Flores, 2019). To engage in this provocation, however, the observer is required to pass through the retinal trauma the author proposes. The concept of two individual mentalities; 'Purist' and 'Tourist', becomes crucial to this thesis aim. Design experiments will take notions from these two entities not only as the inhabitants, but specifically as the two main interpretative processes used to generate speculative design outcomes themselves. Abloh's contemporary take enacts the research into how we can collectively remember traumas of Peranc to how we can collectively remember traumas of Perano Whaling station, and [re]present historical context through narrative-based designs that engage in the [re]interpretation of palimpsestuous drawings - thereby suspending preconceived notions of past trauma to expand on the potentials of the fictional future.

To understand the lust of man-made industrial ruins, this thesis engaged with the work of Antoine Picon, specifically his 'Anxious Landscapes: from the Ruin to Rust' (Picon, 2000). Picon presents methods to explore derelict spaces, which experience similar such erasure, as easily forgotten landscapes - deleted from history - as context-driven architectural projects as layered traces. Picon's observations spawn interest to question how [re]presentation can inform [re]interpretation of architecture - as this thesis begins to rewrite and re-interpret spatial history. Mattias Qvistrom adds, derelict ruins occupy a transgressive state; "Every place has a past and a former order, and if abandoned it will disintegrate into ruinsor, become ruderal . " (Qvistrom, 2007. p. 271). The ruin is thus used as a story that manifests 2007, p. 271). The ruin is thus used as a story that manifests itself into the architectural objects - a story of the forgotten traumatic pasts of an erased historical site - a premise that resonates with Abloh's constructs.

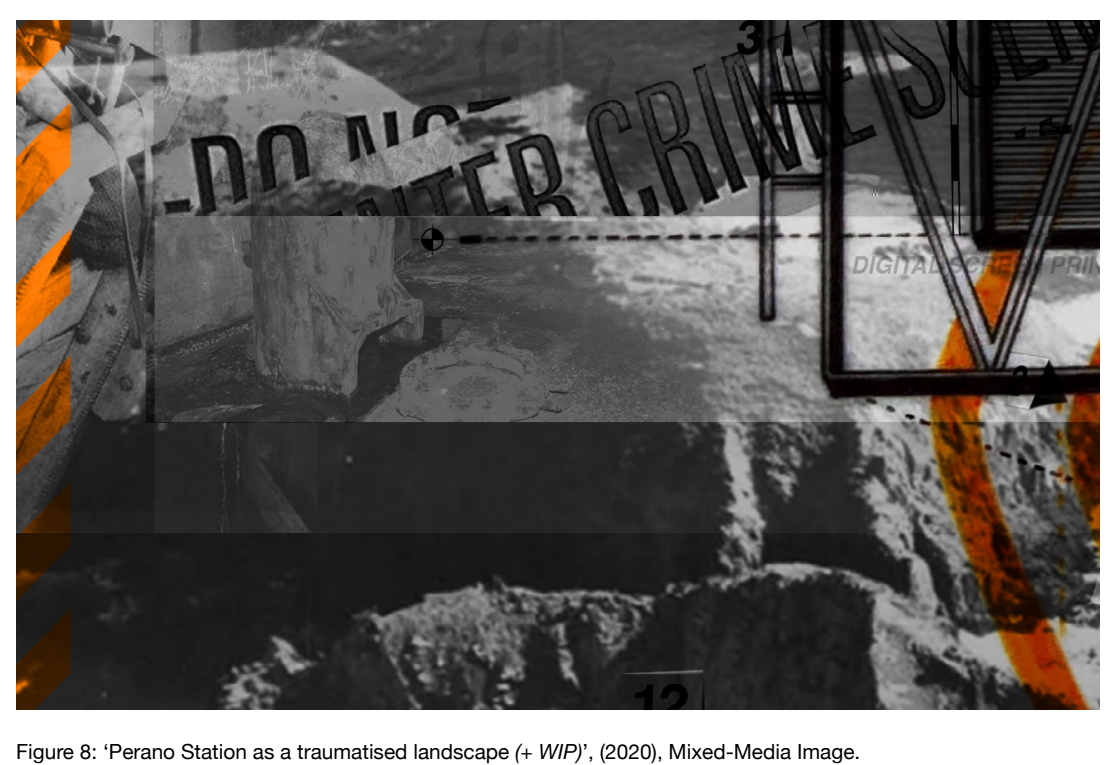

Figure 8: 'Perano Station as a traumatised landscape (+ WiP), (2020), Mixed-Media Image 


\section{Problem Statement:}

"The activity of making anything, including the speculative, is on one level an assemblage, or [re]construction of pre-existing fragments into a new whole" (Dodds, 1992, p.77).

In light of cultural and environmental changes transpired over the past 100 years in New Zealand, architectural intervention has seemingly ceased in the selected historical landscape. This once bustling context now resides along New Zealand's shore as an architectural ruin, scarring the landscape and our memories. Implications of the whaling industry has proven dangerous and immensely harmful overtime, yet, forgetting Perano Whaling Station completely lays waste on the landscape. Year by year, whalers would continually on the lan scar the landscape, literally and figuratively, carving their respective whaling catches into the architecture. Your blood boils [when we spot a whale] because it's another one we have found. Everybody has got their own chair, and those are the rules, when you spot a whale and lay claim to it, you put a notch in your chair... You could read Charlie's chair like a book," said Perano whaler Joe Heberley (Yarwood, 2002).

As a society, we have not learned to destroy industrial ruins, thus, these remain an on-going process that scar the landscapes. There remains an underlying problem with the architectural ruins: their skeletal and disparate fragments lay present, yet, their history and memories are nothing lay present, yet, their history and memories are nothing but blank erasure. This design-led thesis proposes that architectural representation of erasure as suggested by Tim Edensor and Andreas Huyssen, can speculate allegorical interventions as a strategic catalyst to unlock memories suppressed by these scars. This method can further enable the understanding of the role architectural drawing and [re] presentation play on our memories of environments, acting as an on-going process rewriting through time. Thus, linking , portun engaging such erased scars. 


\section{Research Proposition:}

In literary fictional readings, underlying allegorical ideas arise for todays architectural landscapes, both literally and figuratively. This design-led research thesis emerges from Andreas Huyssen's allegorical theories of ruins as factual indicators that records ruins as palimpsests of historical events as an ongoing process (Huyssen, 2010, p. 17). The layering of graphic information is such that the past happenings merge with the present explorations to create a distinct narrative in itself. This represents provocative and enigmatic allegorical response to the provocative and enigmatic allegorical response to the loss of forgotten landscapes in architecture today: Post Traum This investigation thus seeks to interrogate architectural ruins scattered at Perano Whaling Station as repositories for collective memory through enacting allegorical interpretations - challenging the conventions of historica fragments through [re]presentational techniques, weaving them into an experiential narrative. This narrative builds upon these forgotten scars as palimpsests - interpreting and [re]interpreting their [re]purpose - rather than removal from existence all together. Huyssen's theories of enigmatic experiential ruins acts as an allegorical provocateur, the initial point of immersion - an evocative starting point to engage in the [re]presentation of Perano's context. The Perano

Station, much like all ruins, possesses a liminal characteristic on its remaining spaces. An eerie threshold to a brutal past, aggressively carved into the landscape and its inhabitation. These scars act as a literal portal to evocative experiences an act of trying to understand a traumatised landscape. The need for distinctive architectural elements that can translate the essence and experiences of this liminal and transitional space, between both sides of a threshold; past and present, presence and absence, living and dissolving.
Tim Edensor intrinsically positions ruins as a 'fragile and ephemeral place' (DeSilvey and Edensor, 2012, p. 472). Alice Mah also shows in her study 'Industrial Ruination, Community, and Place', ruin[ation] may be 'a lived process' in which memory is rooted in the experience of decline. "The present has not moved far from the past, and the future is at best uncertain" (DeSilvey and Edensor, 2012, p. 410). This can be understood as a response to the views of architectural ruins as monuments left behind by collapsed destruction and unfulfilled dreams; existing outside the destruction and unfulfilled dreams; existing outside the
realms of productive structure. The problem this thesis aims realms of productive structure. The problem this thesis aims
to address is not the visual problem of sight, but the visceral to address is not the visual problem of sight, but the read
problem of drawing - using different mediums to read traces of past happenings. It is through this act of drawing that engagement with Virgil Abloh's 'Purist' and 'Tourist' mentalities that this thesis began "Playing with mediums and materials to make an expression" as Abloh notes (HighMuseum, 2020).

Including drawing as a medium of speculative inquiry to Irelinterpret Perano Whaling Station's contextual scarring; [re]interpret Perano Whaling Station's contextual scarring; layering and juxtaposing information built upon the architectural narrative and proposition. This questions drawings role in architectural interrogation and how it can erase preconceived notions. This is motivated by a personal journey of engagement with such erasure, it took moments of critical reflection upon these scars, to try imagine them as mnemonic devices. Triggering a conversation within ourselves - reflecting on these transformations - toggling between the 'Purist' and 'Tourist' mindsets that Virgil Abloh poses for excavating and expressing modern design to an audience. 


\section{Emerging from such Erasure, This thesis asks}

how the medium of speculative architectural drawing can be used as an inquiry tool for interrogating and reinterpreting, an erased architectural ruin as a repository of memories?

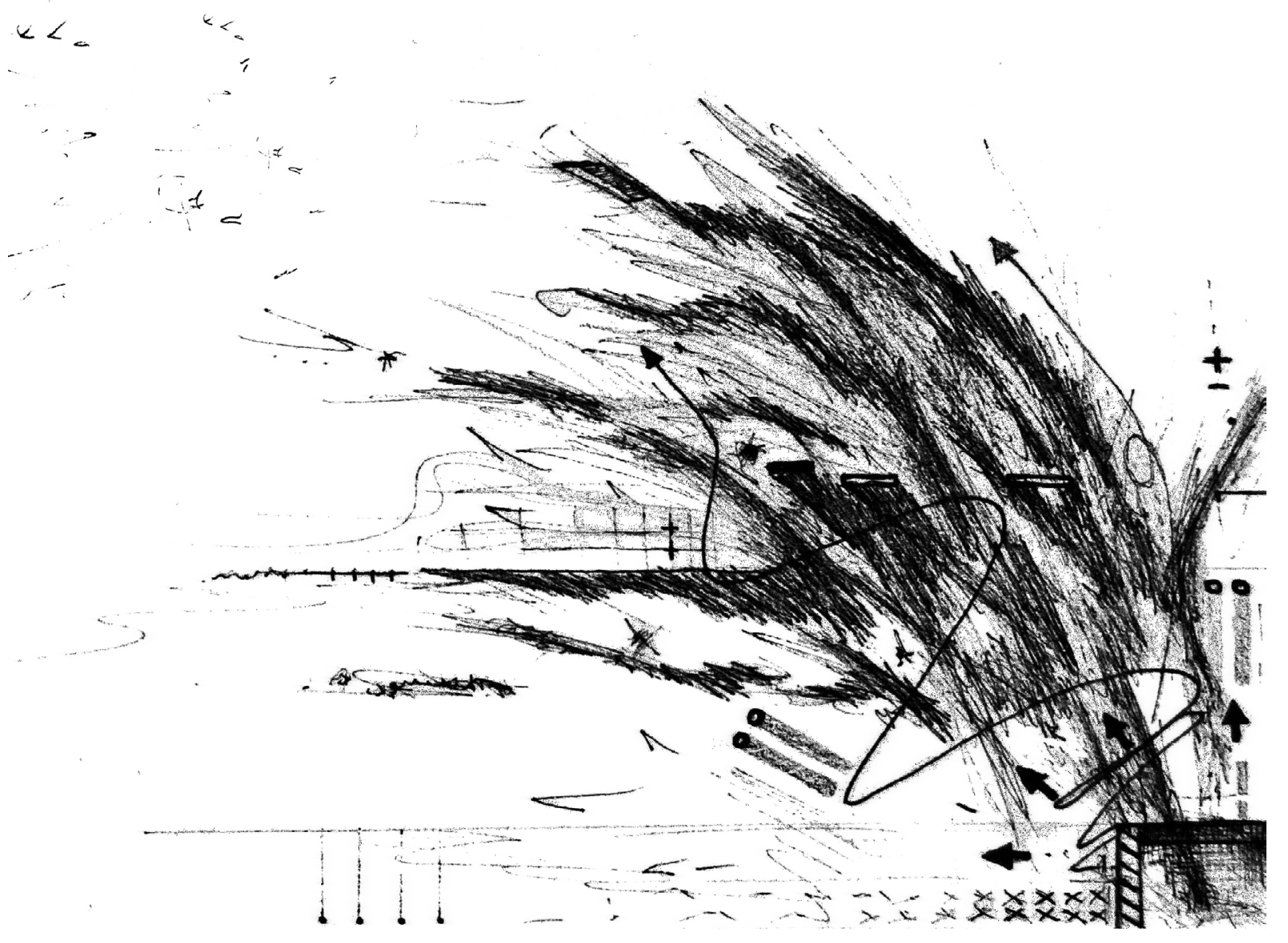


Research Aims and Objectives:

The primary aim of this design-led research investigation:

- to test speculative architectural drawing and making through narrative constructs as inquiry tools to actively interrogate and [relinterpret an erased architectural ruin as a multi-layered repository of memories.

The primary objectives of this design-led research

investigation are:

- to explore how fictional narrative can incorporate allegorical constructs to form a critical framework that invites narrativebased architectural interventions to [re]interpret and [re]present an on-going process of contextual erasure.

- to examine physical (real) and conceptual (imagined) notions of architectural ruins through the evocative experience of speculative architectural drawing in order to actively contribute to an ongoing architectural narrative.

- to develop architectural ruins as repositories of memory through new architectural interventions that activate experiential

narrative constructs of a 'Purist's' and 'Tourist's' spatial mindset, narrative constructs of a 'Purist's' and 'Tourist's' spatial mindse, inviting speculative design outcomes. 


\section{Design-Led Methodology:}

The methodology for this design-led investigation

engages in a variety of strategic speculative approaches. Design outcomes will be tested through iterative drawing and making as the primary [re]interpretation tools. This

methodological process employs ideas from Peter Downton's model for design research, where he proposes, "knowing is embodied in the outcomes of inquiring. It transforms and evolves as collective knowledge of design, provides a basis for learning" (Downton, 2003, p. 131). Adopting this approach allows interventions and investigations to build collectively, allows intencis layered findings. This thesis is thus employing the process layered findings. This thesis is thus employing the process
of design through discovery; the context of Perano Whaling Station acts as the repository for such findings. Learnings from each experiment allows reflections that encourage a feed-forward process for following design experiments.

Following this design-led approach to interrogate speculative drawing and making as primary mediums to reflect upon memories will allow this thesis to interrogate its aim: to mest speculative archisectural drawing through narrative constructs as inquiry tools to actively interrogate and re constructs as inquiry tools to actively interrogate and [re] interpret an erased architectural ruin as a multi-layered repository of memories. The process of research 'for' desig and research 'through' design will be adopted thoroughly throughout. This process is defined as allowing for "selfscrutiny, done with caution and thoroughness, then, what is revealed and understood can be incrementally assembled into knowledge within the discipline" (Downton, 2003). Literature and Project Reviews interrogate key theorists and case studies that align with the Research Objectives - to be explored in the design phases.
Three key architectural themes are engaged in this investigation: Narrative, Representation and Interpretation. These primary methodological themes allows such produced workings to act as suffuses for each design stage, representing initial incentives and leading the viewer into the unconscious realm of collective memory and architectural possibilities. Texts and Case Studies are integrated as catalysts to form robust and captivating allegory as a narrative construct in Part One. This allows drawing as the primary modium to speculative program. This method parallels Perry Kulper and his research tactics. He specifies, "ideas are augmented his research tactics. He specifies, "ideas are augmented
through an emerging visual field study that is discovered through an emerging visual field study that is discovered
in the act of constructing a drawing" (Kulper, 2013, p. 59). It can thus be said this thesis employs primarily, but not entirely, of theoretical research, speculative drawings, hybrid cartography, and making to construct design outcomes that align with theoretical provocations.

The combination of both analogue and digital hybrid drawings allows for an immersive approach to a narrativeled design investigation. Final representations of the design outcomes propose an intrinsic repository of memories, outcomes propose an intrinsic repository of ment drawing methods - explored throughout all three research objectives. Each respective illustration enacts a breadth of research and contextual style to enhance an expression. Case studies and theoretical analysis are combined into relative design phases, each progressing from one another. 
[ Design-Led Research Process ]

\section{Post Trauma}

:Memory as a Catalyst

THEORETICAL GROUNDINC

【NTRODUCTION》

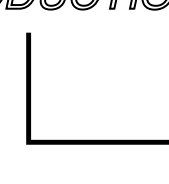

\section{DESIGN RESEARCH}

$\left[\begin{array}{l}\text { 1: Virgil Abloh - Narrative Construct } \\ \text { 2: Antoine Picon - Traumatised Landscapes } \\ \text { 3: Bryan Cantley - [reJpresentation }\end{array}\right]$

PROBLEM STATEMENT

RESEARCH QUESTION

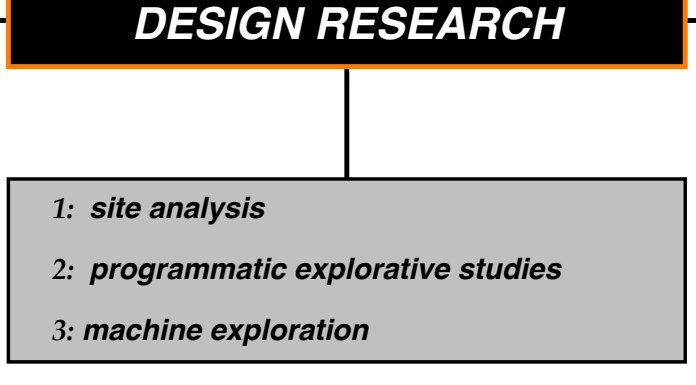

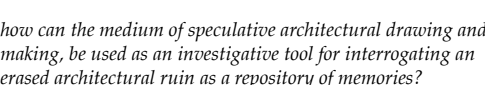

\section{$\frac{\text { PRELIMINARY DESIGN }}{\text { Irefections I }}$}

beginnings of mnemonic design phase

01 [ ALLEGORICAL DIALOGUES

02 [ DRAWING + MAKING [studies]

03 [ CURATION INQUIRY [relpresentation

PRELIMINARY DESIGN 2

[ DRAWNG TARKNG REFNEMENT

支 


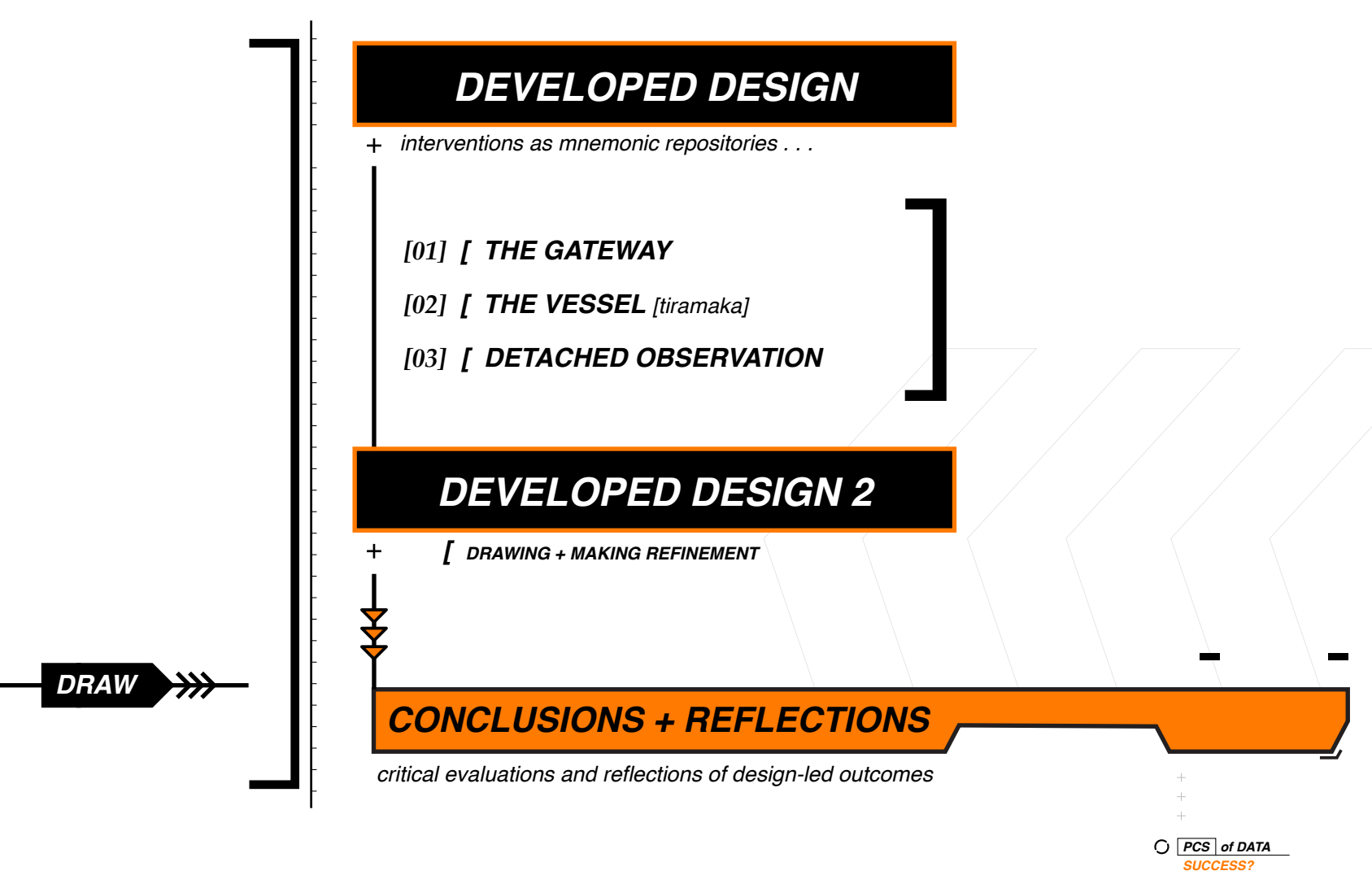

- CIOBEN WADE (O) 2020 
Thesis Scope:

"We are no longer outside of the realm of a past that we still experience but situated at time and place through drawing memory" (Rossi, 1982, p. 107).

It is important to state that this design-led research investigation exists in the contemporary yet speculative architectural domain. It seeks out architectural approaches that extend beyond traditional modes and experimentations - proposing enigmatic drawing as a methodological approach. With this investigation drawing from literary and narrative-based opportunities, as well as time and cost constraints, resource limitations, architectural interventions and consistent visitations of context fall outside the scope of this research investigation. This limited the continual re thamination of the site in relation to on-going findings re-examination of the site in relation to on-going findings - reiterating drawing as a stimulus to speculate the site's potential opportunities. As Neil Spiller mentions, "...due to constraints in time, resource limitations and scope, the drawing acts both as a site of potential imaginaries and a working surface" (Spiller, 2011, p. 26).

This investigation undertook a speculative approach to unveil the complex real-world implications surrounding ruins, formulated through narrative interpretations as a framework of investigation. Following renowned critic a rramewt "allow theorist Walter Benjamin, "allegory is a sensibility as well as a critical method. Allegory can distance the architect from conventional beauty, positioning them as an examiner of spatial phenomenon of traumatic history, better explored through enigmatic images" (Benjamin, 1977, p. 178).

Examination of fragmentary traces opened up the thesis scope too critically approach these ruins through a set of 'destabilised' conditions. The erosive division of past and present memories aims to create a distinct engagement of interpretative drawings and reflections from both 'Purists' and 'Tourists'.

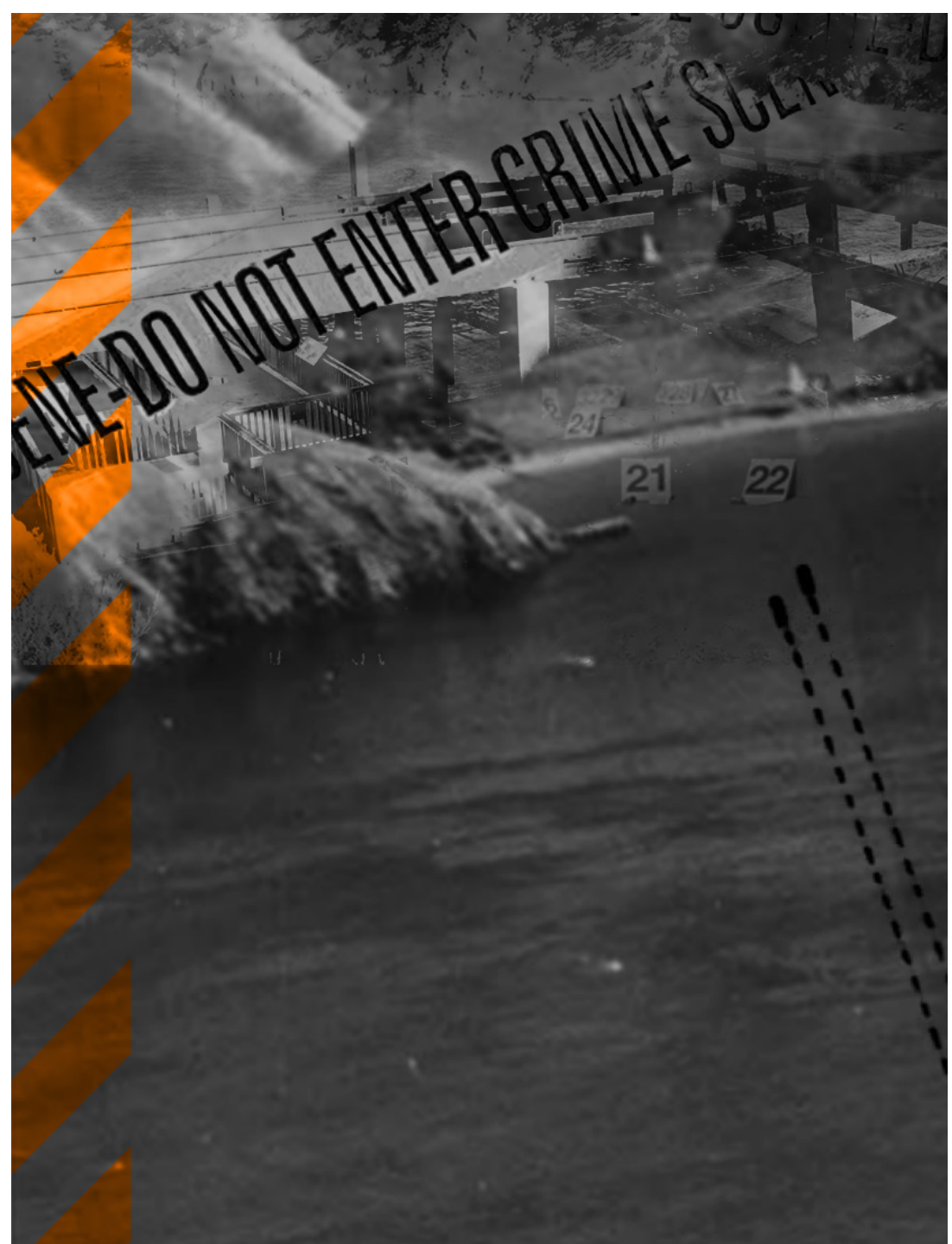

Figure 12: 'Perano Station as a traumatised landscape (+ WIP)', (2020), Mixed-Media Image. 
Thesis Structure:

\section{. Project Introduction}

introduces abstract and preface, providing a clear reasoning for exploring this topic as a design-led research thesis, whilst outlining the problem statement

II. Fictional Literary Context

introduces fictional context

III. A Proposition

proposes allegorical constructs as a critical method for exploration

\section{Thesis Scope}

establishes the project's scope

\section{Design-Led Methodology}

Dorking method for the project

VI. Research Aims and Objectives

outlines the principal research aims and objectives

\section{Thesis Structure}

describes the thesis' document structure

\section{Ruin [lust]}

exploring allegory as a method for engaging ruins

IX. The Place

provides insights into the contextual setting for interventions to interact

\section{Preliminary Design Research}

preliminary design sequence

\section{Developed Design}

developed design sequence

XII. Conclusion and Critical Reflections

critically reflects on the body of work against proposed aims and objectives 
Part One [ Allegory in Architecture: Validating a Method ] Research Objective 1: to explore how fictional narrative can incorporate allegorical constructs to form a critical framework that invites narrative based architectural interventions to [re]interpret and [re]present an on-going process of contextual erasure.

Part I of this thesis will explore robust allegorical traits and constructs that provide a working strategy for critical engagement for narrative-based design that [re]presents such present erasure as an on-going and palimpsestuous process. Implementation of allegory within this thesis methodological construct allows design interrogations to form a poetic engagement with the scarred architectural ruins. Further expansion of Tim Edensor and Andreas Huyssen's enigmatic interpretations of ruins 0 cour in this Huyssen's enigmatic interpretations of ruins occur in this

Part I also introduces Walter Benjamin's 'The Origin of German Iragic Drama' as a literary premise that extracts storytelling as a means to create a critical method that engages narratives to be translated into the architectural project. Relative case studies and literature bring this process to light - unlocking how speculative architectural representations can sequentially engage and respond to the underlying forgotten stories of Perano Whaling Station. Translation of Benjamin's allegorical constructs in relation to provide Abloh's 'Purist' and 'Tourist' mindset to design to provide Abloh's 'Punst' and 'Tourst' mindset to design both spatially and poetically.
Part Two [ Speculative Drawing + Making ]

Research Objective 2: to examine physical (real) and conceptual (imagined) notions of architectural ruins through the evocative experience of speculative architectural drawing in order to actively contribute to an on-going architectural narrative.

The primary aim of Part II is to explore ideas of the fragmented site in relation to the narrative of evoking physical and mental memories - translating such theories into speculative drawing and making. Investigation into how fragmented and disordered spaces can interrogate and contest the normative way in which memory is spatialised through architecture was a key aspect in this chapter. Neil Spiller celebrates the abstract messier sides to architectural discourse, which takes in myth-making, alleged semiotics, ancourse, which takes in my and moreover the untidy art of narrative. Part Il deploys a post-industrial aesthetic, created from collaged assemblies that are dismantled, restructured and recomposed. 'The explorative, or 'magical' drawing is a site of both understanding and emergence, a repository of information and a 'working' surface on the one hand, and the location of multiple potential imaginaries on the other" Spiller, 2013, p.55).

Based on these concepts, the goal of Part II is to interrogate the site and relative potential findings, whilst applying learnings from previous chapters to engage and reinterpret the mechanic geometries sottered within Perano. Peter Zum chan geon Zumthor entails how portrayals of unrealised architectural works represent an attempt to give a voice to something, which has not yet found its place in the world (Zumthor, 2010, p. 12-13). One of the vital roles of drawing for an architect serves as a reference to the recording of discovery. Often fragmentary, this highlights the critical relationship between sight and memory as critical. 
Part Three [ Exhibitive Repositories of Memory ]

Research Objective 3: to develop architectural ruins as repositories of memory through new architectural interventions that activate experiential narrative constructs of a 'Purist's' and 'Tourist's' spatial mindset; inviting speculative design outcomes.

Part III will explore the role which memory has when creating mnemonic architectural devices through the two spatial mindsets proposed by Virgil Abloh; 'Purists' and 'Tourists' This part will aim to seek out different modes of [re] presentational; focusing on the [re]interpretation of the draw to speculatively represent the different design outcomes generated in pursuit of the 'Purist' or 'Tourist' mindset. The relative drawings that manifest act as unorthodox devices for mnemonic contemplation an

\section{Based on the discussed principals, Part III aims to apply} previous learnings from Parts I and II - morphing these seculative architectural techniques into what serves as final design outcomes for this research investigation. It seeks to apply allegorical traits and notions of erased ruins, rendering outcomes that act as engaging allegorical architecture; an invitation for [re]interpretation of a scarred landscape. Textual and visual descriptions will give insight into how an allegorical architectural project can break conventiona architectural constructs, and speculate a landscape in a new light.
Conclusions and Critical Reflections:

The final chapter of this design-led investigation critically reflects on the strengths and weaknesses of the design research and processes employed; as well as the resulting investigative findings in relation to the scope of the research, and relative research objectives. It briefly reviews the nature of the research problem, and reflects upon the effectiveness of research investigations to address the issues in relation to the wider architectural context as a profession. Evaluations into the effectiveness of the methodology occur, and

into the effectiveness of the methodology occur, and conclusions acknowledge relative constraints and limitations of the research direction identifed in the design-led research processes. It also gives an observation into how findings from this research could translate into similar architectural, or other design-based disciplines framework of knowledge. Further expansion of implications which could have arisen had this research extended the scope of this investigation. 


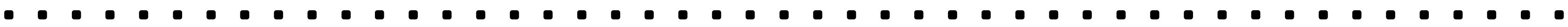

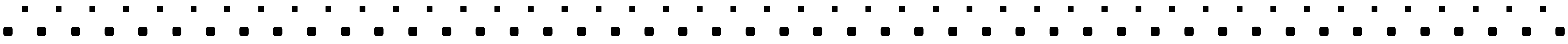

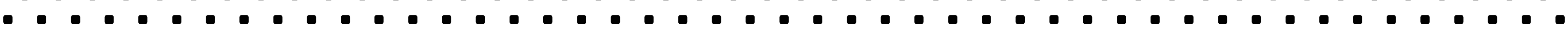

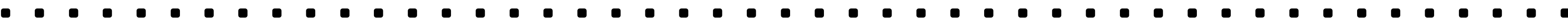
0

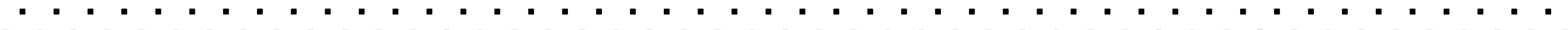

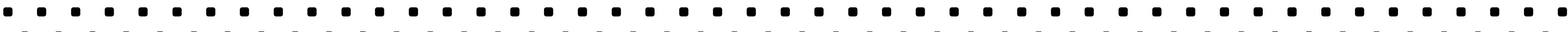

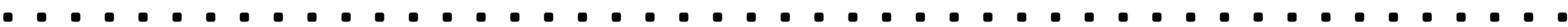

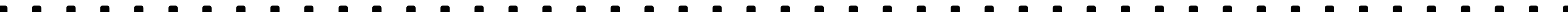
(

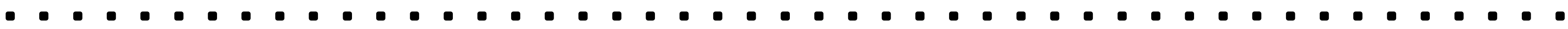

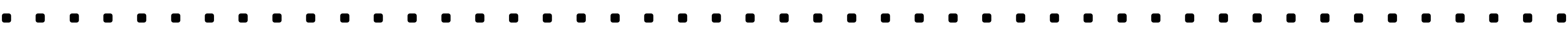

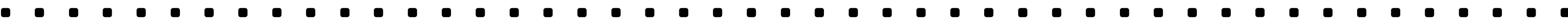

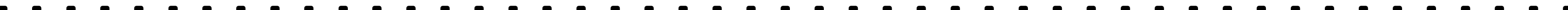

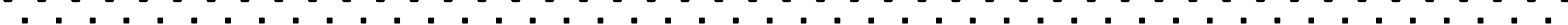

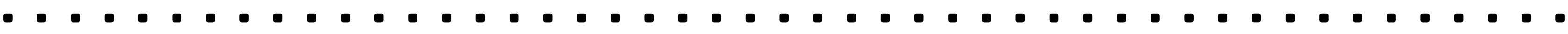

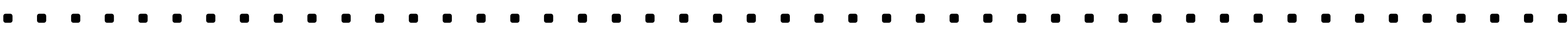

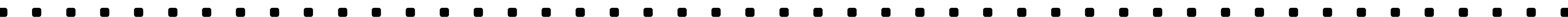
0

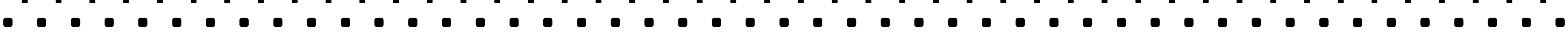
๑

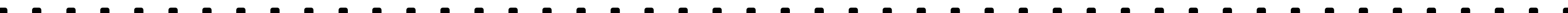

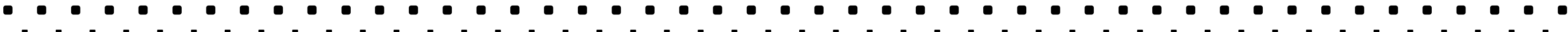

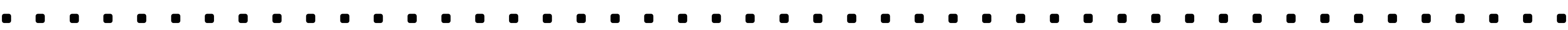

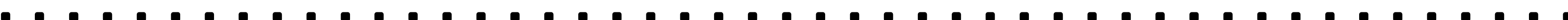

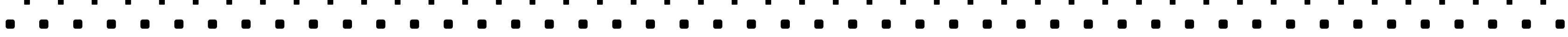




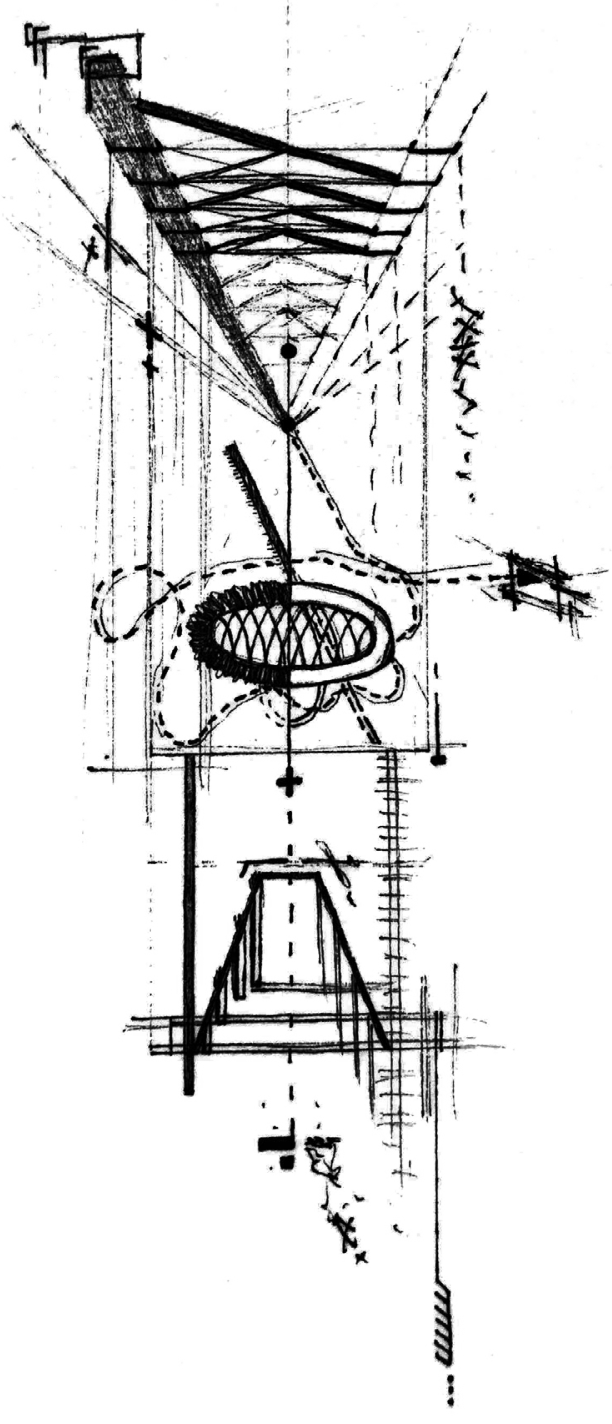

4

'THE RUIN' HAS BEEN DESCRIBED

AS A POEM OF CONTRASTS

BETWEEN PAST AND PRESENT,

BETWEEN HUMANITY AND ITS WORKS, BETWEEN THE EPHEMERAL AND ENDURING, BETWEEN THE LIVING AND THE RUIN.

:Margot Lamy, 2019 
- Those characters whom define movements, trends, styles - Define certain paradigms / dogmas / tenets

- The "Intellegentsia" - knowledgeable of relative industry[s] - Restricted to past rules / teachings to define how the experience spaces - too rigid in their interpretations - Understand historical values - filtering life via a connoisseurs perfectionist eyes

- Deconstruct meanings of objects [machines] further[more] - Create functional, pragmatic, linear, literal spaces

- Knowledge base creates gravity [makes them grounded] - Knowledge base creates gravity [makes them grounded - Rem Koolhaas - purists often disregard the tourists
- Find value in meaning [based on an underlying premise]

- Draw CONCLUSIONS [close doors]

The goal is to make exhibitive work that

W Making the curiosity of a TOURIST...

A person whom is both

As the designer for this thesis, I want to toggle between work similar to a pedagogical structure - aiming work to
They are misty eyed for knowledge - open to new learnings, but do not attach or respond to paradigms, dogmas, tenets - Absent to question the Purist's mindset / constructs; only to observe and dwell on aspects as they please

- Incorporate and reference elements derived from multiple movements / trends / styles / philosophies - without

necessarily having full understanding or intension

- Open to interpretation [viewing through the figurative lense in respect to the literal design / space / drawing]

- Unravel other interests viewing the work - ambition to seek mbition to seek out [un-pack complexities]

Curiosity eliminates a sense of gravity [not grounded] - Breakdown the architecture, work, drawings differently - Ask QUESTIONS [open doors]

interacts and crosses paths [tourists don't see this type] ...without losing the discerning eye of a PURIST

can make meaningful design

a Purist and Tourist mindset, drawing and presenting address both audiences simultaneously as one. 
1.0 Introduction: Apologue

"The ruin becomes a playground of speculative strategies that tell $u$ s more about the beholder than about the ruin itself" (Schonle, 2010, p.7).

Apologue interrogates the role of robust allegory in a narrative based architectural project. It will aim to highlight key narrative structures and explore case studies that express similar allegorical traits to create a palimpsestuous framework moving forward. Tim Edensor and Andreas

Huyssen's enigmatic interpretations of ruins as an allegorical provocateur to an architectural project is further expanded upon. Narrative theory is engaged through Wellington Reiter (b. 1957), in his book 'Vessels and Fields', which explores typologies as connective tissue between forgotten or imagined pasts - and a shifting present or future - as well as offering subtle metaphors for design. "Vessels and fields is an idiosyncratic epic of the modern city. Contexts and conditions are established; characters and stories unfold, intersect and overlap, creating an atmosphere from which a vivid - if sometimes disturbing - depiction of the city ( vivid - If somethes disturbing - deplction of the city Hejduk, Bryan Cantley and Wes Jones, who will be discused Hejduk, Bryan Cantley and Wes Jones, who will be discussed further in this thesis. Collectively, these precedents deploy a syntax of objects and vessels to allow viewers ('Purists' and 'Tourists') to exhibit their own interpretations of scarring and re-write urban program (Hejduk, 1985, p. 323). Key features are extrapolated from Reiter's work to establish a robust framework for a narrative based architectural project, dentifying key design decisions coming. Andreas Huyssen's enigmatic theory of ruins initiates the allegorical provocateur - the initial point of immersion for this thesis. Visting the Perano Whaling Station, accompanied by later historical Perano Whalling Station, accompanied by later historical findings infused an evocative starting point to interrogate a history

Intertwining the presented narratives under a framework of 'Purists' and 'Tourists' interpretation, we can begin to understand the architectural world as a fragmented landscape - recombining isolated fragments to create new meanings. Part One utilises Walter Benjamins 'The Origin of German Tragic Drama' as a literany premise to extract allegory as a critical method that engages narrative aspects to be translated to the architectural project. Apologue will use this as a guide to create stories of Perano that parallel real-world problems - acting as a response through interventions to come that speculate an alternative spatial future. Benjamin's translation of allegorical constructs, what he describes as, "the allegorical way of seeing" can distance the designer from conventional methods - positioned as both a 'Purist' and 'Tourist' to examine the traumatised landscape (Benjamin, 1977, p. 178)

Translation of Benjamin's allegorical constructs enables Virgil Abloh's 'Purist' and 'Tourist' design methodology to unfold through enigmatic drawings that engage such ruined traces as a fragmented field of possibilities. In the context of this thesis, the fictional narrative of the 'Purist' is explored through a design intervention layering on Perano's footprint how the ambiguous constructs can act as a sequence of architectural drawings from "intelligentsia". Paralleling is the fictional narrative of the 'Tourist', explored primarily through fictional nar a design in outside looking in, allegorically understanding whalers and voyagers happenings that once scarred the landscape. The principal aim of Apologue is to explore a captivating story as a fictional narrative that engages in a landscape experiencing historical erasure, inviting speculative design outcomes. 
1.1 Allegorical Architecture as Critical Method:

Walter Benjamin

German philosopher, cultural critic and essayist Walter Benjamin (b. 1892), employs allegory as a formal narrative construct to act as an enigmatic vehicle for engagements and criticism in his paper, 'The Origin of German Tragic Drama' (Benjamin, 1977). Benjamin employs allegory to Drama' (Benjarin, 1977). Benjarin enploys allegory to expose implicit eschatological structures, utilising the tensions to distinguish the historical constructs. Following Benajmin's ideas, allegory can be implemented as a critical method to achieve specific sensibility in the architectura project. Deconstructing Benjamin's literary allegorical constructs, design experiments were developed through the idea that the ruins of Perano Whaling Station can be conceived by a 'Purist' or 'Tourist' - as a spectacle of historical trauma, representing allegorical expressions in the structural realm.

Using Benjamin's phrasing, it repeatedly enacts allegory as a focal point on which to reflect things, referring to allegory as a means to unclose the mind and 'go beyond' as an attemp to break out into the historical world (Benjamin, 1982, p. 178). In this thesis' context, it is through both an examination of remaining scarred traces that me, as the allegorist, can approach ruins through a 'Purist' and 'Tourist' framework. Speculative architectural practices will be employed to enhance the notions of historical context, culture and the ruin, as fragmented. The use of an allegorical framework is to ence multiple interpretations of spatial compositions, to enhance will now ou cons will now outline and excavate allegorical traits presented by relative case studies, primarily through drawing.
1.2 Constructing a Narrative:

Wellington Reiter \& Virgil Abloh

Architect and Senior Adviser at Arizona State University Wellington Reiter's 1999 book, 'Vessels and Fields', is used as a framework to establish narrative theory for this used as a framework to establish narrative theory for this design-led investigation. Whether viewing Reiter's works through a wide-angle lens, or a microscope, his architectura projects reside in rich thinking narrative constructs that use critical thinking in the reconstruction of human perceptions. According to Reiter, "It is through hypothetical propositions that we begin to identify and encounter the inestimable forces and human choices that inscribe character on contemporary cities" (Reiter, 1999, p. 5).

Multi-hyphenate Virgil Abloh adds premise to the narrative in his lecture 'Insert Complicated Title Here', 'your ideas are analogies, your thought process could apply to something analogies, your thought process could apply to something else that you thought might not have been previously thinking of [...] But, it's okay to very off and before you know it, you'll be realising ideas in different spaces that can inform what you're all about" (Abloh, 2017). By extracting theoretica arguments of narrative-based design from Reiter, and translated into contemporary multidisciplinary design work of Virgil Abloh's 'Purist' and 'Tourist' concept - a narrative unfolds - [re]interpreting architectural drawing can explore the restructuring of viewers spatial memories of Perano through speculative architectural designs.

The following sections will dive into case studies, and how they act as premises in the context of this design-led thesis. Design experiments follow accordingly, and are explored in relation to principals raised in literature reviews and case studies presented; addressing the research question posed for this thesis. 
1.3 Narrative Architecture and Design:

Artifact $\mathrm{N}^{\circ} 1$ - Alfredo Thiermann Riesco (2012)

Exhibiting a metaphoric piece of narrative architecture, Alfrefo Thiermann's 'Artifact No1' exhibits a narrative

based design that can be compared to Wellington Reiter's narrative design works. This case study allowed similarities to be extracted from Reiter's 'Vessels and Fields' to allow possible insights into this design-led investigations narrative in architecture. Relationships can thus be made between 'Artifact $N^{\circ} 1$ ' and Perano Whaling Station's context.

'Artifact $N^{\circ 1}$ ' was constructed in 2012, in Paine, Chile, and was designed as a response to Thiermann's own inability to tell the difference between fiction and reality inability to tell the difference between fiction and reality
in the architectural discipline. It provides insights into the relationship between subject and object - how narrative architecture and storytelling provides a diffused ground between architecture and form. This design correlates to both the first and second research objectives, where Theirmann uses the construction of an allegory to arrange imagery and spatial sensations that relate to archetypical objects which have historically paralleled the process of deterritorialisation, abandonment and exile; where he used past traumas and events to present a narrative baes past traumas and events to present a narrative based restructured architectural response.

This case study helped propose a set of narrative design principals to be explored in future design experiments, that include:

1.3 [.1] interaction of materials, water and viewpoints

1.3 [.2] dialogue between interventions ['Purist' and 'Tourist']

1.3 [.3] archetypal geometries allow multiplicity of Interpretation[s]

Allegories are, in the realm of thoughts, what ruins are in the realm of things

Benjamin, W. (1977). p. 1878 
1.4 Traumatised Landscapes:

Antoine Picon - 'From the Ruin to Rust'

French professor, architect, and historian Antoine Picon (b. 1957), Co-Director of Doctoral Programs at Harvard Graduate School of Design, presents his paper 'From Ruin to Rust' which provides discussion on exhausted architectural landscapes can be rejuvenated through architecture (Picon, 2000). Picon advocates that through the works of designers, exposed landscapes can be completed and transfigured. "Considered in this way, human interventions present numerous analogies to the art of the gardener, who makes use of fabricated objects in a park in order to draw attention to its features and beauty" (Picon, 2000, p. 66). For the to its features and beauty. "(Picon, 2000, p. 66). For the context of this thesis, this analogy can be interpreted as an ongoing process of narratives, where through considerate design applications, both 'Purist' and 'Tourist' can viev' chapters of past existence through new happenings.

The attractions to ruins play out possible futures, and pasts, of violence and decay to pleasure and sublime. These dualities circulate the notion of disenchantment [battle] and re-enchantment [progress] (Picon, 2000). The allegorical journey of Perano can then be conceived in a battle and progressive state; an opposition between dualities and progressive state, an opposition between dualities and to allow us to [re]present Perano's narrative tructure figurative urban artefacts - mediating between the past and present.

"More than the threatening skies, stormy atmosphere, jagged rocks and raging sea, it was the postures, expressions and gestures of the characters that impacted upon the spectator" (Picon, 2000, p. 70)
Picon as a theorist also offers insights into how heritage can be maintained in traumatised landscapes amidst an ongoin process of erasure; framing how this can be architecturally curated through relative site narratives.

Perano's context can adopt this process and be reimagined through the insertion of the figurative gestures as new interventions of history. Furthering this notion of historic contextual conservation, Tim Edensor, a specialist in cultural contextual constiol geography at Manchester Metropolitan University elaborates in his book 'Industrial Ruins - Space, Aesthetics and

Materiality' (Edensor, 2005). Edensor notes ruins are in their essence, enigmatic, their disjointed fragmentations can be weaved into a direct narrative to allow interpretation in a multitude of manners - related to a frame of reference in which viewers position them. "Ruins can therefore embed memory permanently or weaken memory through decay... It is upon the beholders subconscious awareness to decide" (Edensor, 2005). Through this literature and following case study, strategic design principals once again arise that can actively be incorporated in future design explorations. Design tions. Design principals uncovered include:

1.4 [.1] re-use of 'old' traces through the 'new'

1.4 [.2] this is an ongoing process; this adds to the traumatic narrative of the context

1.4 [.3] past scars can be reinterpreted through multi-layered drawings 
Case Study:

The Retreating Village - Laura Allen (2005)

'Retreating Village' by Laura Allen represents a case study that acts as a context-driven project - responding to a landscape experiencing traumatic happenings that aligns with Tim Edensor and Antione Picon's theories. This project looks at the effects of coastal erasure occurring in Happisburgh, North Norfolk, and questions whether vulnerable sites can be re-programmed for occupancy. How may this manifest?

It proposes to use architectural language as investigation This is a project that similarly exists in the conceptual design This is a project that similarly exists in the conceptual desig realm; making specific reference to issues of landscape retention and consideration of past historic context. Traces of former buildings existence and paths leave blanks and hollows in the ground, representing a previous narrative of land use. This case study exemplifies a speculative example highlighting the benefits of repurposing a traumatised

landscape as a palimpsest scarred by previous happenings.

Drawings for The Retreating Village arise from developments of sketchbook investigations and representations, which similarly parallels this investigations design process. In this context, this thesis argues similar principals of site renegotiation, with the introduction of contemporary architectural interventions into a scarred site, beneficial 'new' layers can be explored which leave traces of 'old' past layers. Thus, the framing of interventions as additional layers in the site's narrative can enable the understanding and significance of past scars. 
1.5 The Experience of Site Locus:

Renzo Piano + Aldo Rossi - 'The Architecture of the City'

Italian architect Renzo Piano (b. 1937) describes context and identity as a tactic matter, which can become lost in the architectural process. Piano thus attempts to address the loss of cultural identity in architecture, consciously designing through the fragmented individual as a whole. The design philosophy of Piano reminds us as designers to engage with every aspect of site, designing with a sensitivity to the concept of place. In relevance to this design-led investigation, following Piano's lead can unlock architecture that engages with an erased historical context tactfuly in an interview with 'The Independent', Piano stated, "I thin it [style] is a trap. But what I don't hate is 'intelligence' or 't [style] is a trap. But what I don't hate is 'intelligence' or coherence'. Because coherence is not about shape, it is about something stronger, more humanistic, more poetic even" (O’Hagan, 2012).

Italian architect and speciality theorist Aldo Rossi (b. 1931) provides insights that can contribute to aspects of all three Research Objectives for this design-led thesis. In his book 'The Architecture of the City', Rossi defines the locus as a The Archecture of the chy , Rossi defines the locus as a form, but most importantly a theatre of events thography, orm, but most importantly, a theatre of events that contain me Rossi, 1982, p. 7). Interventions act as signs of events tha have occurred on scarred sites, where this relationship becomes a characteristic of an urban artefact. In this manner, Rossi abstracts locus as a relationship between a historic site (place) and memory through interventions interaction with such traumatic erasure (Rossi, 1982, p. 103). Locus can thus be employed in this thesis to help assess the physical (real) and mental (memory) of a speculative architectural project - principally through the medium of drawing. The visceral problem of drawing thus is the locus of site and its memories - drawing is the medium of inquiry and evidence of past traces.

Peter Eisenman adds to this in 'The Architecture and the City' where discusses the relationship between the text and drawing in relation too site. Eisenman argues the drawing has become the locus itself. "The architectural drawing, formerly thought of exclusively as a form of representation, now becomes the locus of another reality. It is not the site now becomes the locus of the suspended time of both life and death. In this place of the suspended time of both life and death. In this way, it [the drawing], and not its built representation, becomes architecture: the locus of a collective idea..." (Rossi, 1982, p. 16)

Rossi adopts the term 'Analogy' in this sense when

designing for locus, where construction by parts can act as a compositional whole; using existing figurative elements in a new light of conceptual analogues... Life, death, memory, imagination (Rossi, 1982, p. 80). The reinterpretation then of such scars, figures, and artefacts fundamentally creates new locus. Rossi further adds, "I have always claimed that places are stronger than people, the fixed scene stronger than the transitory succession of events..." Future desig interventions aim to incorporate some of the following principals to highlight new spatial narratives:

1.5 [.1] the repetition of figurative geometry can act as 'vessels of interpretation'

1.5 [.2] locus creates obscured memories through accumulated

element

1.5 [.3] drawing can act as the locus for a speculative design inquiry 
Case Study:

Memorial Bridge - Warren and Mahoney (2017)

Exhibiting a piece of architecture that resembles narrative design and provides an enigmatic and more speculative landscape outcome, award-winning firm Warren and

Mahoney provide insights into aspects of all three research objectives. Completed in 2017, 'Memorial Bridge' acts as a powerful gateway for 'tourists', and functions as a transport solution to enhance the sense of place. As a civic project, the architecture acts as a silhouette of the Southern Alps, responding to such views that mimic contours. Motorists, passengers travelling by air, and other viewers gain a sts, passengers travelling by air, and other vewers gain a sense of convergence from overlapping arcs, symbolising the convergence of Meror and European settlers (purists and tourists). Pathways portray different perspectives when viewed from different angles. The brief for this project outlined a set of principals that can draw parallels to this design-led thesis.

- respond to different viewpoints and perspectives - effective integration with surrounding land

- acknowledge Tangata Whenua historical values

-enhance the intersection as a 'Gateway'

Warren and Mahoney strategically designed the bridge to enhance Christchurch's robust historical identity - the past history influenced future architecture, and how these 'converge' into one. Reinterpreting these themes addressed by Warren and Mahoney gives insight into architecture can enhance locus as a medium of inquiry. Simultaneously, integrating Rossi's theories on drawings relationship to locus offers insight into the analogical fragment of figurative interventions interacting as one landscape can create

mnemonic devices (Rossi, 1982, p. 107). 


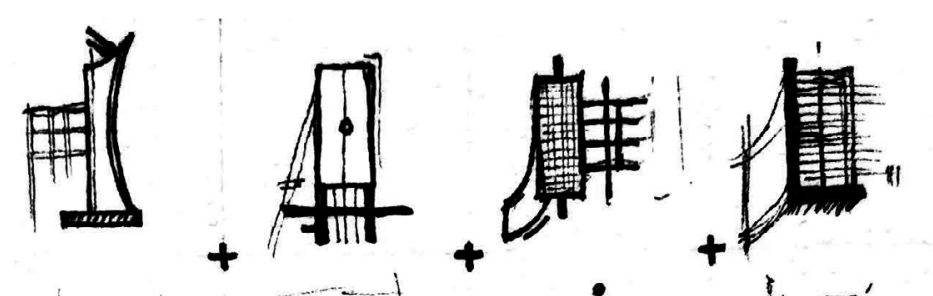

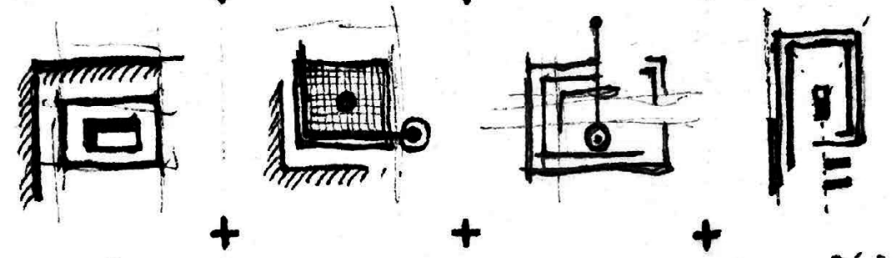

P.t.

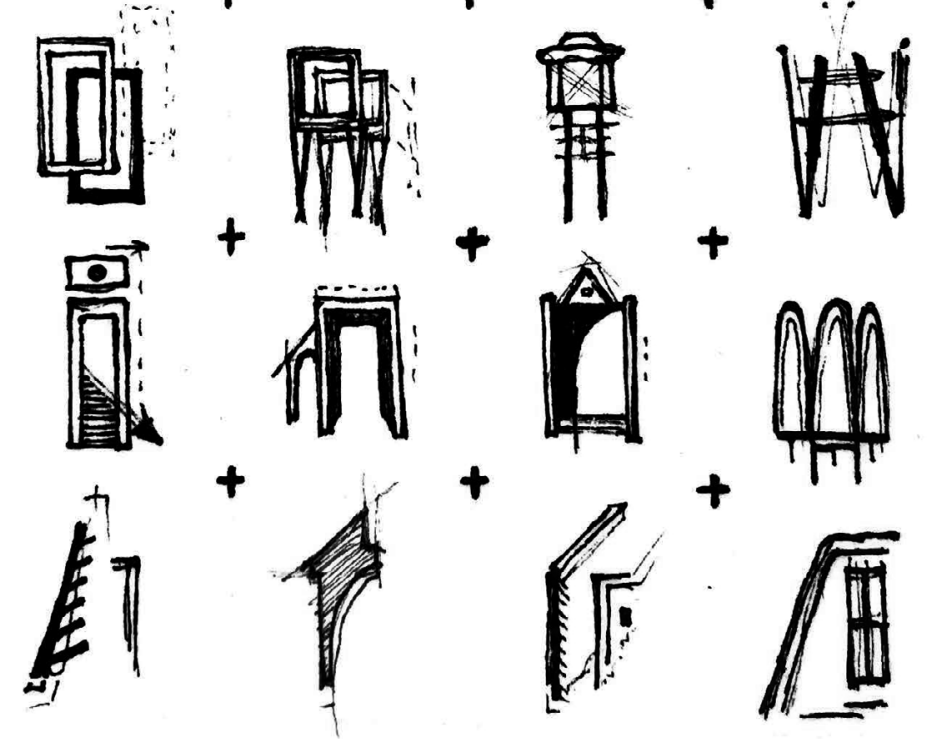

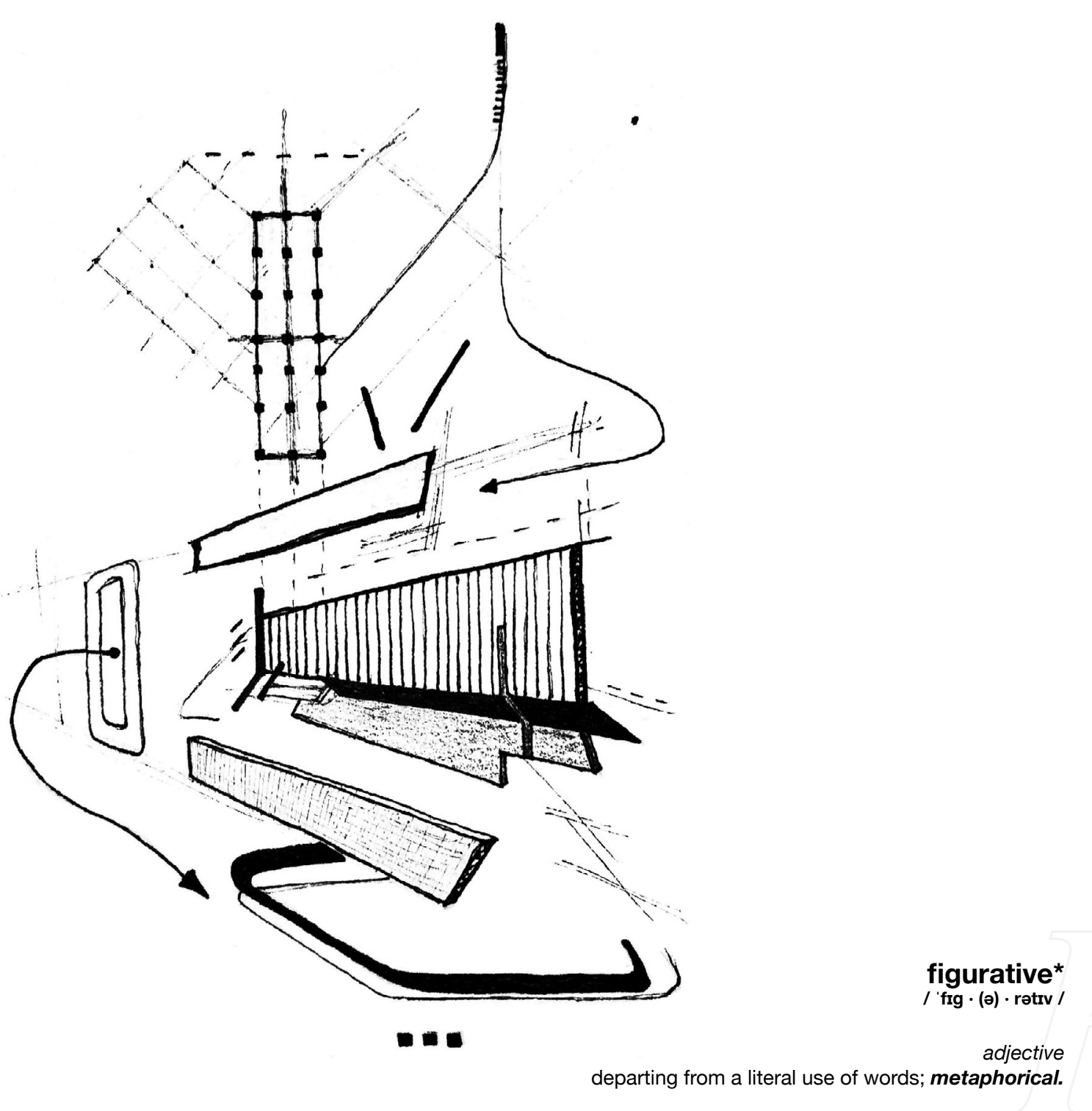


1.6 Drawing as an Investigation Tool:

Form:uLA - Bryan Cantley

Accompanying case studies that highlight narrative-based architecture and how design-led architectural projects can explore allegorical methods as a framework, drawing as an investigative tool also unlocks key ideas to [re]present a narrative. Owner and spatial orchestrator of Form:uLA Dimension Laboratory; an experimental design practice that blurs the intermediate zone between architecture and its representation lies Bryan Cantley. Cantley describes drawing,
like text, as having the opportunity to produce a myriad of rea text, as having the opportunity to produce a myriad of eadings and interpreftions. Architectural drawing is often initial take on orchitection that an archistectural that initial role of a relationship of occupant/viewer to the subject [matter]

The motif of Form:uLA's design language is the architectural machine - the man-made form in its most generic state.

At first glance, Cantley's drawings look like confusing

mechanical diagrams, yet, the drawings multiply into

progressive generations of images that morph off the single page. In his book 2011 publication 'Mechud the Rhetorics for Architecture', the first chapter explains the process and its reasening, process and its reasoning, where Cantley adds, the whole mage may seem incomprehensible at first, but individual moments aim to stand out and engage the viewers' (Cantley, 2011, p.84). "The drawings were rarely pure abstractionthey dealt with communicating vision through representation. But the models are pure objects. They represent nothing but themselves." Adopting this approach has allowed Form:uLA to [re]think the phenomenological relationship between page and objects, antifact and artefact. It makes us ask the question, where does the act of drawing take place? The page, or in the subconscious?
A key tactic in surrealist architecture is to dislocate objects from a set context or function, and insert them into new contexts and prescribe new functions for them (Spiller, 2018, p.94). Cantley explains this within the concepts of the 'Antifact' and 'Artefact'.

\section{THE ANTIFACT}

'Antifact': defined as the possible documentation of an object THE ARTEFACT

'Artefact': defined as a handmade object.

"I think I very much look at the building performance, and the performance of the drawing in a very similar way [...] As the performance of the drawing in a very similar way [...] As
I'm drawing something, I think about circulation as a series of spaces but also how you might navigate the drawing as an artifact itself - not as a representation of a built form" (Cantley, 2013, p. 36).

From these teachings of drawing as an investigative tool, it provides insights into how destabilising architectural conventions of narratives can use fragments of (existing) fonventions of narratives can use fragments of (existing) figurative geometry as a whe continuous reinterpretation of such geometries and their figurative other, to further our understanding of the role memories play in our interpretation of scarred landscapes. Drawing concepts to explore moving forward include:

1.6 [.1] ruins as a 'battle' and 'progressive' state [opposition between the two as a journey]

1.6 [.2] figurative geometries [incorporating figurative geometries through structural relationships

1.6 [.3] multiplicity of meaning [interpreting one thing that may mean another] 
Case Study:

Dirty Geometries + Mechanical Imperfections - Bryan Cantley

To further the understanding that drawing has on this thesis objectives, focus elaborates on the 'Dirty Geometries + Mechanical Imperfections' body of work curated by Bryan Cantley. Discussing the project at the Bartlett International Lecture Series in 2017, Cantley added, "Dirty geometries is about doing these very detailed, layered architectural drawings that don't describe an object; they describe sort of the deconstruction of the meaning of objects and the views of objects in what I call different chronologies, different tim frames happening at the same time" (Bartlett SOA, 2017) 'Dirty Geometries + Mechanical Imperfections' is a seeming 'Dirty Geometries + Mechanical Imperfections' is a seemingly enigmatic and speculative multi-media project, formulated primarily through a series of palimpsestuous drawings. These architectural drawings, models and images present a body of work that suggest an alternative spatial discourse - a methodology intriguing for this thesis proceeding. Migrating between two distinct, yet transecting conditions, the experimental architectural drawings [image] and the mechanical architecture [object] are exhibited as conjunctive informants in the process. The 'Dirty Geometries' portion houses a series of over 30 hybrid drawings that attempt to houses a series of oves 30 hybrid drawings that attempt to enhance the audience as both an inhabitant and navigator of the draw. The 'Mechanical Imperfections' section presented 10 conceptual projects that engage in a dialogue of imperfect machines struggling to construct perfect architectural

moments. Experimental drawings that deconstruct unknown views that remain unrecognisable act as vehicles to explore spatial occupation - [re]connecting lost spaces with

imaginary realms to support inhabitancy. Challenging the

conventions of architectural drawing, Cantley reveals a range of approaches that cumulatively trace the development of fragmented fields - drawing remains vital in architecture fragmented fids c drawing remains vital in architecture today - and

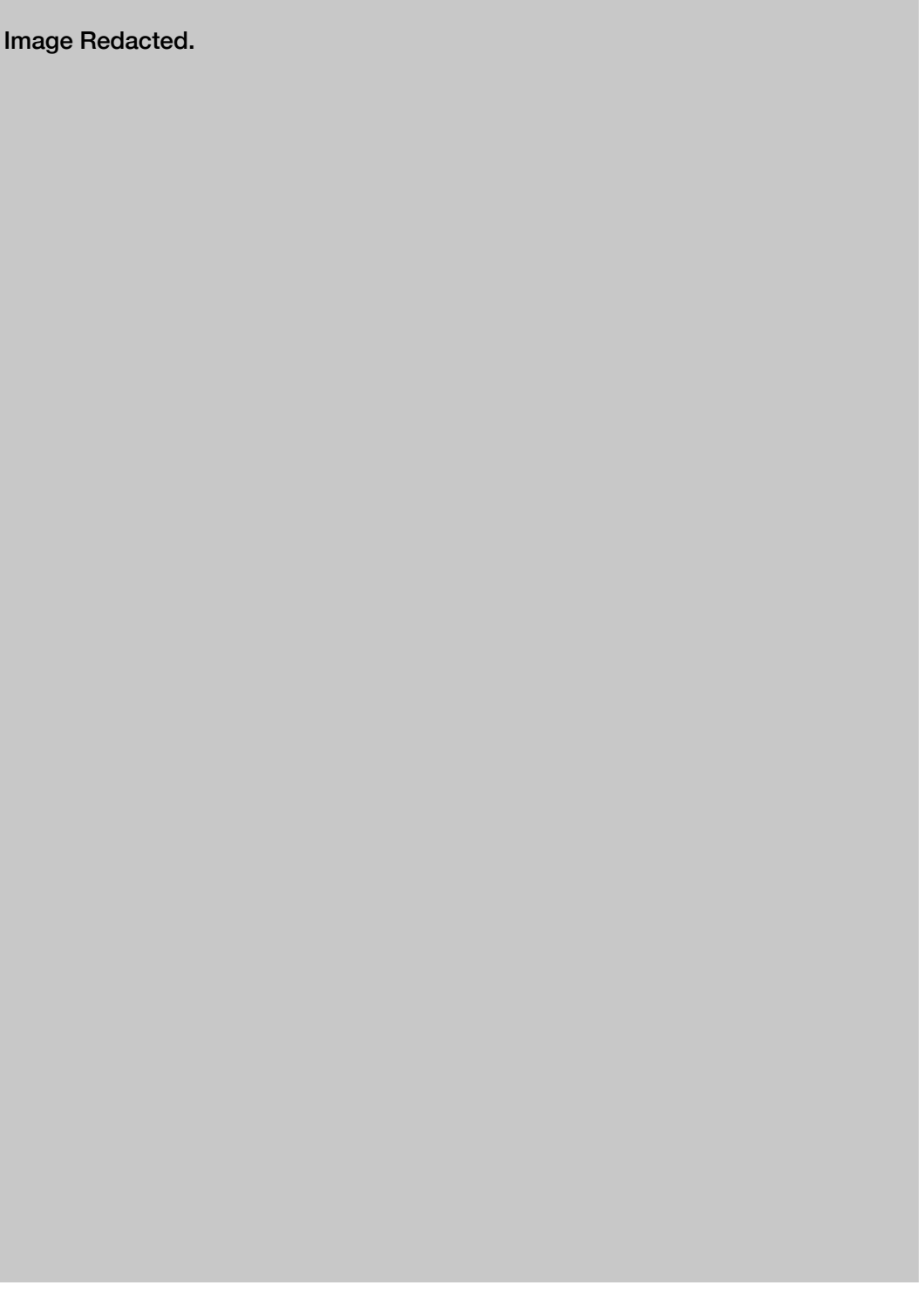



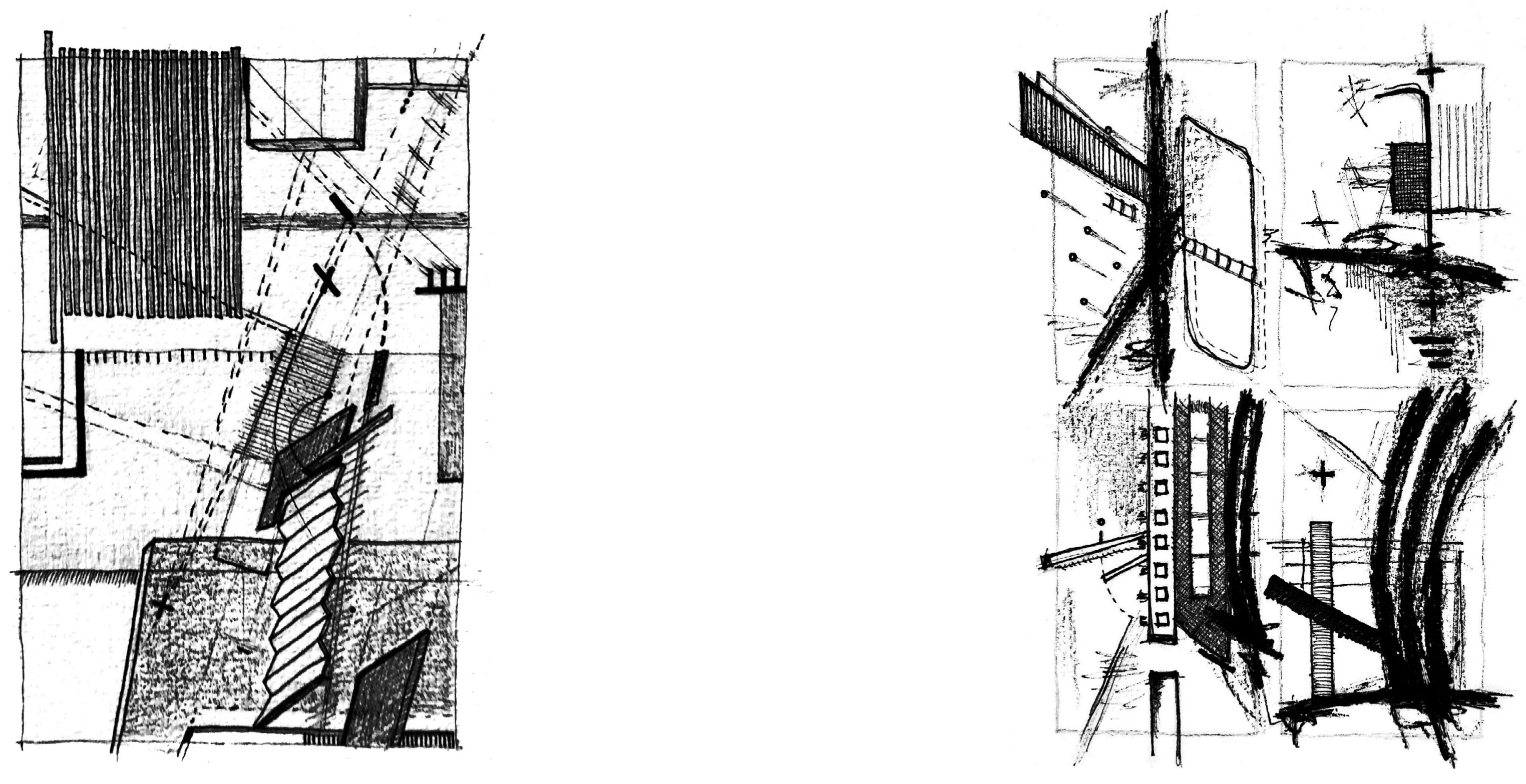


\section{Critical Reflections and Analysis:}

In this chapter, Walter Benjamins 'The Origin of German

Tragic Drama' provided insights into allegorical traits to enact a successful fictional narrative for an ongoing architectur project - allowing the designer to unclose the mind, and shift conventional design thinkings. Application of Wellington Reiter's theoretical framework of narrative design in his book 'Vessels and Fields', gave ideas on how typologies can act as connective tissue between past forgotten, or imagined pasts - and can act as a shift to the present [future] of design thinking.

Virgil Abloh's contemporary take on the 'Purist' and 'Tourist' in relation to this design-led thesis, in accordance with Antoine Picon's theories on site heritage and reinterpretation, allowed a critical framework to be established moving forward. The Perano Whaling Station in the Tory Channel will be explored as a fragmented historical context. Excavations through the [re]interpretation of drawing, the 'Purist' and 'Tourist' can begin to [re]imagine Perano as a new figurative urban artefact - migrating between past and present formally creating a new historical context.

Bryan Cantley's experimental 'Form:uLA' methodologies and projects became some of the largest inspirations for design experiments moving forward, extrapolating the relationships to invite the more unexpected speculative design outcomes. The notions provided by relative theorists constantly lie in a dialogue with the design experimentations, and will be critically tested and applied to relative drawings and models. The combining of these theories adds unexpected layers to the design process - to allow differing relationships
Through the application of these theorists of allegorica narrative design, key features for future design experiments were defined:

- the repetition of figurative geometries can act as vessels of multiplicity [interpreting one thing that may mean another] [Purist vs Tourist]

- drawing can act as an effective multi-layered inquiry too to enhance the locus and reinterpretation of a surrounding landscape

- re-using 'old' traces through 'new' architecture adds to the ongoing traumatic narrative

Utilising the above design tactics mined from the traumatic narrative, drawing design experiments were conducted in relation to relevant allegorical case studies. These experiments began to develop an architectural [form]al language for the thesis - excavating case studies for similarities and applicabilities to the allegorical programmes to come; POST Trauma. 


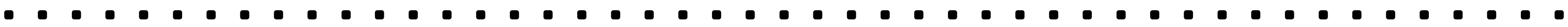

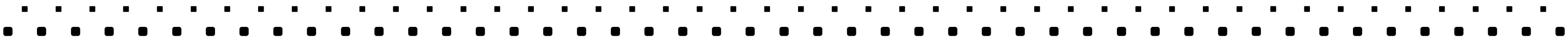

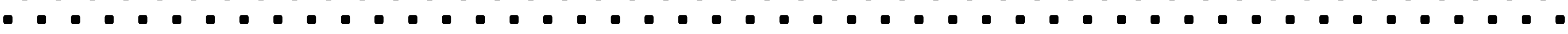

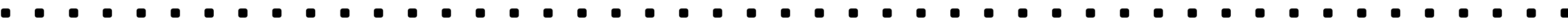

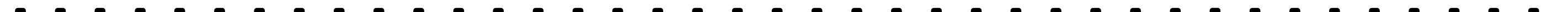

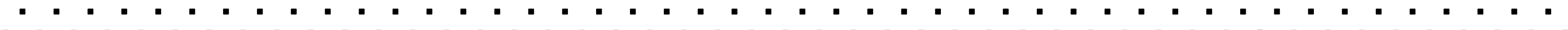

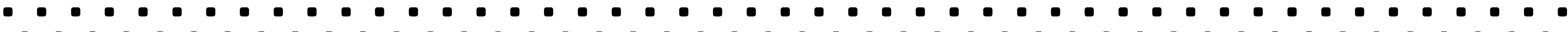

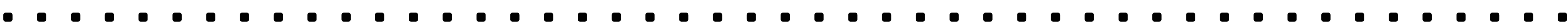

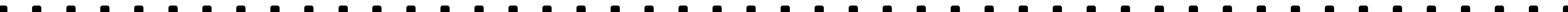
(

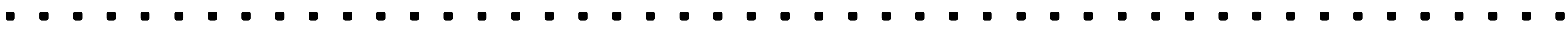

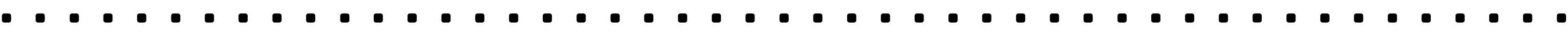

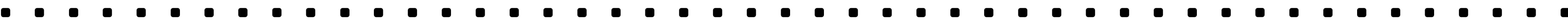

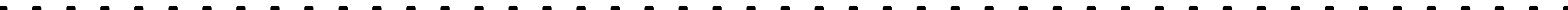

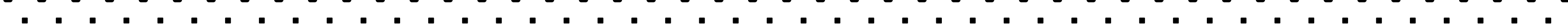

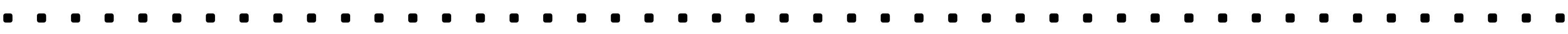

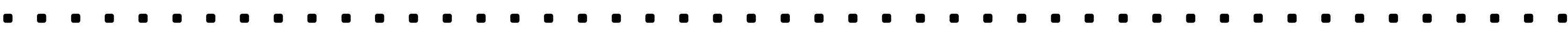

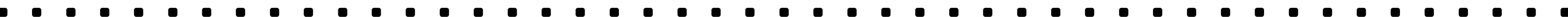
0

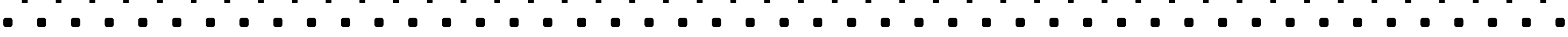
๑

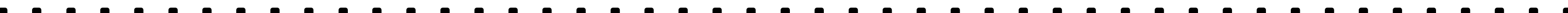

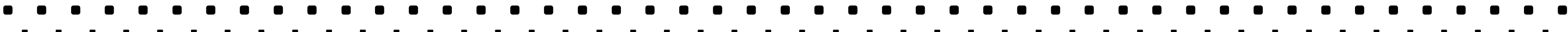

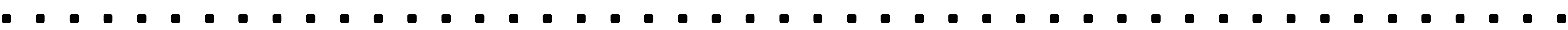

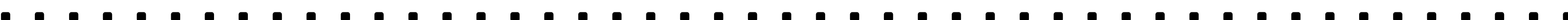

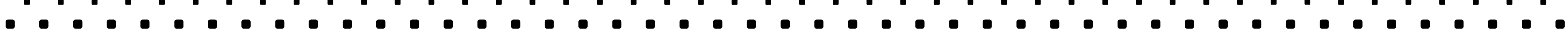




\section{Part Two}

[ Preliminary Design Experiments: Speculative Drawing ]

Research Objective 2: to examine physical (real) and conceptual

(imagined) notions of architectural ruins through the evocative

experience of speculative architectural drawing in order to actively

contribute to an on-going architectural narrative.

$\underset{\text { ana } \operatorname{ang} \operatorname{logue}}{\operatorname{ang}}$

(n)

relating to/using signals or information represented by a continuously variable physical quantity such as spatial position

from greek; analogon 
This chapter outlines and explores contextual analysis of Perano Whaling Station, located on a reclaimed narrow platform on Arapawa Island - residing above the waterline of Tory Channel - where future speculative design experiments are to be sited. This chapter outlines contextua understandings and methodologies to be used for research objectives two and three. The once-thriving whaling station is now skeletal steel and concrete remains. A provocateur for is now this site of Perano Whaling Station was to undo the exploing this station's age-old frustrations and scaring conflicts. Whaling stations suffered in the banning of whaling New Zealand waters in 1964, resulting in the abandonment of historic sites in the industry. These historical ruins and scars are gradually being lost through the transformational decay of architecture and coastal erasure. This puts at risk the permanent loss of our history and collective memories of these architectural ruins.

The Perano West Head Lookout rises up above the entrance to Tory Channel, perched 55m above sea level acting as a to Ton for panoramic viewing. This lookout encapsula sentinel for panoratic an im . 74) Thea $2002, p .74)$. The once small terrace located at the high point of the ridge is now completely broken down remains of the old. Timber boards and corrugated remain scattered, with a concrete water tank reclaimed from World War II that housed a generator. Mark Nelson, a DOC conservationist added, "The Perano site is the most intact of New Zealand's remnant whaling stations so it is a fitting place to remember and learn about our whaling history [...] The Perano family were renowned for their forward-thinking and innovative attitude, including pionering and developing the use of small highspluding pion thering and developing the use of smallighspeed moth Strait."
The objectives of these site speculations and cartography is to signify the beauty and imperfections of decaying ruins to encourage these allegories associated as a narrative of history and site potentials. Interventions by reinforcing structure can enhance the narrative of site to encourage people to act as participants of memories as a repository. By proposing renewal through the existing decaying-scapes, a framework is provided to grow and manifest these memories. Will the analysis of anamnesis propose mnemonic vessels?

Three design interventions will be proposed for this designled investigation, based on the stories of past trauma's uncovered in site analysis and the fragmented installation process. Whaling and industrial infrastructure which scars the landscape can be examined in a similar light, where the introduction of the author (viewer) and theoretical interpretations allows for alternative point of views. Programmes add layers to the past scars, allowing for the historic remnants to tell the stories for future viewers.

\section{The Gateway}

This programme acts as the immersion point to the traumatic stories of Perano, dispersing the fragmented field.

\section{The Vessel (tiramaka)}

This programme represents the stories of the traumatic murmurs that remain on Perano Whaling Station, allegorically reminiscent through figurative
geometries.

\section{The Sentinel}

presents a detached observation tower on West Head Poin that frames the erased landscape in an enigmatic sense. 


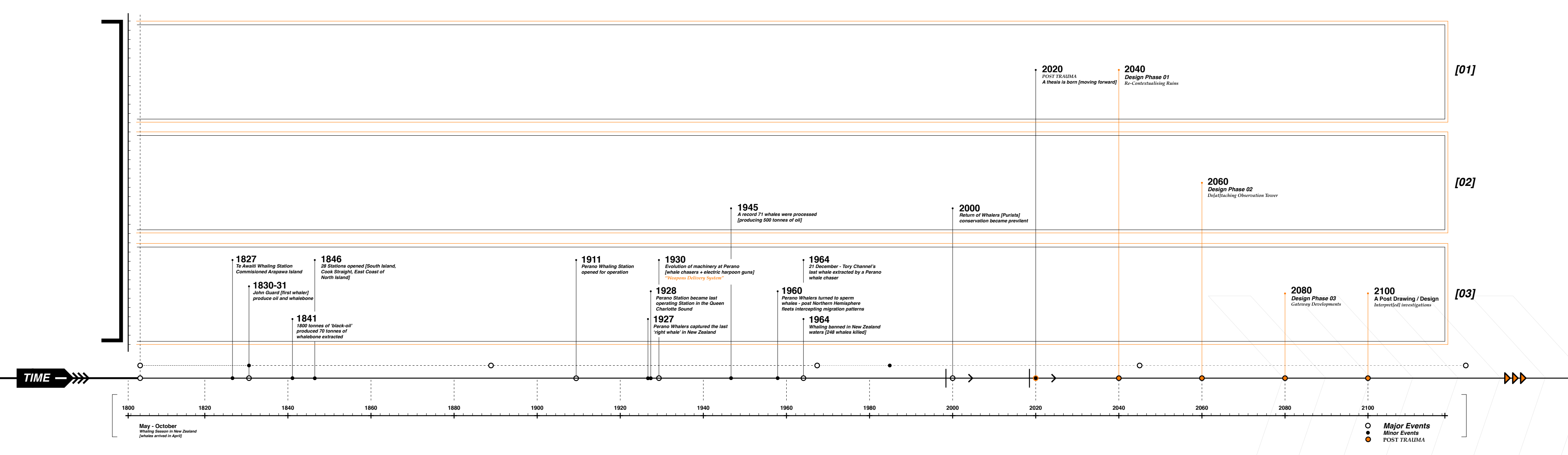



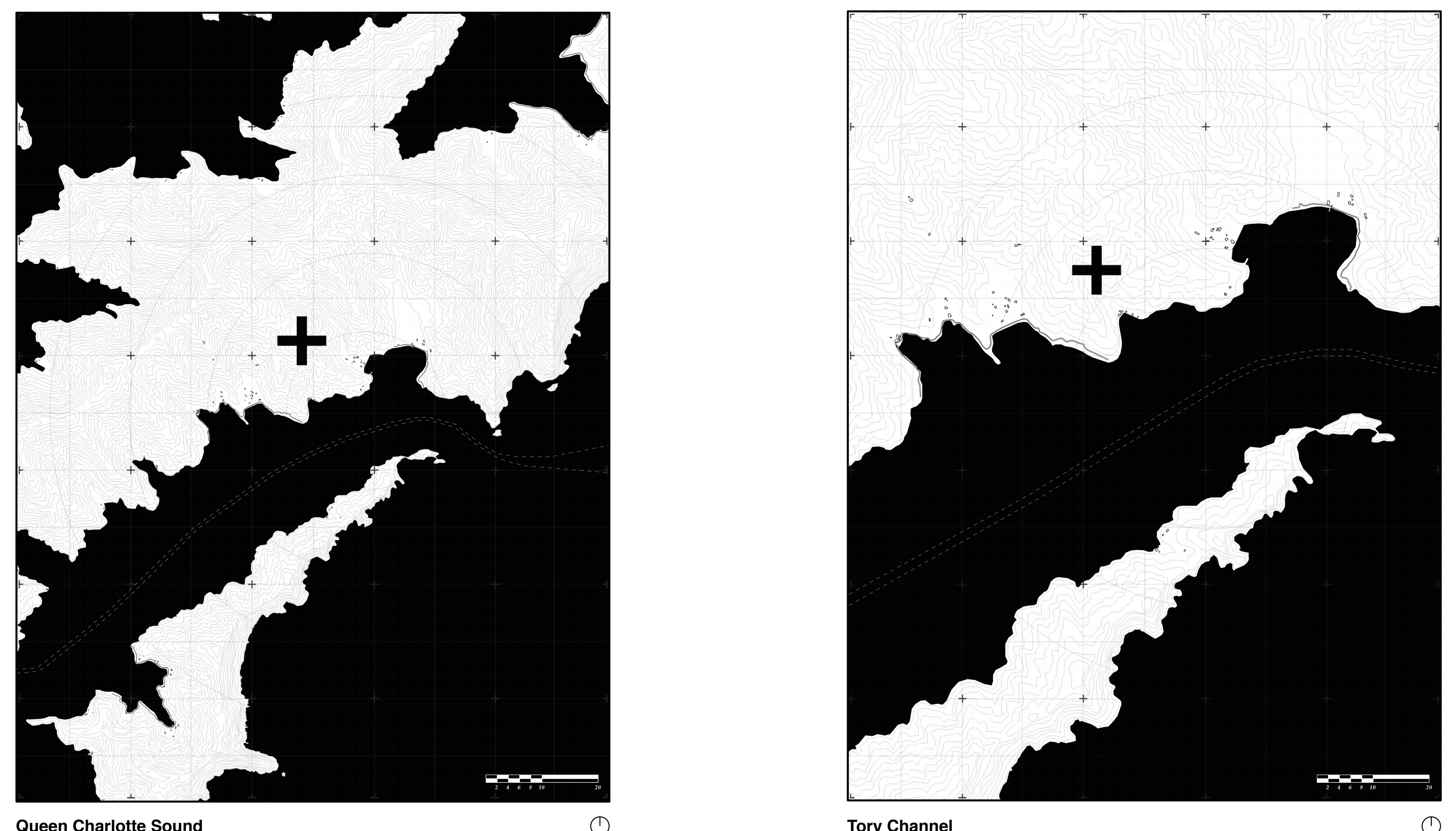

Queen Charlotte Sound 

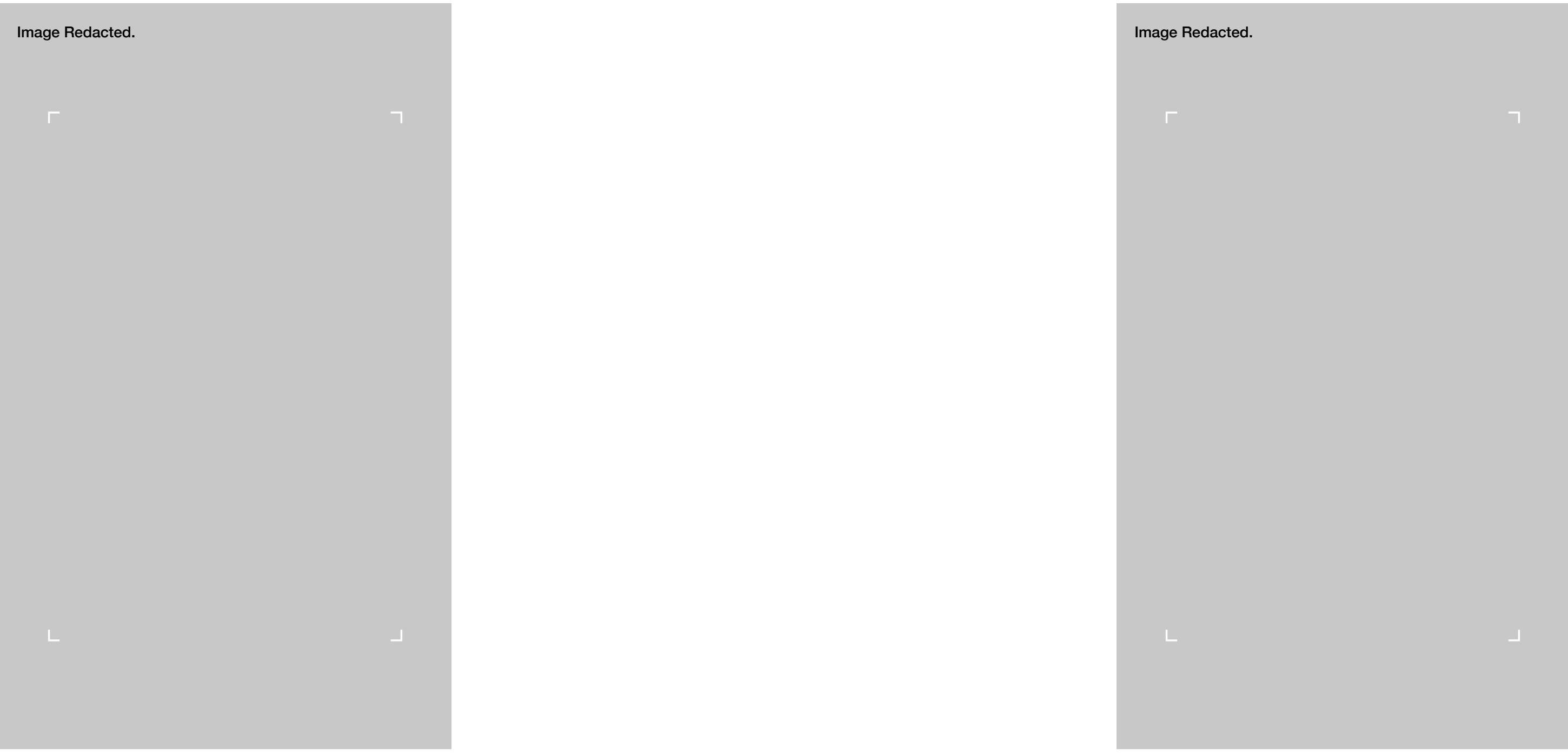

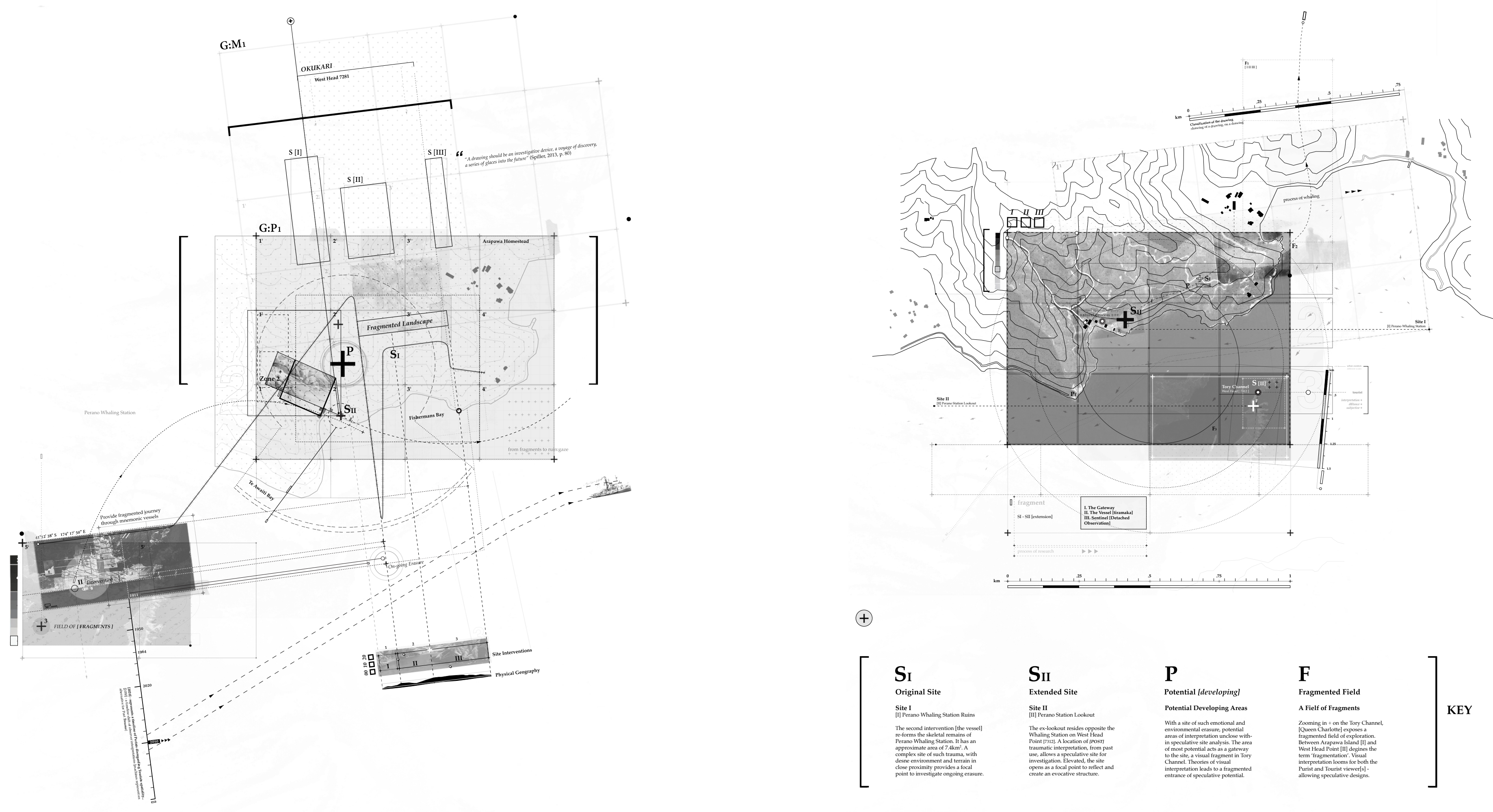


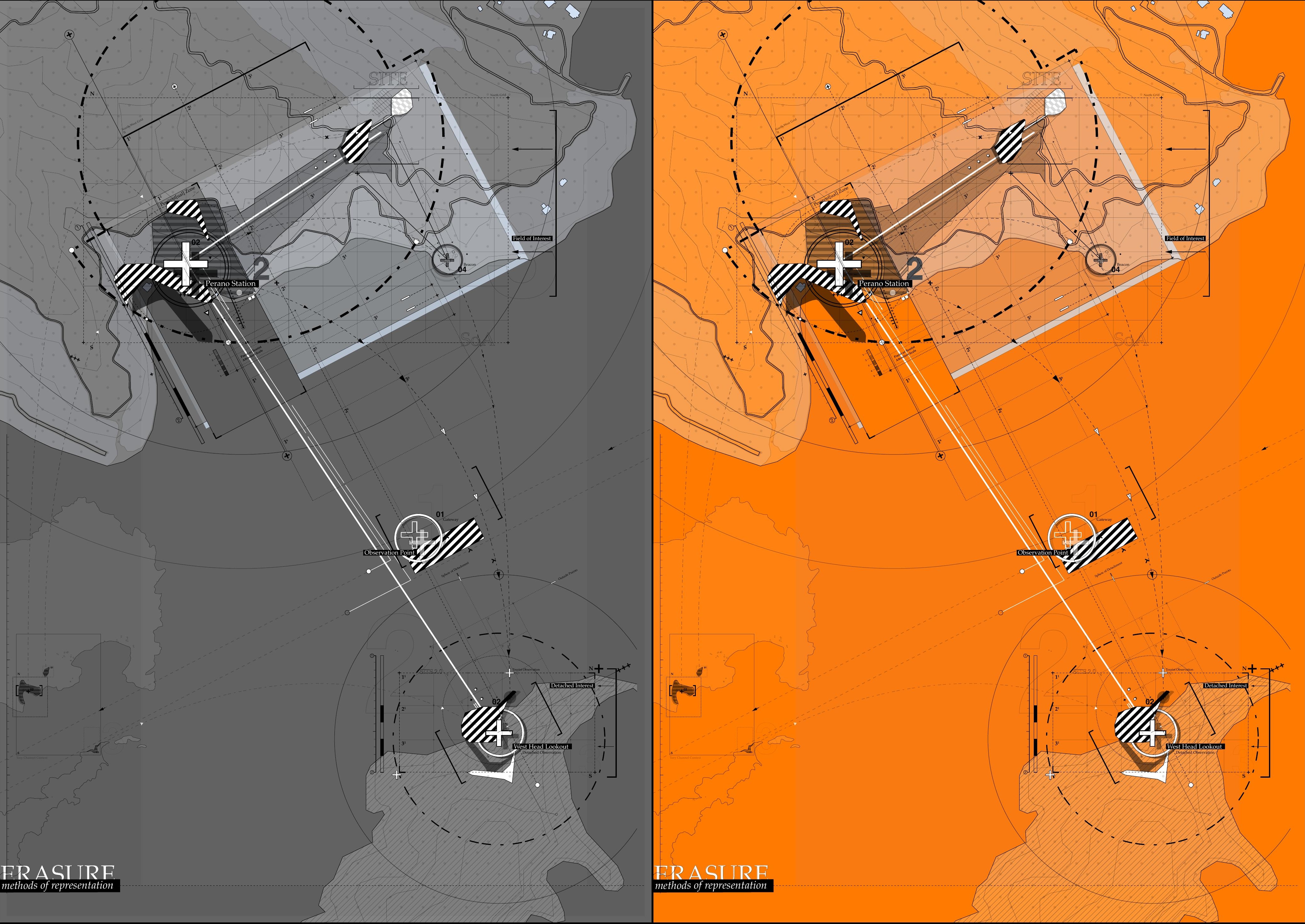




\begin{tabular}{l} 
Image Redacted. \\
\hline Image Redacted. \\
\hline Image Redacted. \\
\hline Figure 40: Erasure in Tory Channel at multiple scales', (2020), Mixed-Medial Images. \\
\hline Image Redacted. \\
\hline Image Redacted. \\
\hline
\end{tabular}




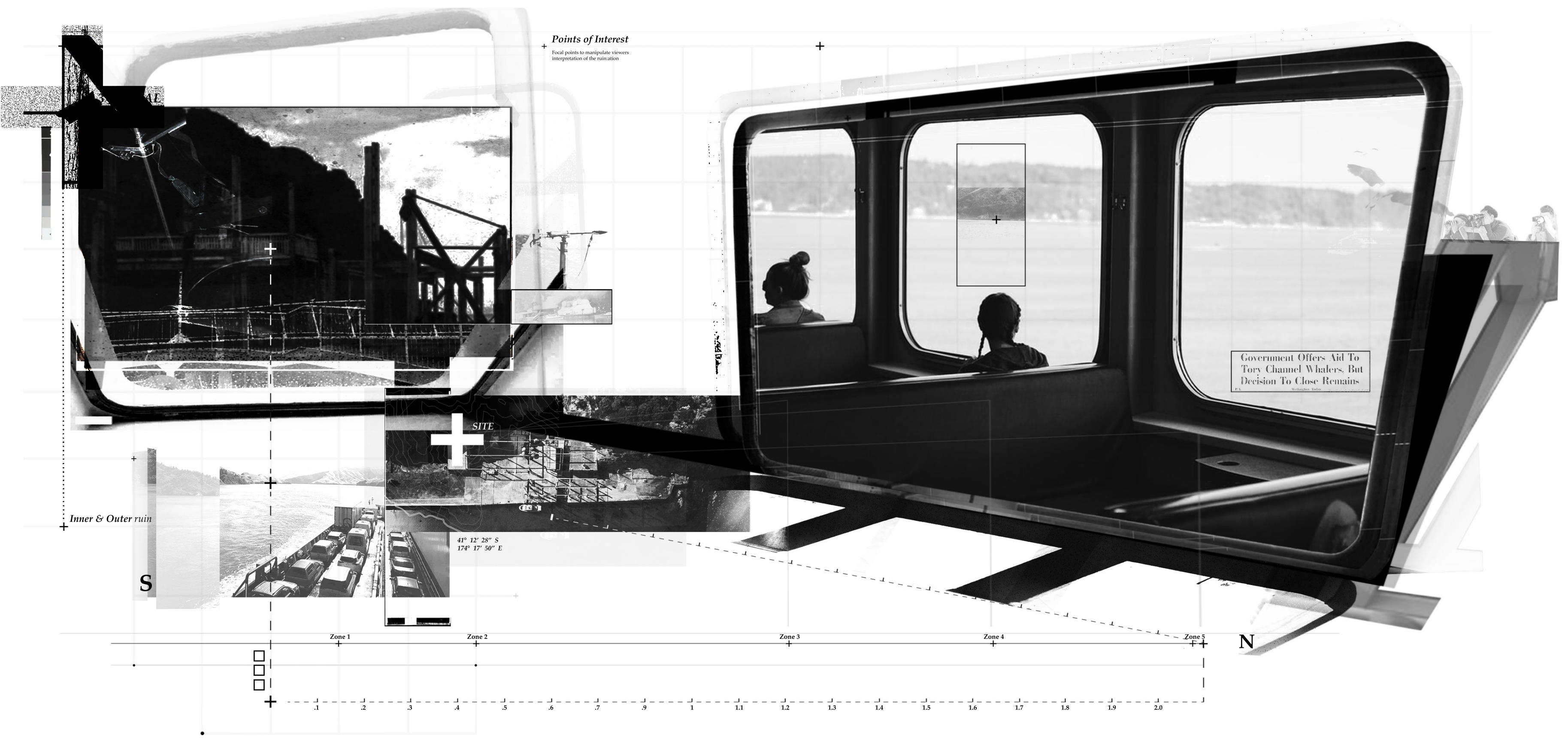




\section{Theatrical Observation}

Aims:

The aim of this design experiment, acting as an exhibitive installation, is to explore the tactile relationship betwee author, viewer, and relative point of views. How can the engagement of the viewers subconscious imagination and spatial experiences shape recorded memories - both real and imagined? By engaging the occupants' perceived experiences, it aims to question how work as an enigmatic device can evolve over time through a space. The series of accompanying hybrid drawings employ multiple techniques to question how the architectural [re]interpretation of drawing aligns with the recollection of memories - through the 'line'.

\section{Method:}

Both speculative and empirically grounded, this first design experiment fell in the realm of drawing capabilities and perceptions based on narrative perspectives of an installation. "In proposing an architecture that engages the fact that perception is not permanent, the emphasis should be placed upon the interweaving viewpoints of creator and viewer, making the subject (viewer) inseparable from its background (drawing)" (Allen \& Pearson, 2016, p. 124). Allegorical in (drawng) (Allen \& Pearson, 2016, p. 124). Allegorical in context, the drawings argue for enigmatic architectural [re]presentation, migrating between typology and perspective, allowing for the viewer to 'finish' the drawing. Parsa Khalili denotes that "drawings involve a relationship that is dynamic between subject, object and point of view, where the surface engages the viewer's anthropomorphic imagination to project human forms even when they are not present" (Allen \& Pearson, 2016, p. 124). This correlates coherently with this installation experiment, drawings act as tools to engage empirical grounds, forging draw rections the relationship between today's presence, and yesterday's
forgotten elements.
Through a sequence of monochromatic drawings derived from fragments of site cartography, figures were displaced and re-assembled to reveal differing viewpoints and provoke mnemonic narratives. These narratives were translated to a 3D physical installation model, which highlighted the cartographic analysis through materiality and a 'forgotten history.' An absence of text requires the observer to engage with the drawings and model, constructing their own memories from such mediums. Using mapping as generative process revealed suppressed conditions and generative process revealed suppressed conditions and hidden historic events, unhinging context from conventiona architectural concerns. Whilst predominantly architectural in nature, the drawings obscure the boundary between what the viewer forms as conceivable space[s]. The robust idea of Virgil Abloh's 'Figures of Speech' installation remains in constant dialogue, inviting dialogue between 'Purists' and 'Tourists' in unexpected design outcomes.

Rather than identifying or designing architectural form, I extracted strata of pre-existing fragmentations of history through [re]presention methods. Using Sketch through [re]presentation methods. Using SketchUp and CAD softwares and analogue media, drawings are thus generated through deep excavation: layering, obscuring, scaling, as modes of abstraction for example. Design decisions were made both iteratively and quickly in the process, allowing this archive of geometric material frame to be tested strategically loosely, inviting unexpected representations. The model as an installation acts as both a physical symbolic and procedural instrument for all to engage. Claire Bishop parallels this, noting an installation as the desire to heighten the viewer's knowledge of objects positioning (installed) in a space and how occupants respond differently (Bishop, skishop, 2005, p. 6). 


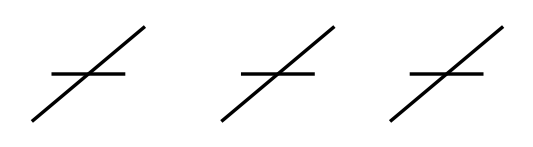

Buildings, landscapes, and materials serve as poignant reminders of our

history. Sites become palimpsests
upon

upon which layers of memory are
und through time ... Buildings act as witnesses of the past.

Markus Berger, 2013. 


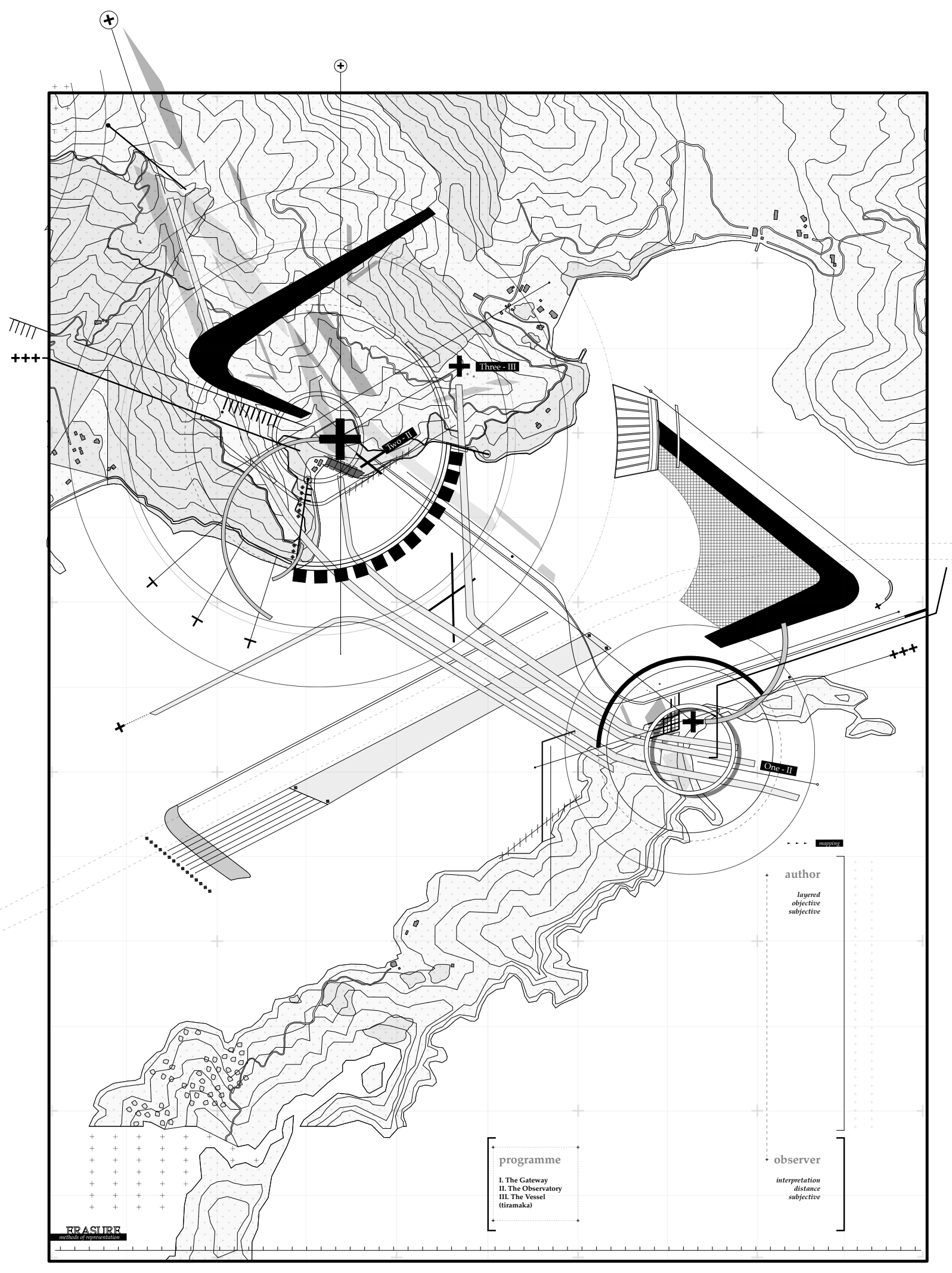

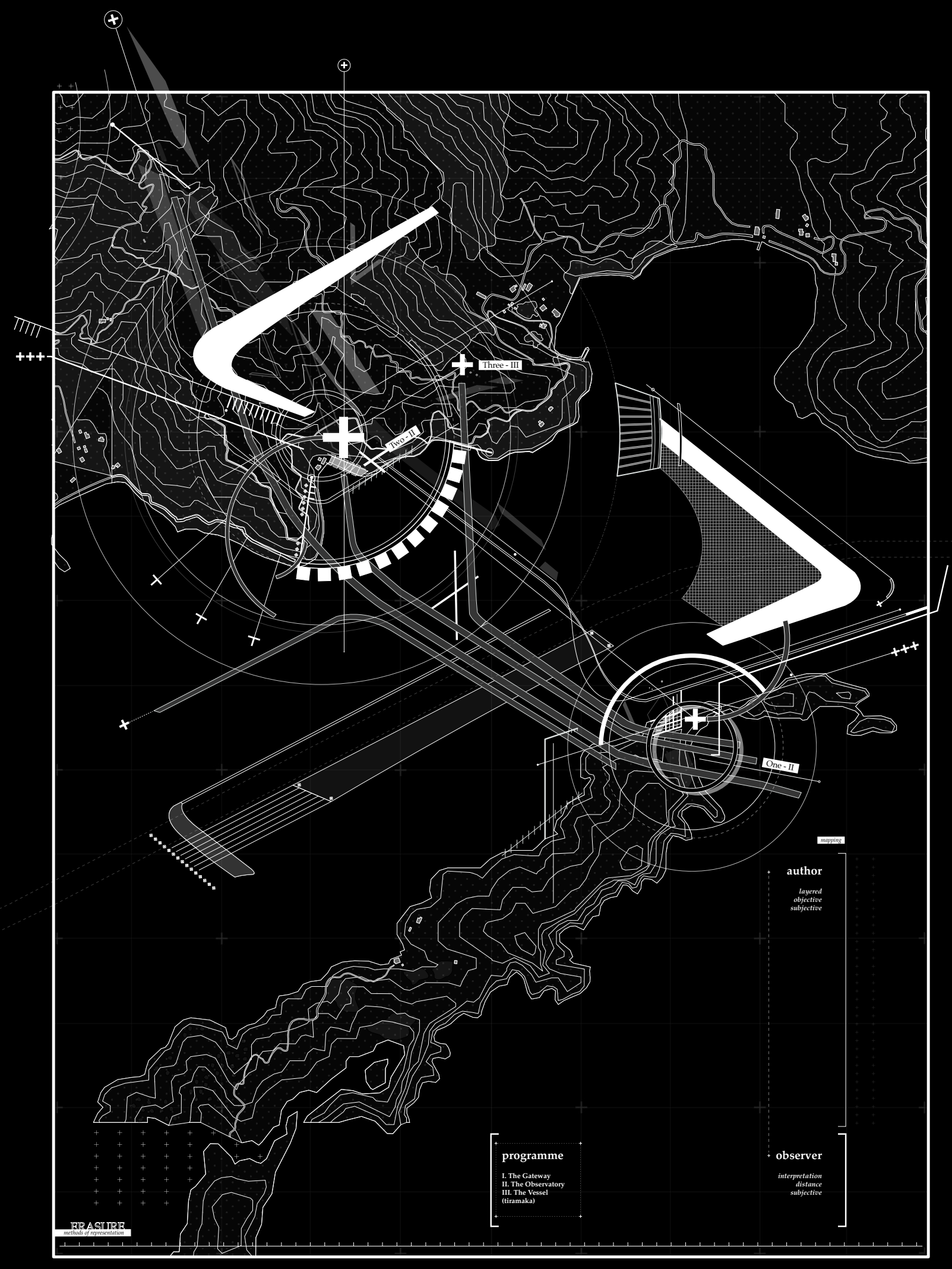

Figure 43: 'Theatrical Observation Cartography [inverted]', (2020), Mixed-Media Image. 

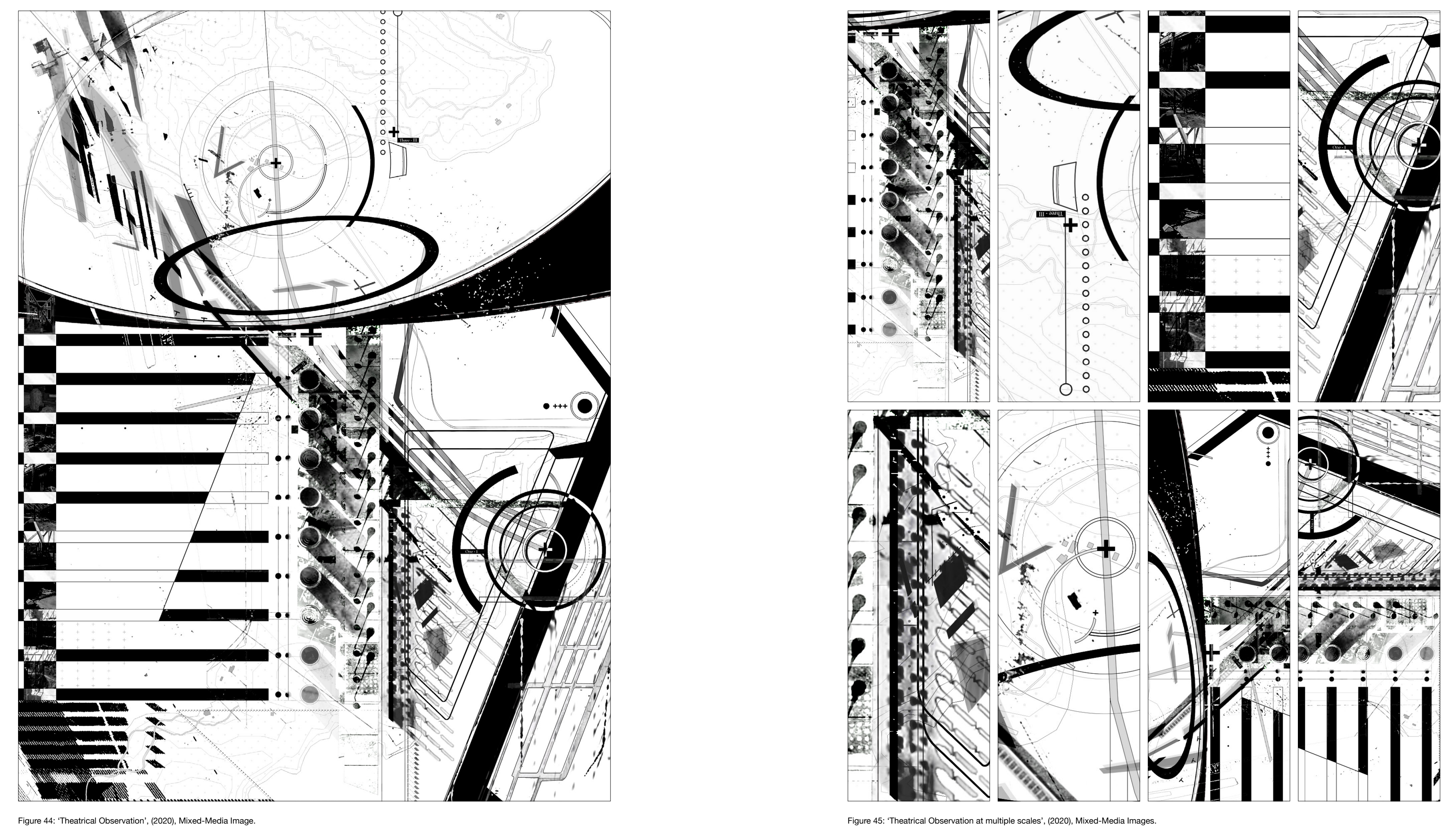

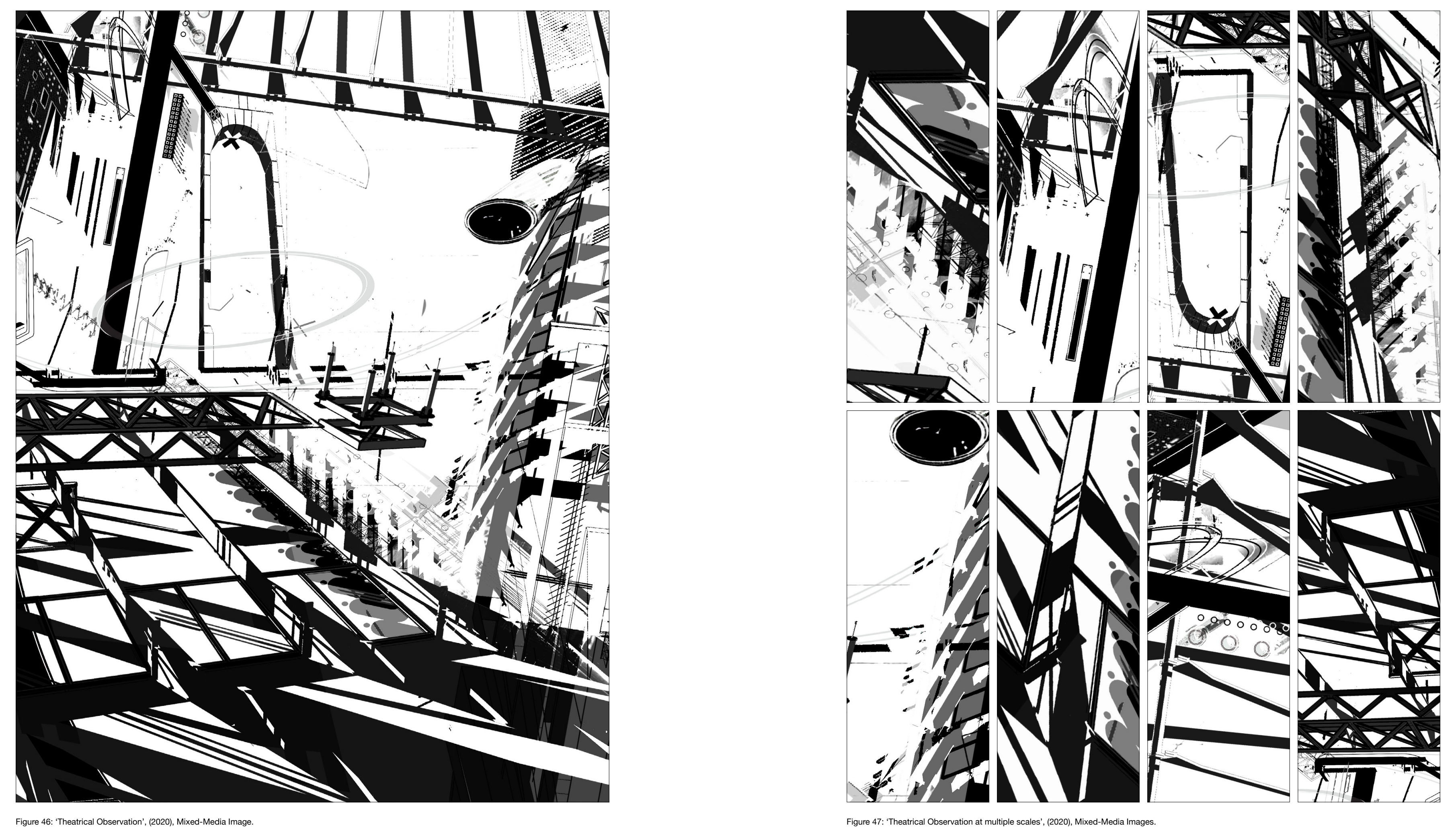

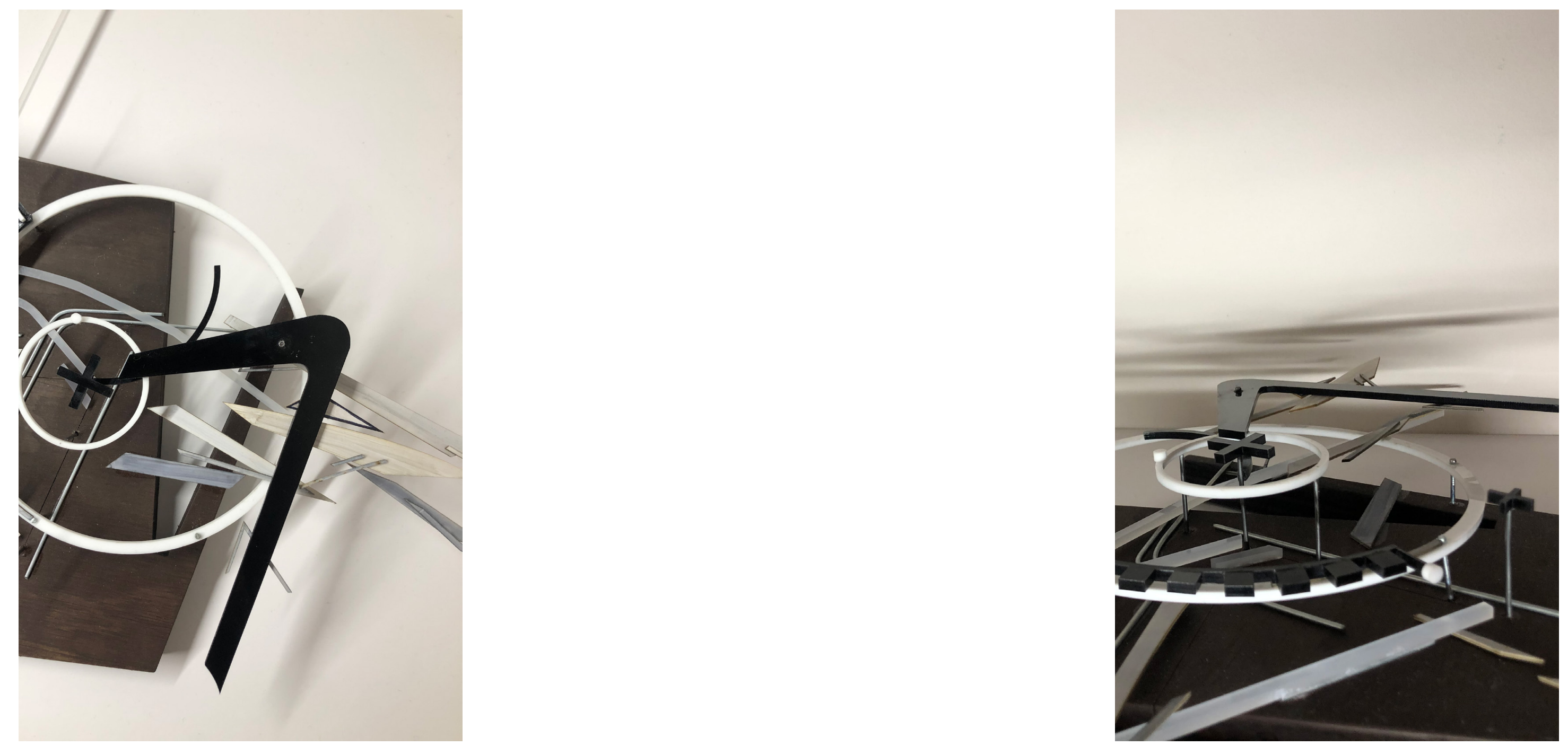


\section{Theatrical Observation}

"In visualizing... Interrelationships and interactions, mapping itself participates in any future unfoldings" (Corner, 2014, p. 198)

\section{Design Outcome:}

The initial design experiment helped established a visual vocabulary for this thesis, [re]interpreting drawing through [re]presentation of allegorical erasure. The aim of this first design experiment was to embrace the 'spontaneous' and 'serendipitous' that Smout Allen class as fundamental to their representative design process. Allen argues for a methodological approach that incorporates drawing and model-making as a robust means to uncover relational model- Furthermore, Allen argues for a desic "as a series of more or Ass distinct phases of syncopated investigations, many of which are trialled and testod scal investigations, many of which are thalled and tested, scaled and exposed in three dimensions, while some, in contrast remain nothing more than a thumbnail sketch" (Allen \& Smout, 2008, p. 82). As such, the outcome of this experiment stems from the robust methodology argued, where drawing and making provide pivotal tools to contextualise a narrative identity for Perano Whaling Station. The drawing and model as devices add to both the objective knowledge and subjective experience of the site to viewers - acting as strategies for architectural tracing and assemblages.

\section{Critical Reflections:}

drawings and model titled 'Theatrical Observation' can be perceived as a fragmented event in the landscape; rendered through a series of panoramic and cartographic observations too spatialise memories. As Smout Allen enacts, drawing and making can be considered "a haptic experience where the physical act of piecing together ideas in two and three dimensions allows one to come into close contact with the very matter of the problem" (Allen \& Smout, 2008, p. 85). The process drawings are worked through multiple perspectives and elements of spatiality, physically and conceptually create an operative dialogue between the mediums. 'Theatrical Observation' invites participants to present an embodied exchange with the methodology principals this design-led investigation employs. Whilst enigmatic in their sensibility, the drawings and model should be engaged at different angles and proximities for the viewer to grasp underlying relationships and traces of a past trauma. This approach adds to the framework and [form]al graphic vocabulary for future design framework and [form]al grar

Throughout this design process, the multi-scaled installation was beneficial in establishing associations of drawing and making as memory devices for approaching a puist and tourist mindset. This initial experiment questions how we begin to construct an erased landscape through interventions that enhance the memories of past scars. How can [re]interpretation of mediums allow new interventions to enhance experience and events? This initial work allowed us to unclose the mind, and ground the scope of the project us to unclose the mind, and ground 


\section{Image Redacted}

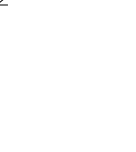




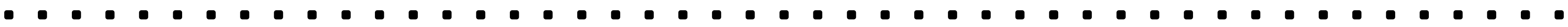

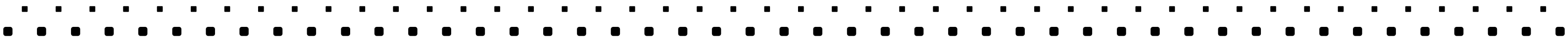

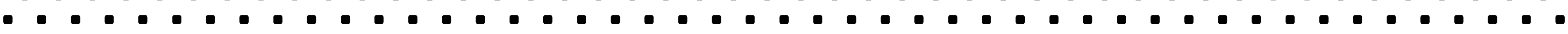

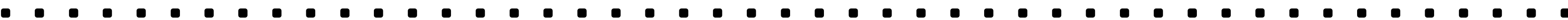
6.

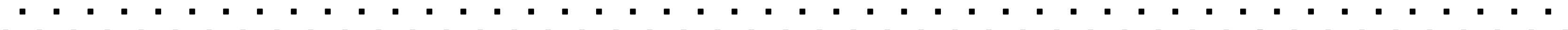

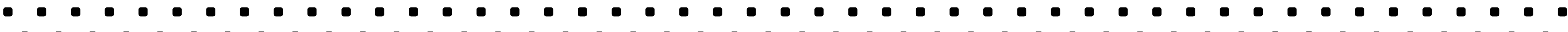

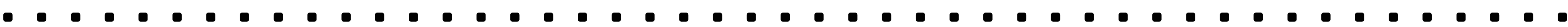

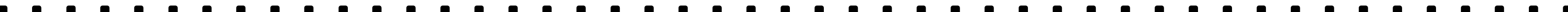
(

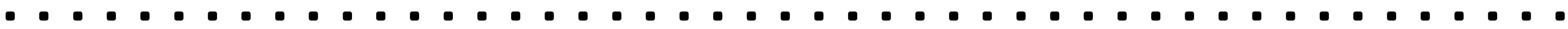

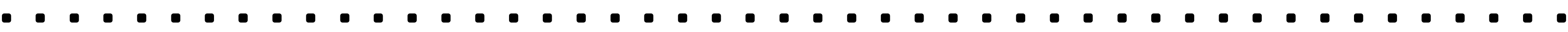

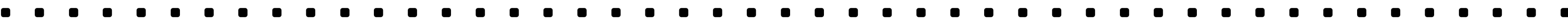

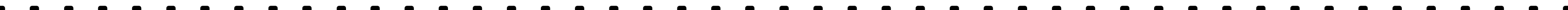

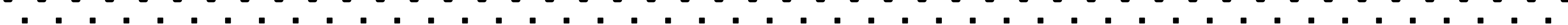

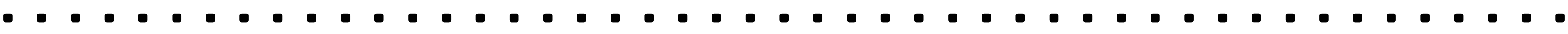

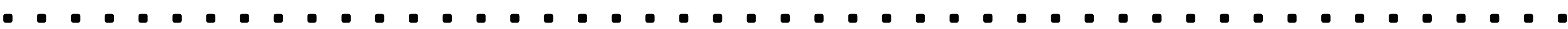

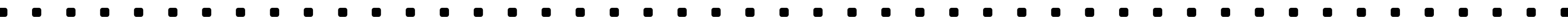
000.000

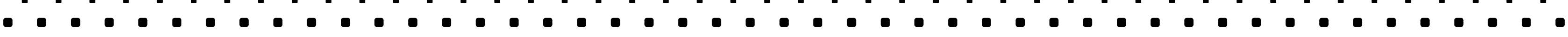
๑

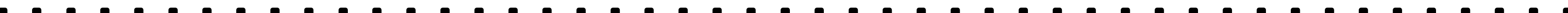

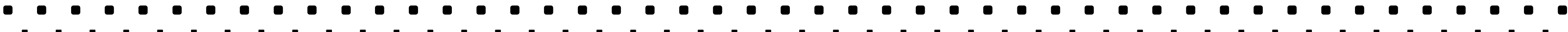

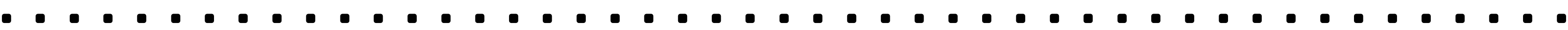

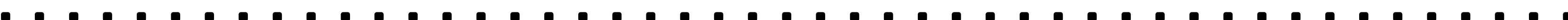

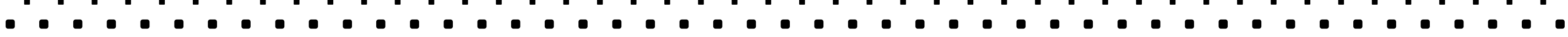




\section{Part Three}

[ Design Experiments: Speculative Drawing ]

Research Objective 2: to develop architectural ruins as

repositories of memory through new architectural interventions

that activate experiential narrative constructs of a 'Purist's' and

'Tourist's' spatial mindset; inviting speculative design outcomes.

catalogue*
/ cat $\cdot$ a $\cdot \operatorname{logue} /$

a list of works of art in an exhibition or collection, with detailed comments and explanations

from greek; katalogos 
Preliminary Design Research

The initial design experimentation helped establish a valid performance criteria [spatial constructs] for coming speculative [re]presentations. The methodological drawing that follow enhance this idea of a fragmented landscape experiencing erasure as a medium for speculation. This [re] interpretation of the architectural drawing and its relative possibilities documents the pasts and alternative futures for the Perano landscape. Smout Allen inscribes that "drawings of this kind are not necessarily intended as an "drawings of is ind as an end themselves, instead the drawing is a tool for the creative process rom which things begin to take form" (Allen \& Smout, 2008, p.82). Drawings that follow begin to examin the site as a series of potentials that can propose 'new' architecture, from 'old', in a traumatic landscape. Acting as poetic devices, the drawings add to both the objective knowledge and subjective experience to inform strategies of architectural reintegration. These drawing investigations unlocked habitable functions and systems through a

speculative and critical process. Can these drawings meet the outlined aims of this design-led thesis - and help act unpack such forgotten memories?

The multidimensional style forthcoming takes influence from relative texts and case studies - which helped establish a provocative design research mode of dialogue for whic this work wishes to be [re]presented - the opening of doors. "Question Everything". (Abloh, 2019). Early sketch experiments take the figurative geometries remaining scattered on site, [re]assembling and [re]programming these 'machines' as new architecture to enrich the design intent. "Drawings deconstruct meanings of objects" to suggest Drawings deconstuct mean (Conter, 2017). Machinest hasnative spatial discourse (Cantley, 2017). Machinery has a negative connotation on Perano's context at current, figurative [re]interpretation seeks a positive outlook for a site experiencing such erasure.

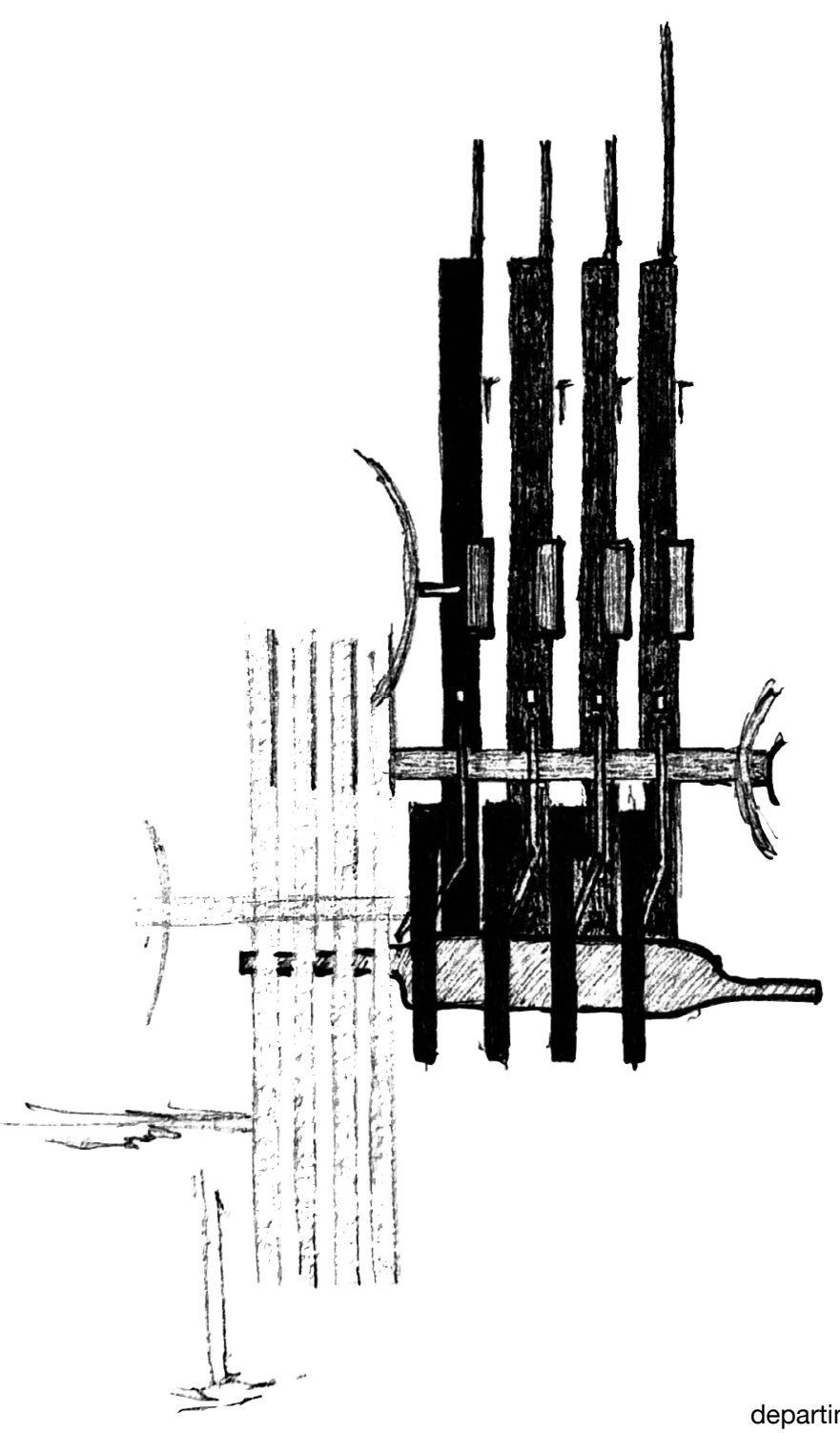

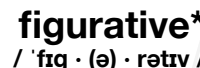

departing from a literal use of words; metaphorical. 
Ruins have long been an obsession in architectural discourse, with the idea of a ruin as a vessel, or;

"An allegory of memory... Fragmentary, imperfect, partial and thoroughly incomplete. There is no clear sign that the meaning of the past is self-evident and easy to decide if you possess the necessary expertise. There is an excuse of meaning in the remains:

a plenitude of fragmented stories,

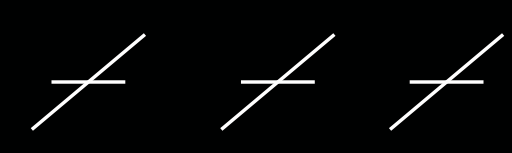

elisions, fantasies, inexplicable objects
and possible events which present

a history that can begin and end

anywhere, and refused to master the narratives of history..."

Tim Edensor, 2005, p. 140. 
$\left[\begin{array}{l}\text { Drawing Methodology } \\ \text { : Spatial Constructs I Performance Criteria }\end{array}\right]$

"OBJECT" I object under investigation

"PROJECT" I documentation of object

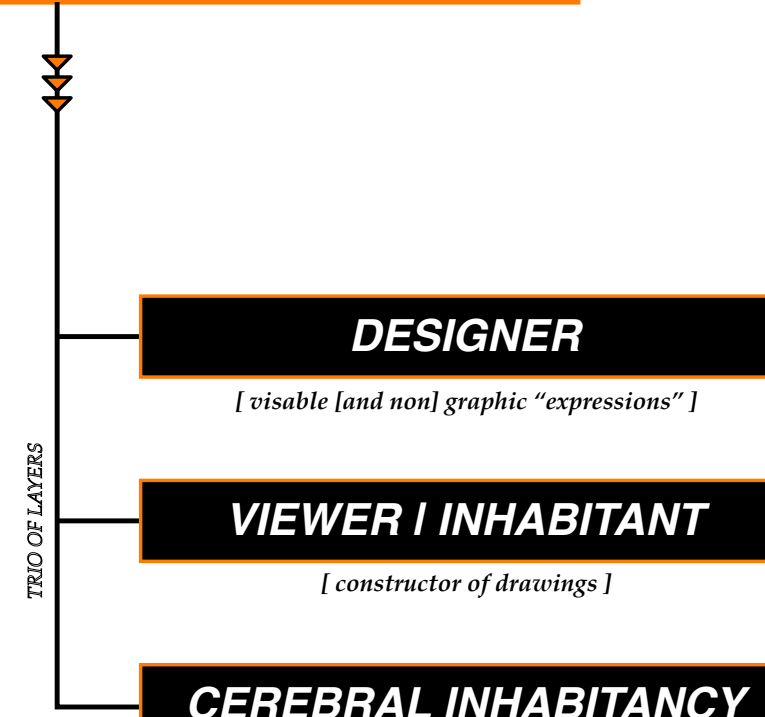

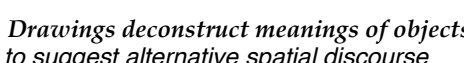

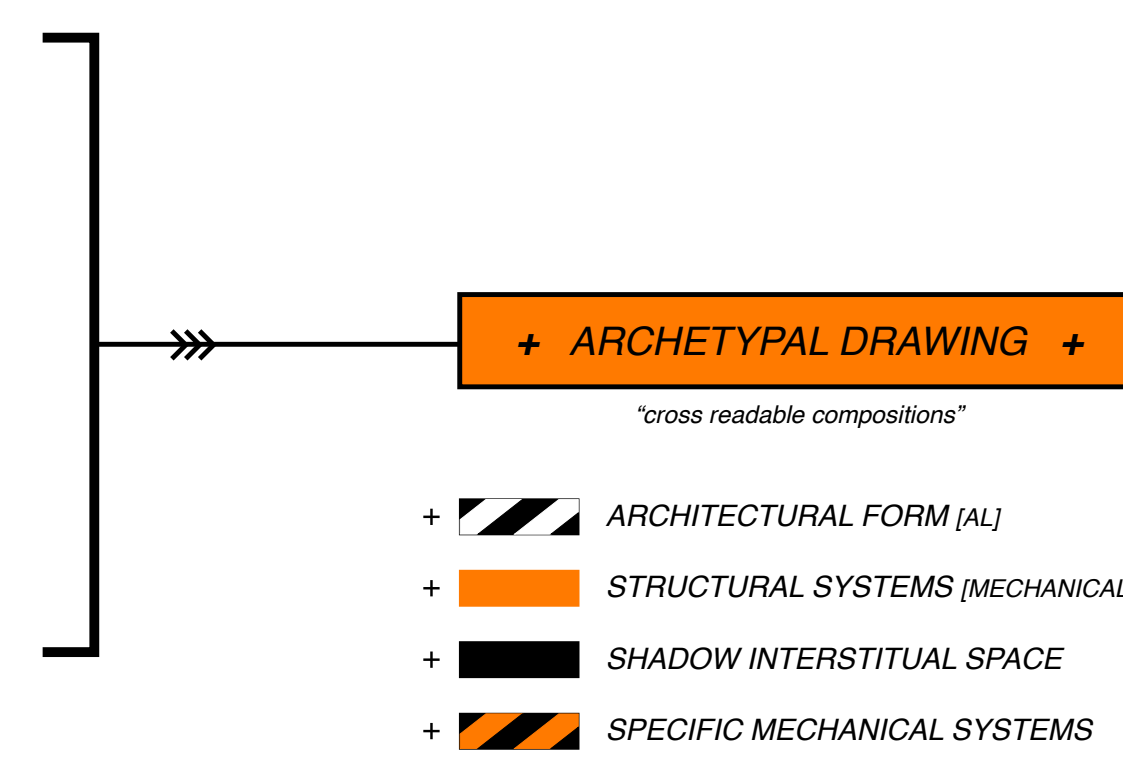

[ INVESTIGATIVE DRAW PROCESS ]

[01] [ OBJECT [ARTEFACT]

[02] [ GUIDE I CONSTRUCTION LINES

[03] [ SHADOWI SHADE

[03] [ TEXT [HELVETICA]

[03] [ REPITITION 
"'As designed and constructed artefacts, architectural machines can manifest themselves along the trajectories of ideas - from initial gestation as device through to its ful scale realisation as installation. However, these manifestains stallations often include devices, a mise-en-scène machine often has an experimental past, and so forth"

(Dunne, 2005, p.84)

$t+t$ 

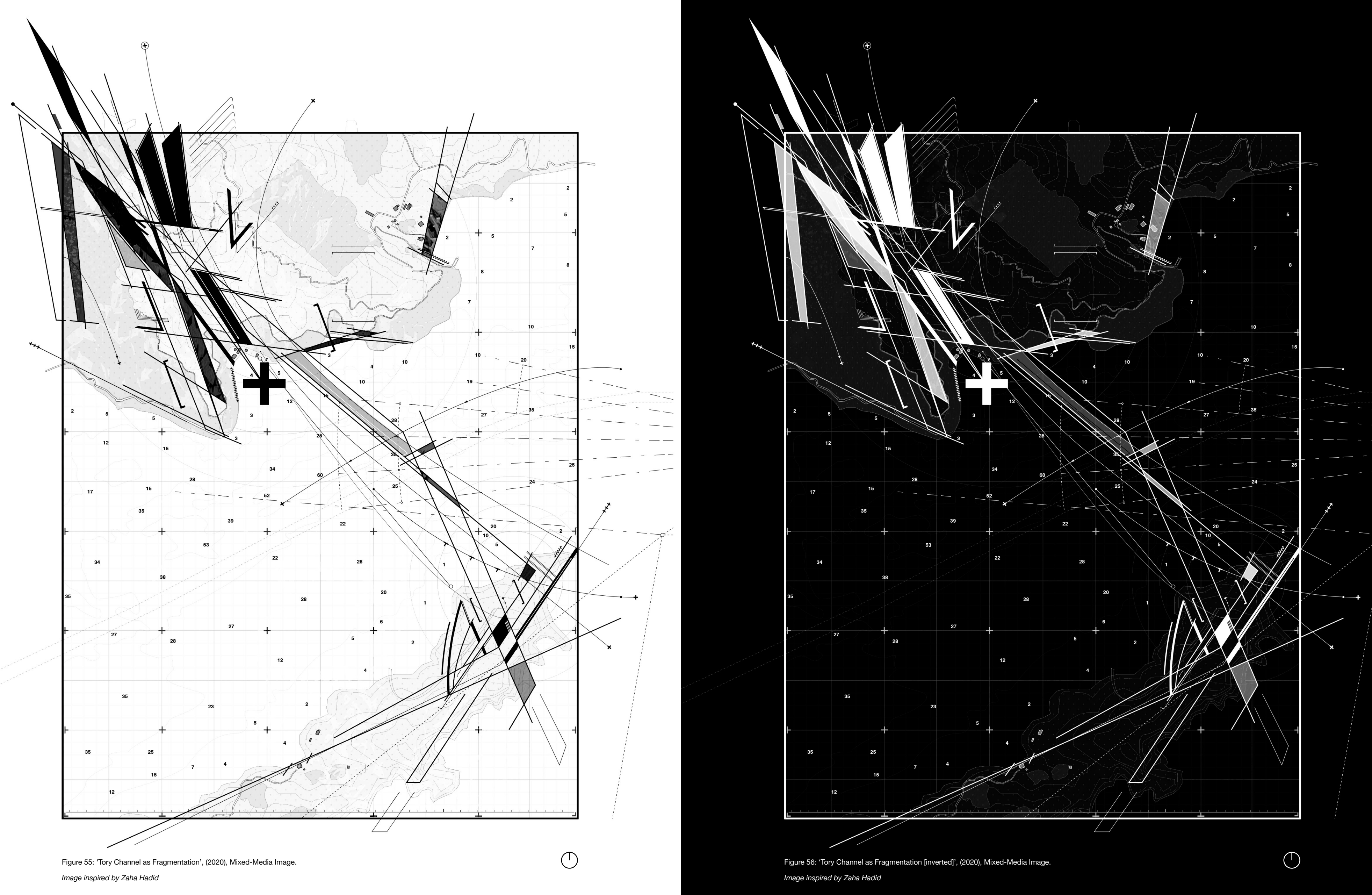

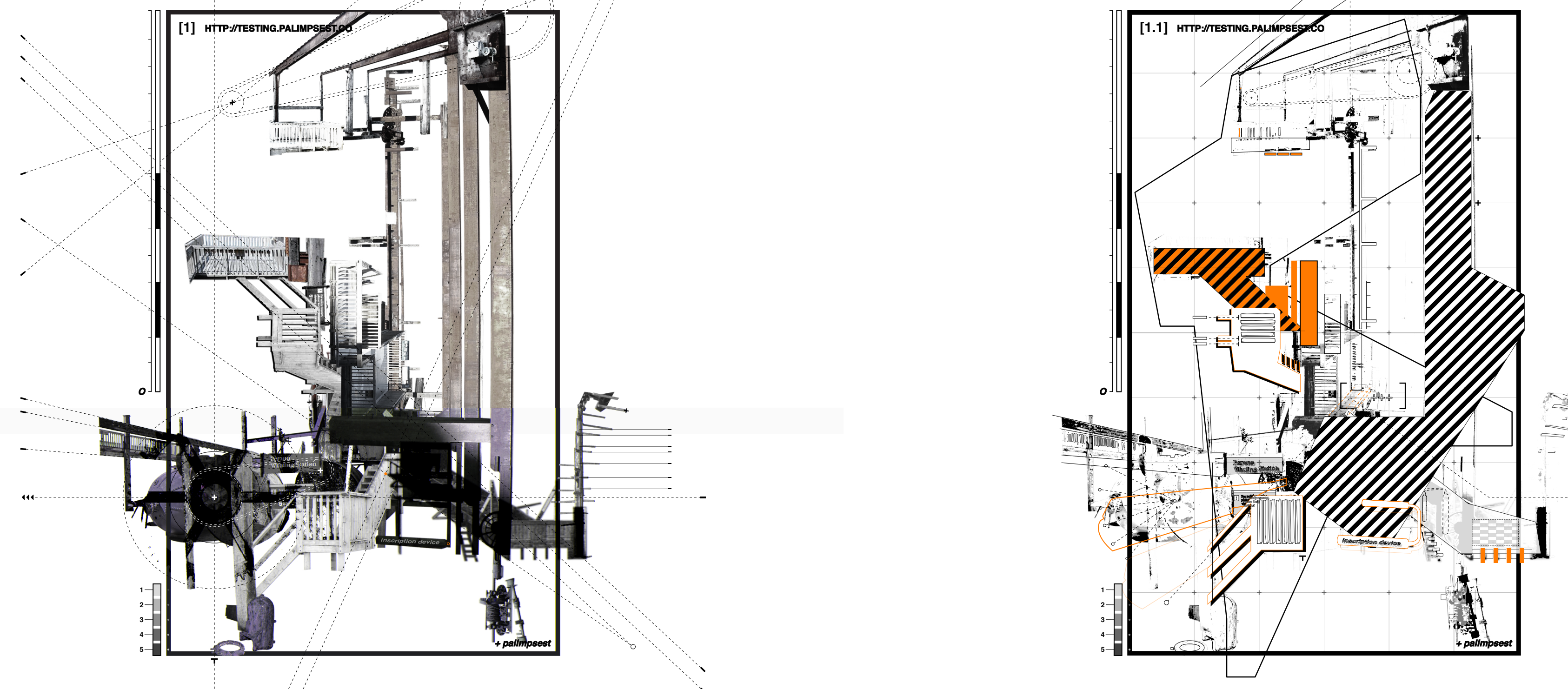


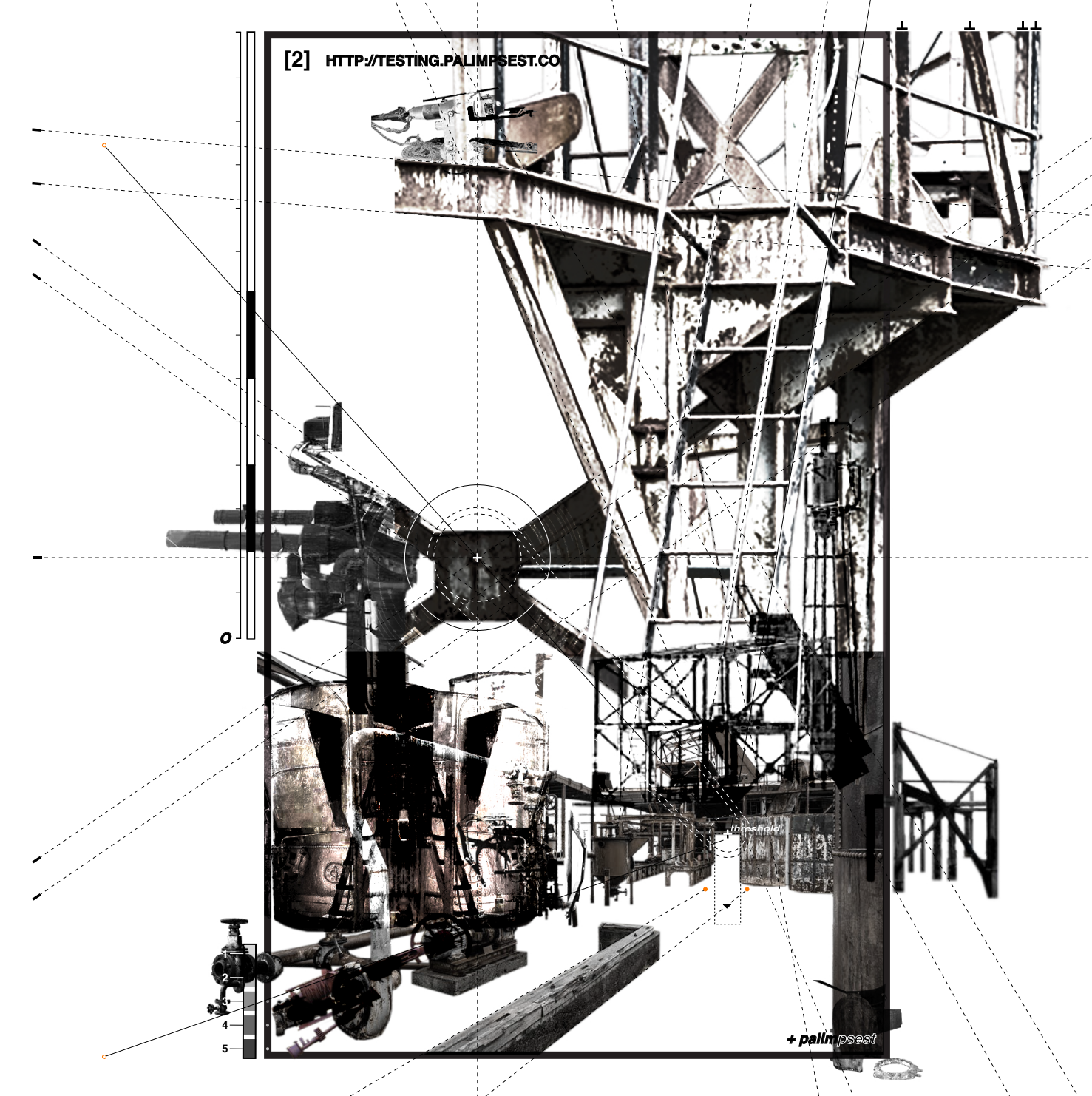

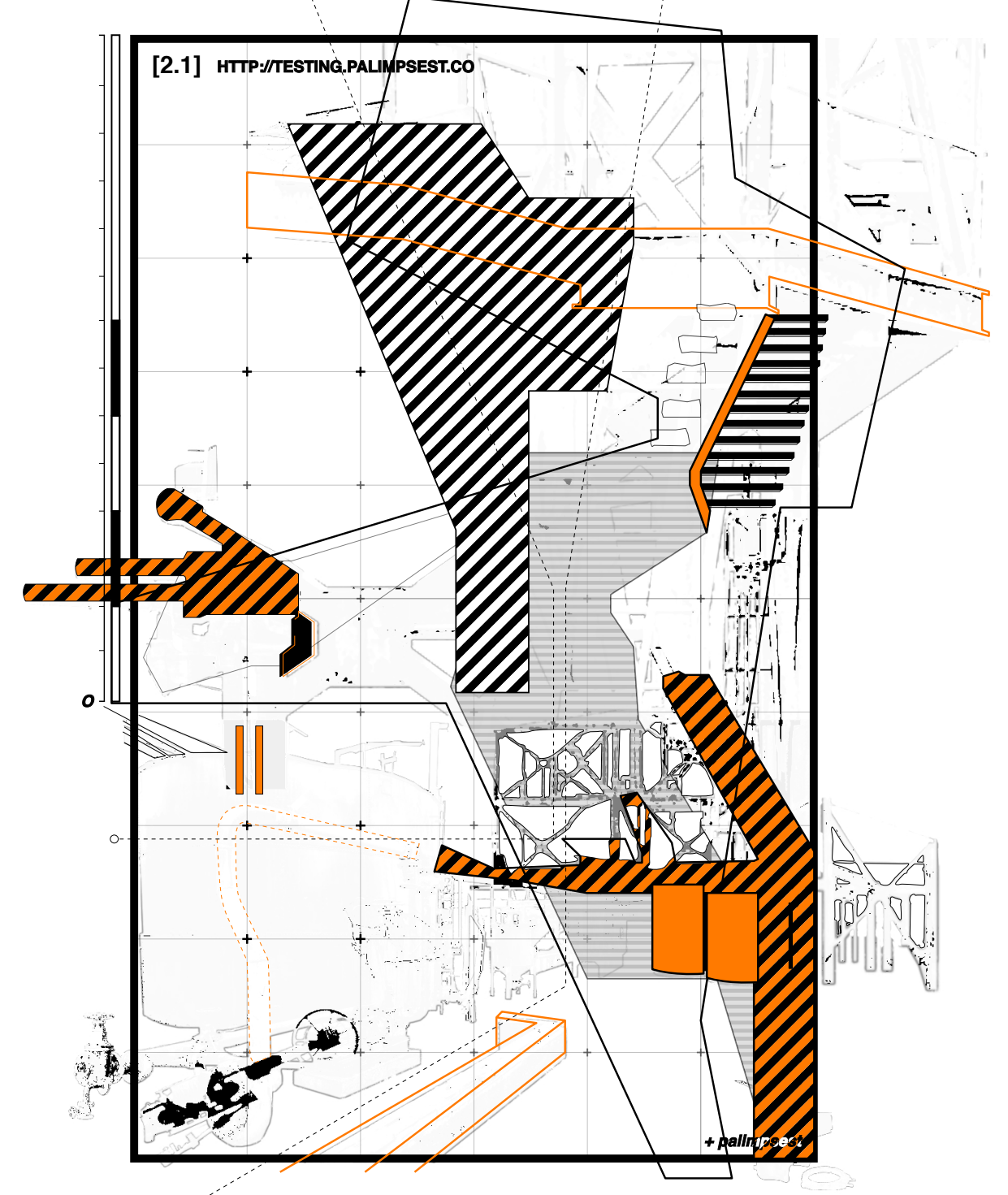



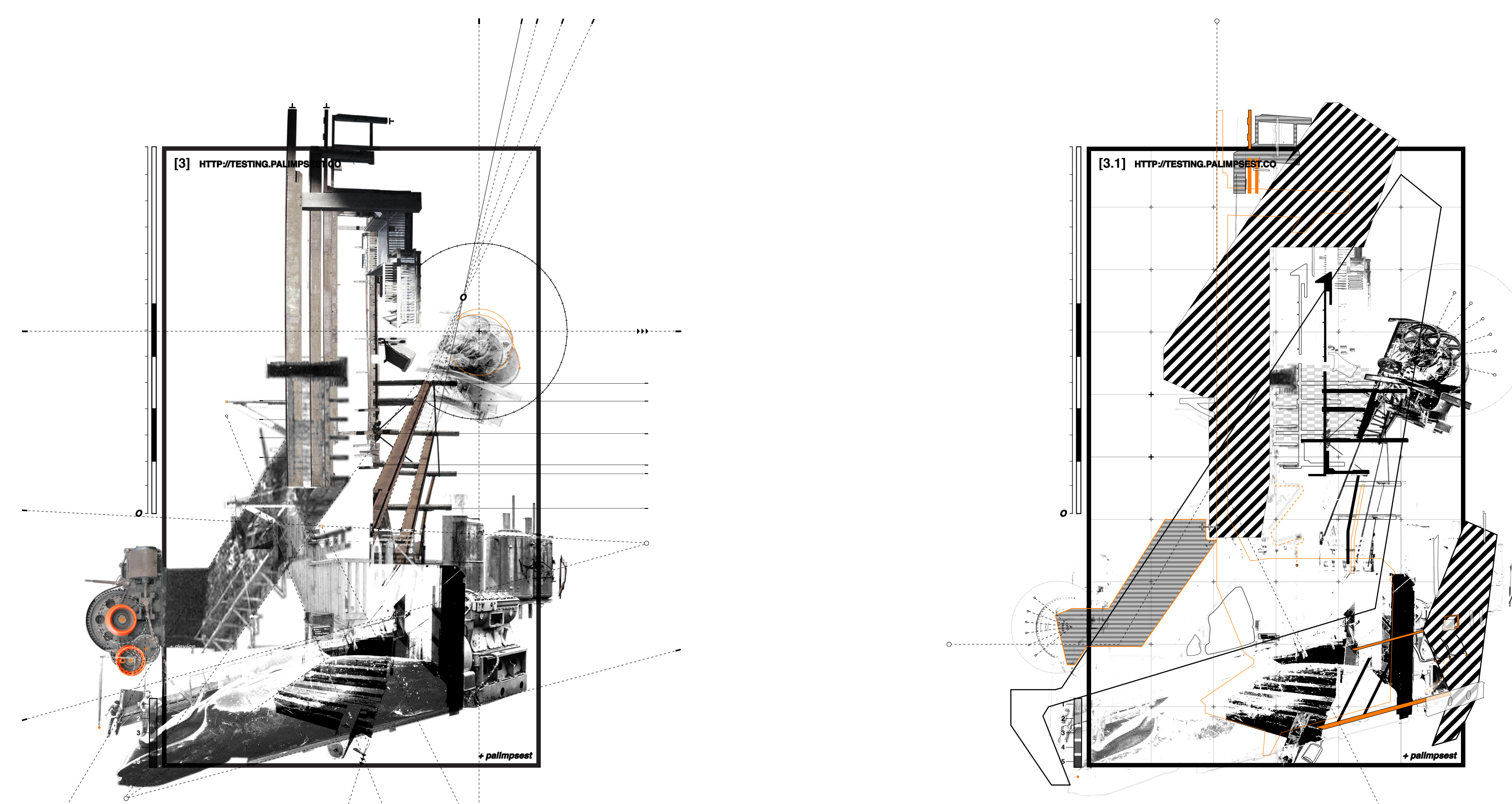


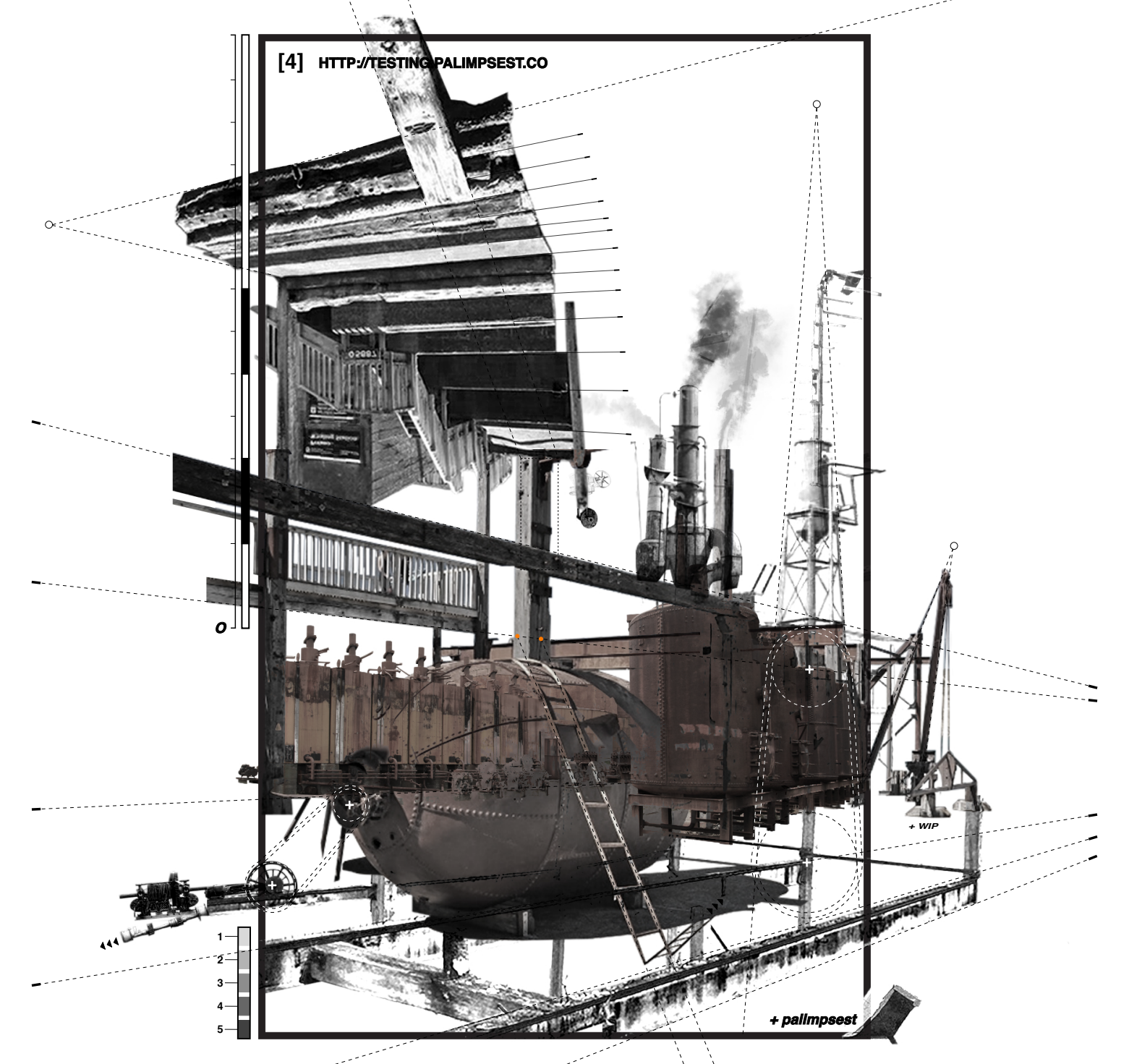

Hgure 65: Palimpsest Montage Four', (2020), Mixed-Media Image.

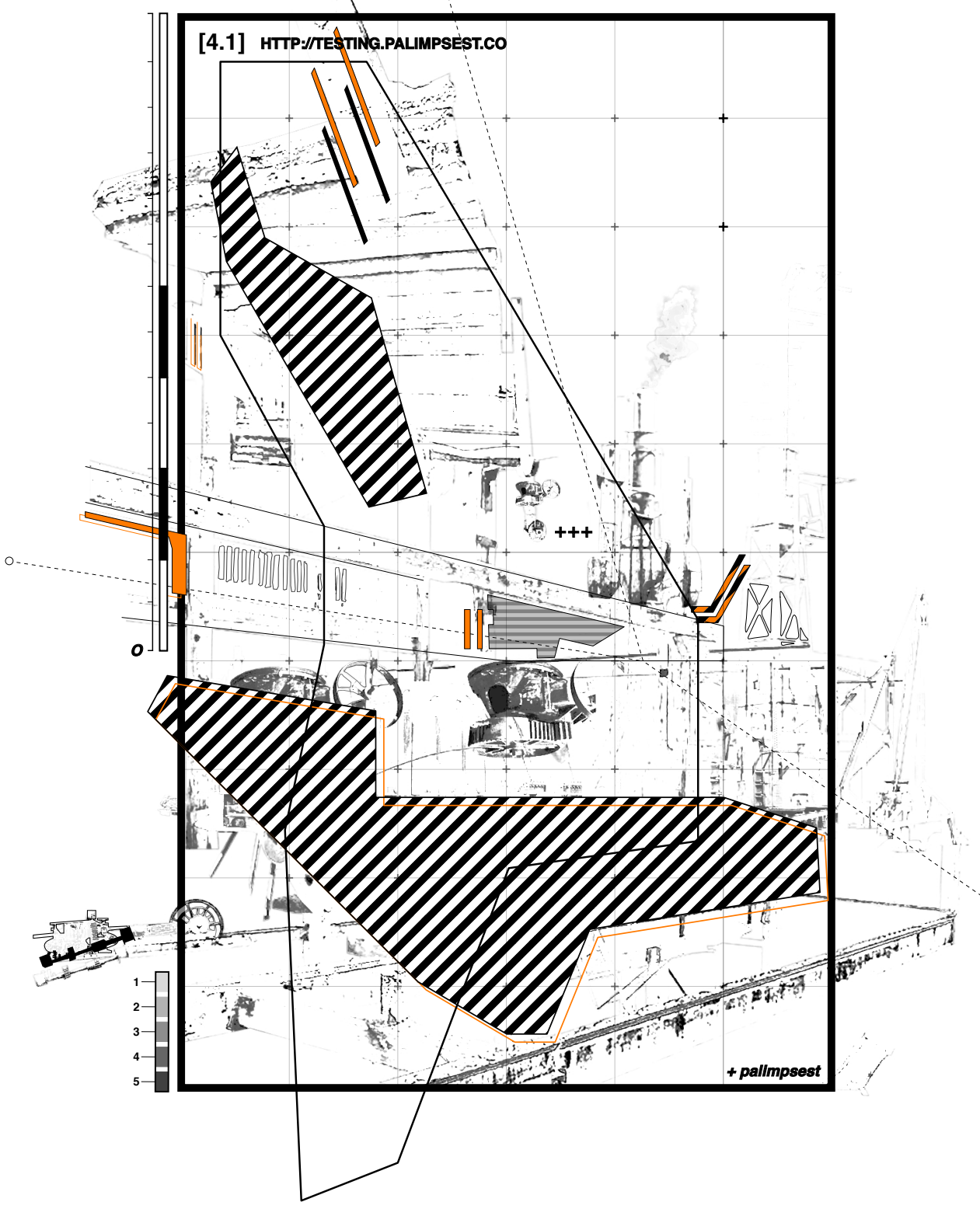

Figure 66: 'Palimpsest Montage Four (vocabulany)', (2020), Mixed-Media Image 
$\pi 001$

Mreforim
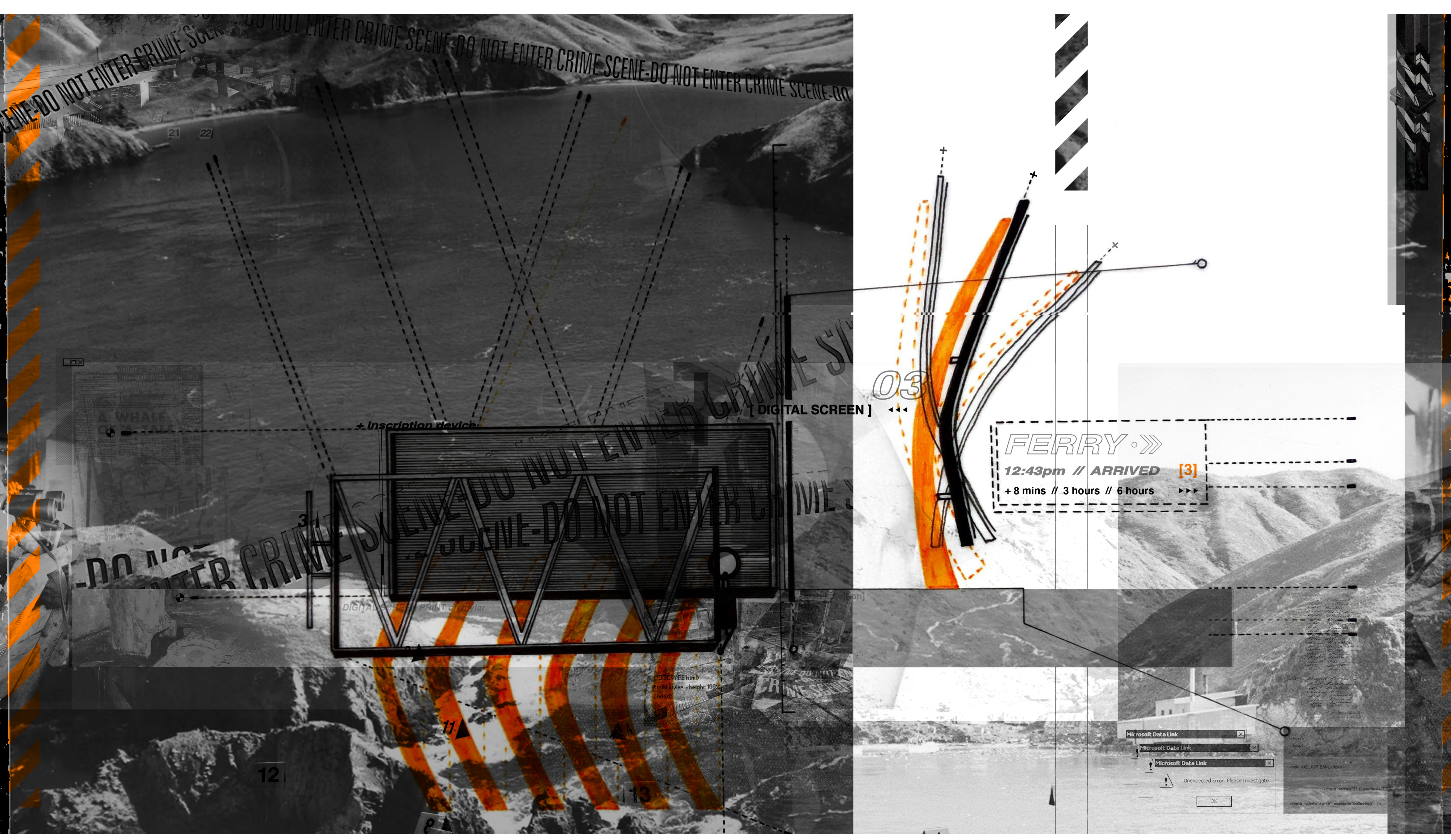


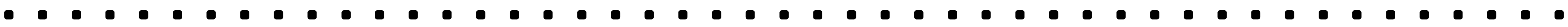

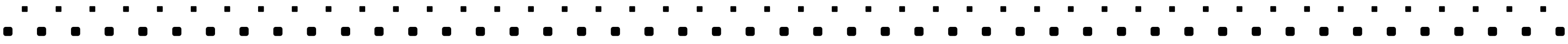

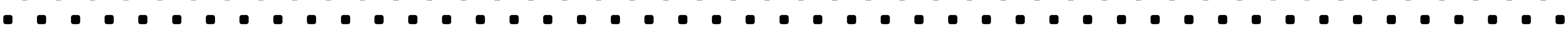

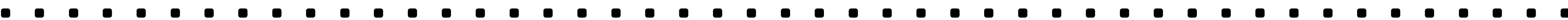
6.

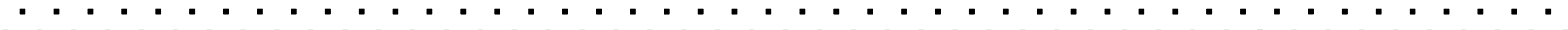

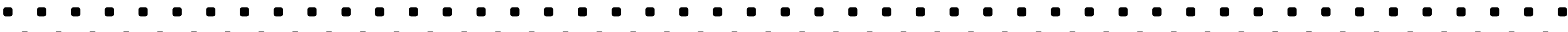

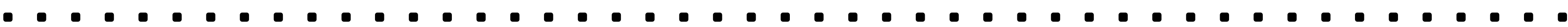

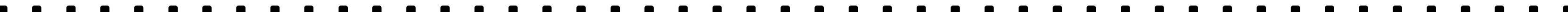
(

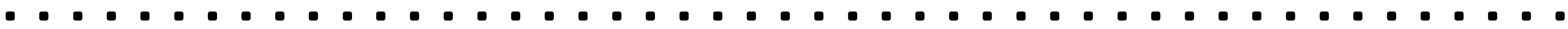

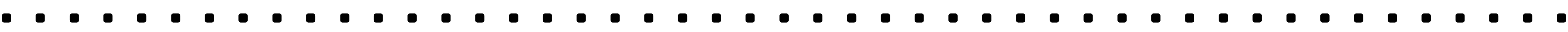

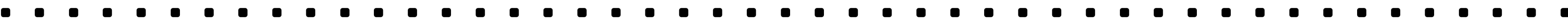

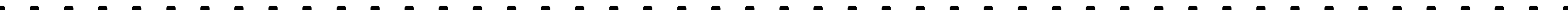

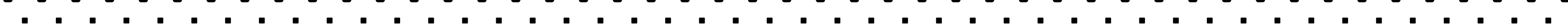

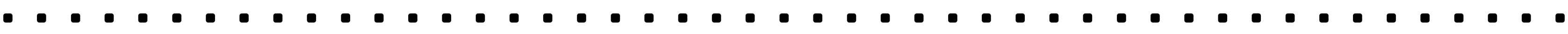

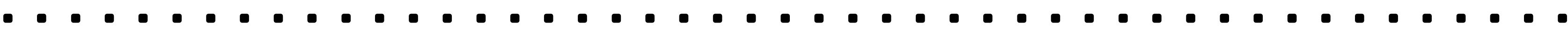

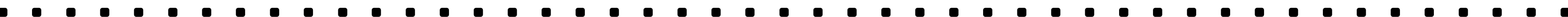
0

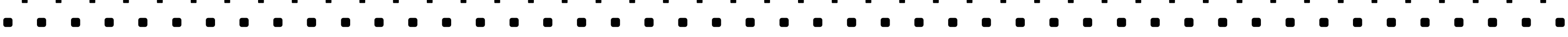
๑

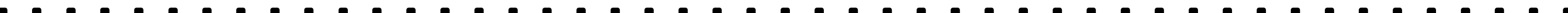

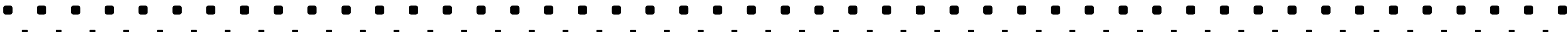

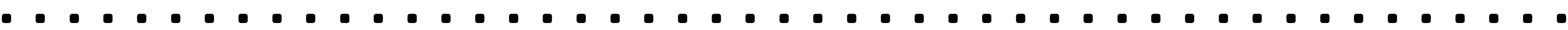

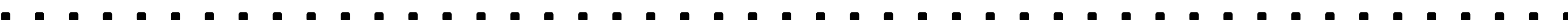

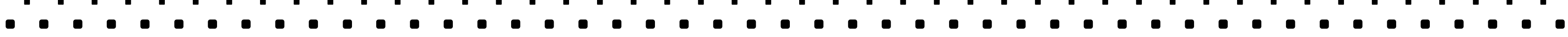




\section{Fundação Iberê Camargo}

Álvaro Siza (2008)

Before the first design intervention commenced, the 'Fundação Iberê Camargo', designed as a competition piece by Álvaro Siza in 2007, was a case study investigated. The location of the work demanded a powerful approach to the scarred landscape - an abandoned quarry that was surrendered to the Foundation for Siza to build into the current landscape - ensuring to not further erase. A few days pre-inauguration, Siza noted that, "there will be more than one fixed way of presenting the works of art. Works by different artists will be displayed together to confront by different antists will be displayed together to confront each other. This place responds to a most particular kind of spatial dynamic that is very flexible, ductile, and has excellent environmental conditions for tailoring exhibitions that tak into account the sensitivity and objectives..." (Laudanno, 2009).

By a means of designing through compression and decompression, openings and closings, voids and light, Siza marks the point of views, perspectives, and paths of the passage of time; allowing visitors, or in this thesis' case, 'Tourists' to navigate as they please through their mistyeyed characteristics. Formal complexities, lines, inversion, eyed characteristics. Formal complexities, lines, inversion, convergence and divergence, cleaving horizontal planes and sophisticated spatial analysis - Siza's Iberê Camargo Museum enables a direct connection between those tourist
(visitors) and the artworks and ideas exhibited. Within the (visitors) and the artworks and ideas exhibited. Within the
context of this design-led thesis, an interest draws from the ideas on convergence and divergence, and how navigation of a space from both a 'Purist' and 'Tourist' characters perspective differentiates. Can the role of speculative architecture, and drawing techniques, enhance memories within the Perano Whaling Station's historical context?

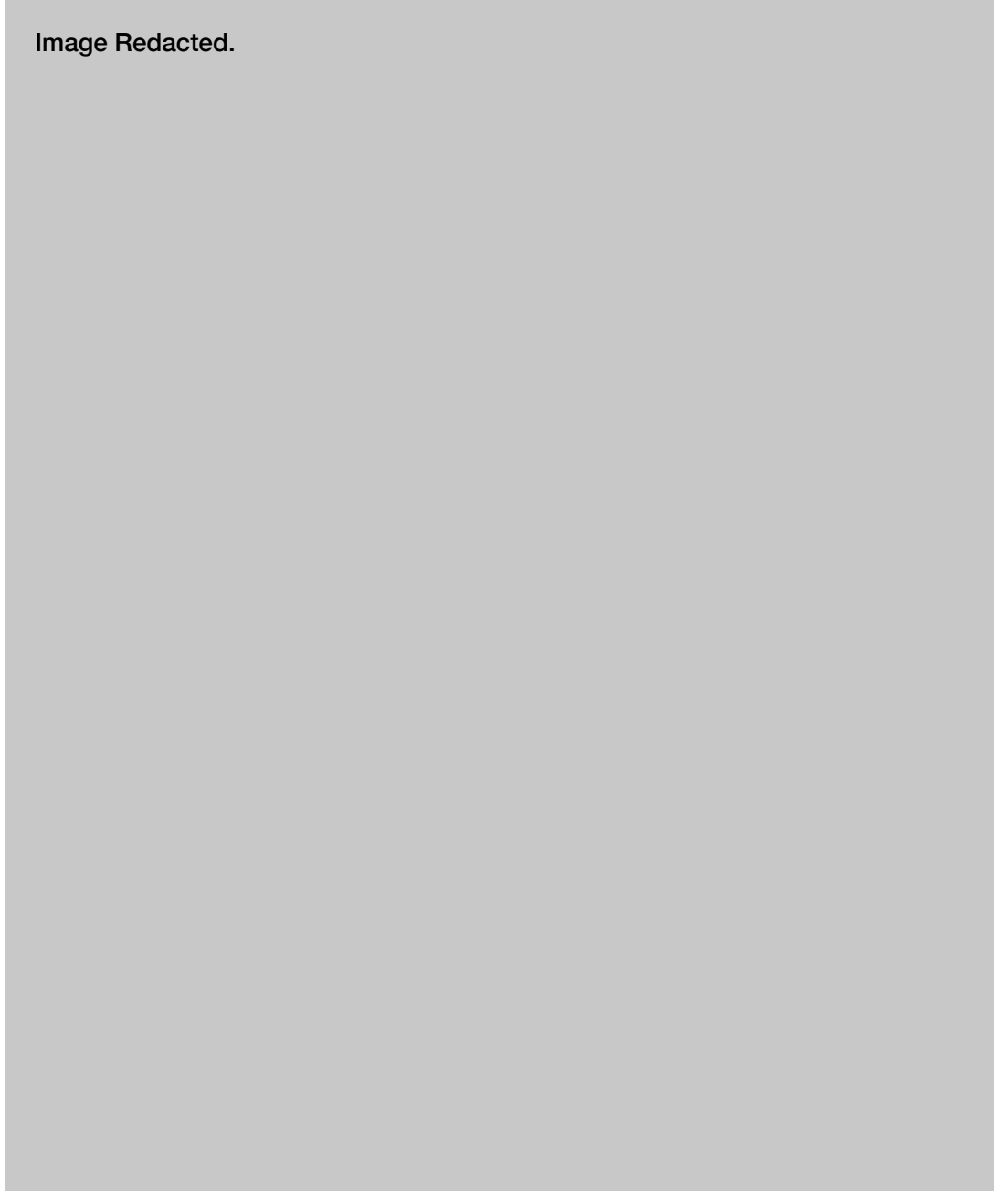



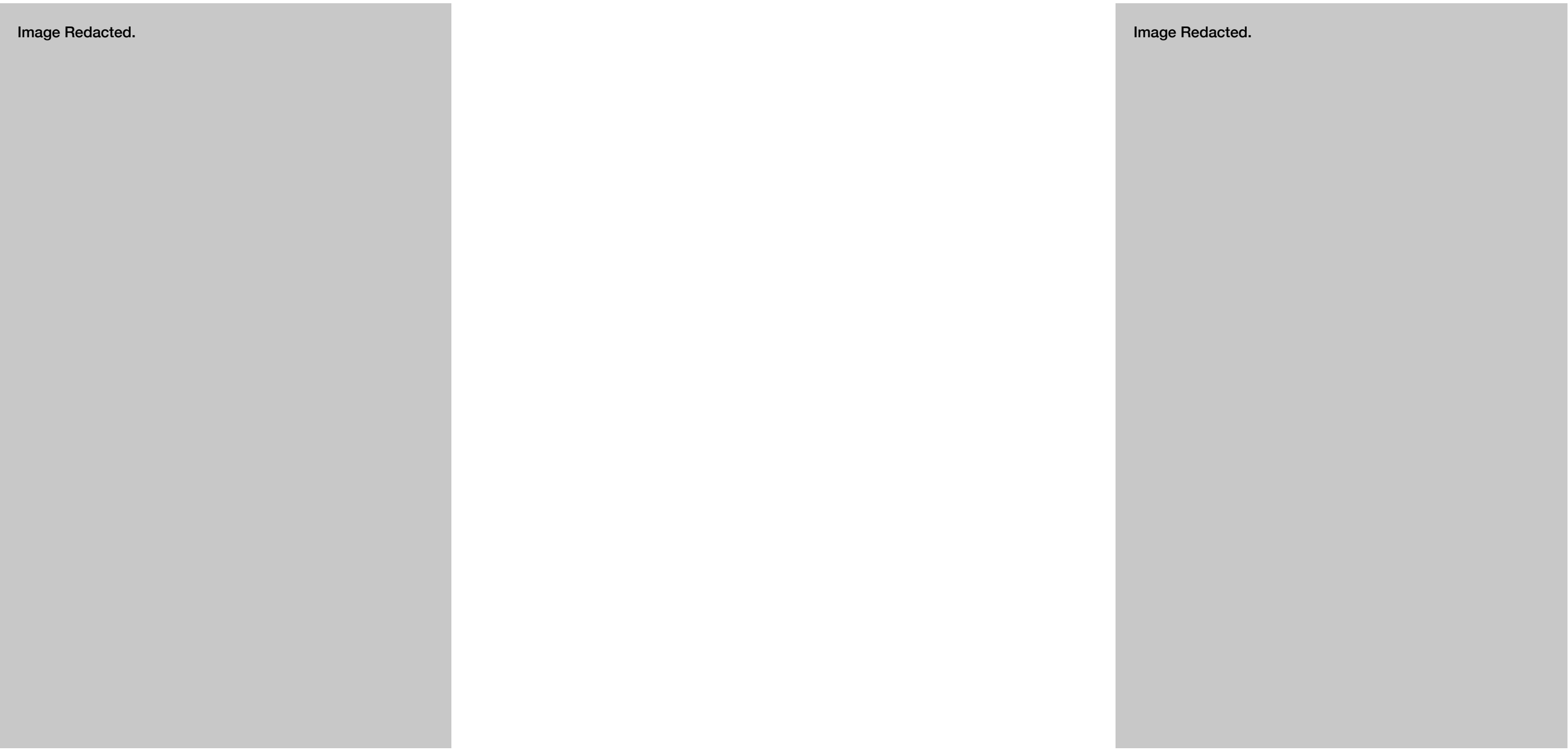


\section{4}

\section{The Gateway}

"Drawings are both an exponential platform and an instrument, the where

\section{Aims:}

The aim for the Gateway was to act as an initial immersion point into the fragmented site; and unearth the traumatic stories of whaling at Perano Station. This programme acts as a contrasting gateway for both 'Purist' and 'Tourist' characters. The 'voyager' is someone who seeks to find out more about this layered history, yet, does not possess all the answers to such questions. This design experiment aims to investigate the role architecture has in facilitating the threshold between an immersive yet traumatised landscape thresho subjective experience of a viewer who occupies the and the subjective experience of a viewer who occupies the how how can archtectural observation act as a catalyst to assis, in the process of arising forgotten memories? Following the methodological approach, drawings can be understood as devices for interpretation, expanding on potential readings and misreadings of the architecture. A viewer who inhabits the drawing can thus engage in their own evocative interpretations.

Character: [Purist - Voyager] [Tourist - Inquisitive] A character who would visit this site would contain the following constructs:

- persists in the realm of New Zealand 'now'

- acts of choice in the present moment of viewer[ship] [o a traumatic past]

- focuses on social and political correctness

- environmental preservation[ist] and conservation[ist]

- misty-eyed; 'open to new learnings'

- understands and responds to historical values; 'filtered'

\section{Method:}

This first design intervention, paralleling the 'Theatrical Observation' design experiment, heavily employs the process of drawing to determine key design decisions. Employing allegory as a critical method for this design-led thesis, the drawings follow similar spatial constructs, arguing for the unique interpretations of viewers - enabling enigmatic responses. Wellington Reiter continually deploys his own mythology of a landscape through a lexicon of figurative signs that encourage active and collaborative interaction. As a rult, his strategic challenging of normal spation. As a result, his strategic challonging or normal spatial constructs invites participation of complex and perplexing architectural metaphors - 'the Gateway' is birthed (Reiter, 2000, p.6). Both 'Purist' and 'Tourist' constructs are explored through a contrasting typological rearrangement that triggers displacement, and thus the [re]construction to the site.

Acting as a threshold for both characters in this design-led investigation, 'the Gateway' through a series of enigmatic drawings explores the [in] habitable relationship between the two characters, and how such objects of architecture the tho give give scale and inthidation to the site, and let those users who visit understand the historical and cultural significance exposed before them. The ferry acts as the primary docking mechanism for this intervention, thus, ferry routes and subsurface contours became vital information to explore within this design process. Multiplicity and a users viewpoint became critical explorative tools that became more evident and explored when the process moved from hand to digital environments. Softwares such as Rhino and V-Ray helped enhance this process involving subjective viewing. 

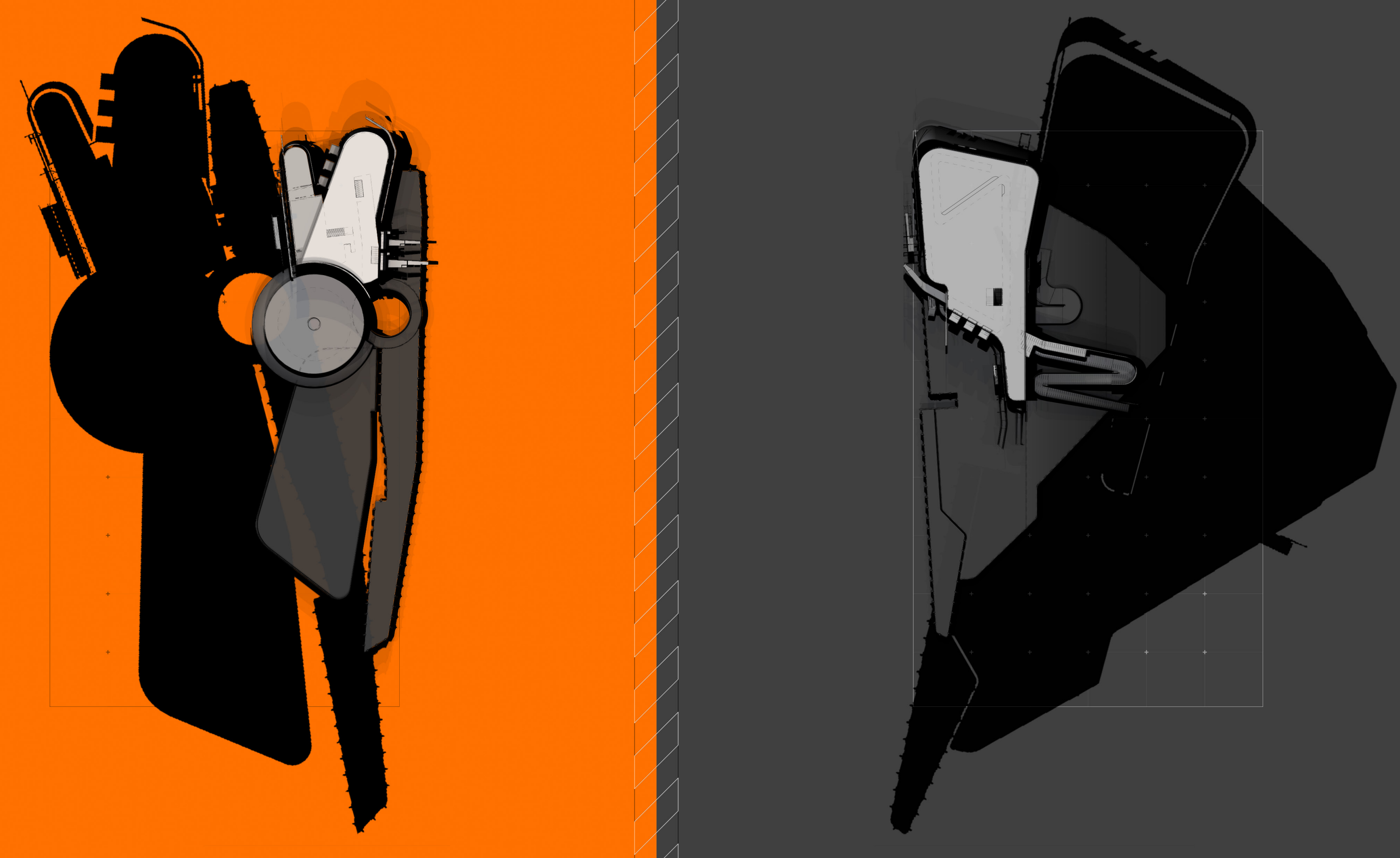


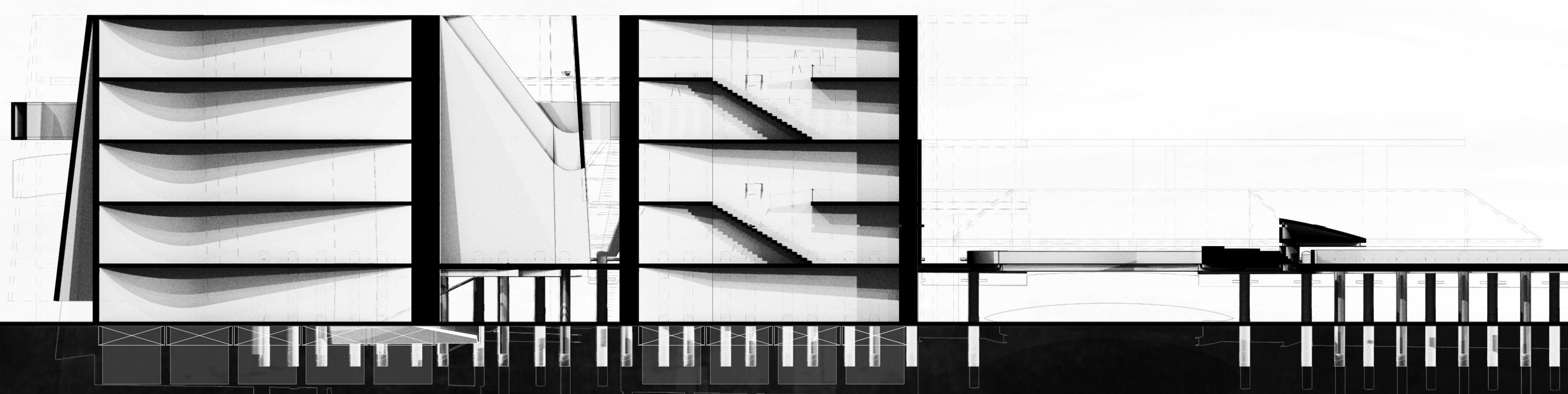




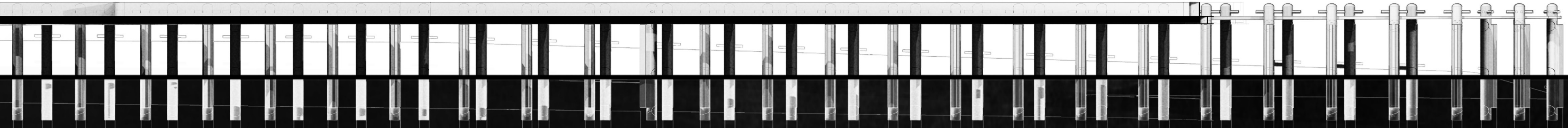




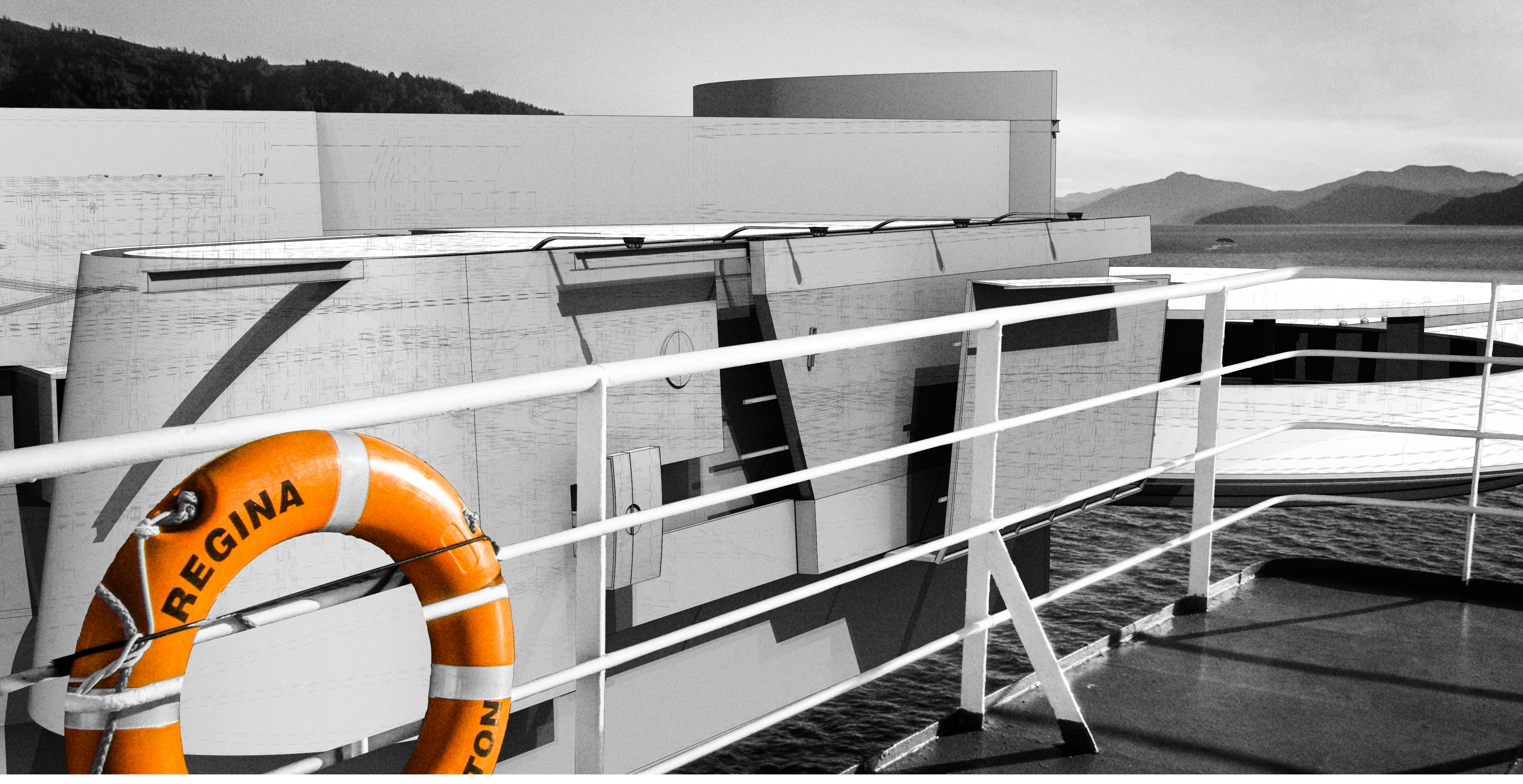




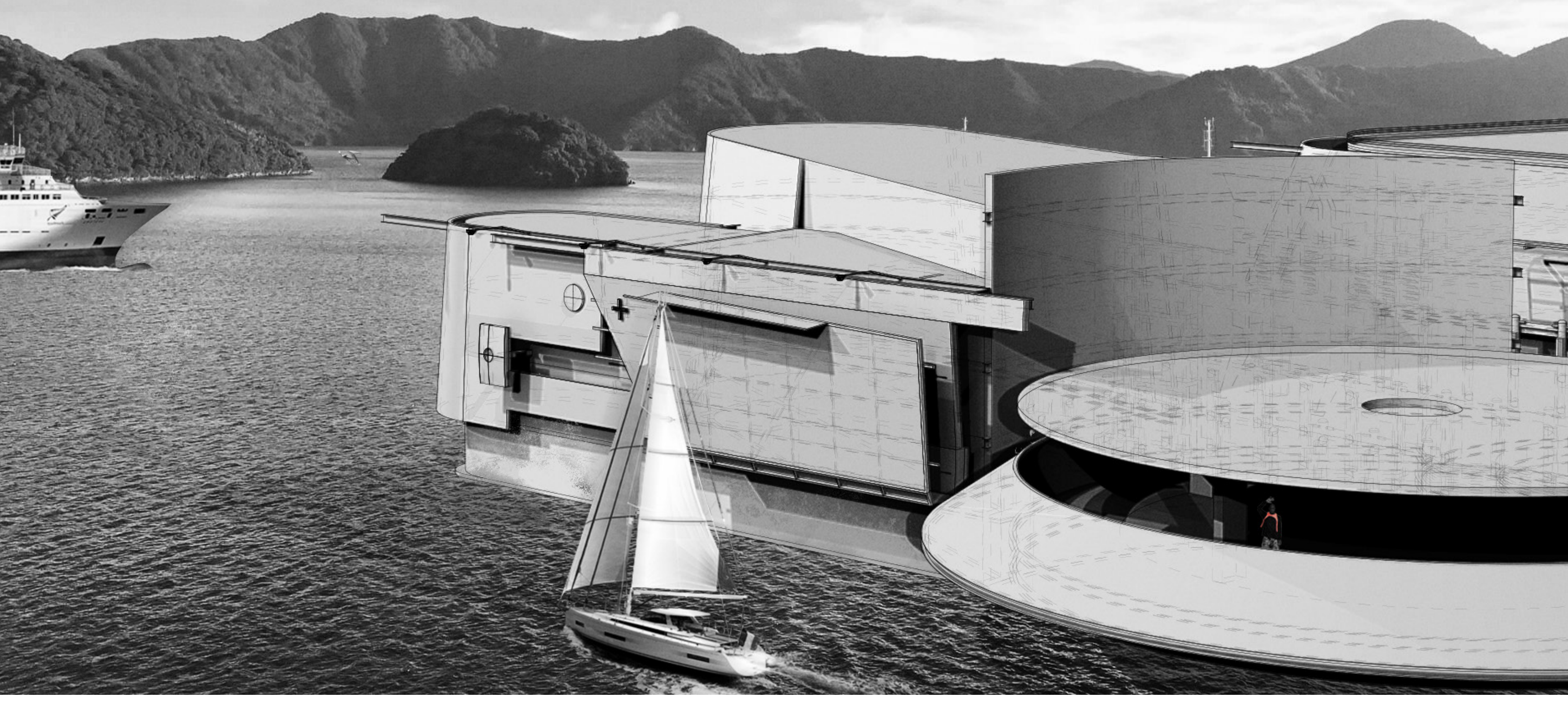




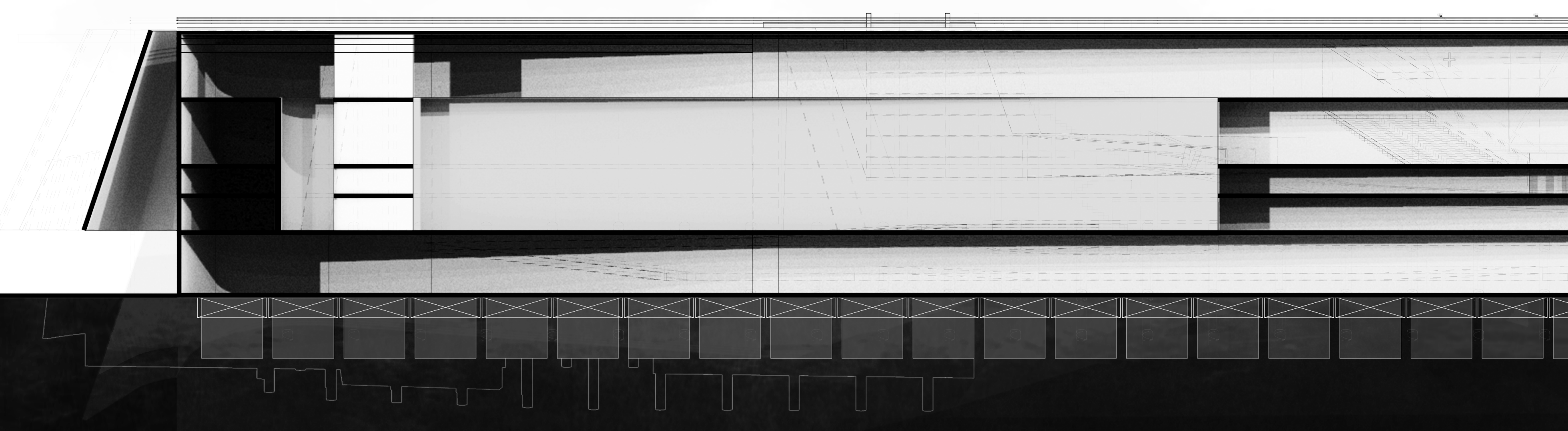




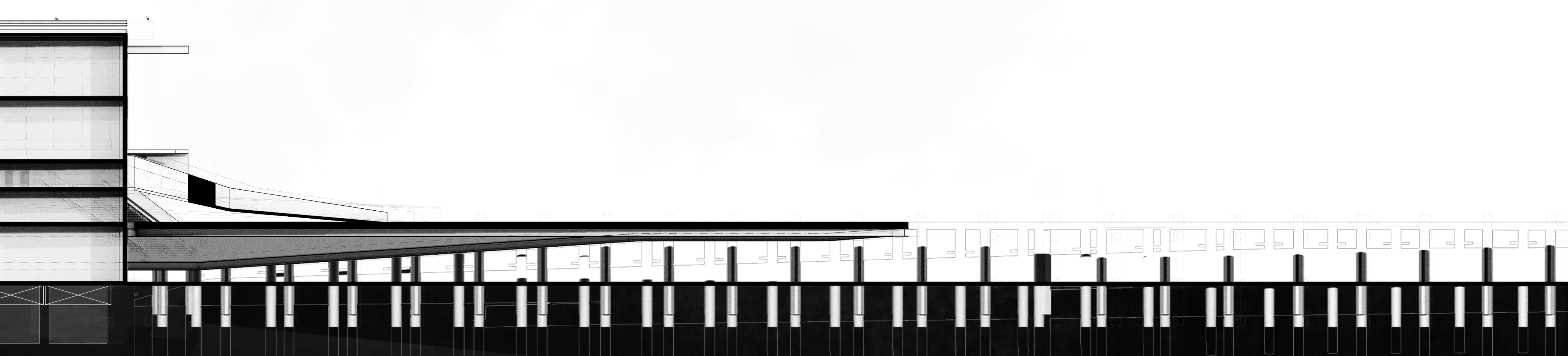



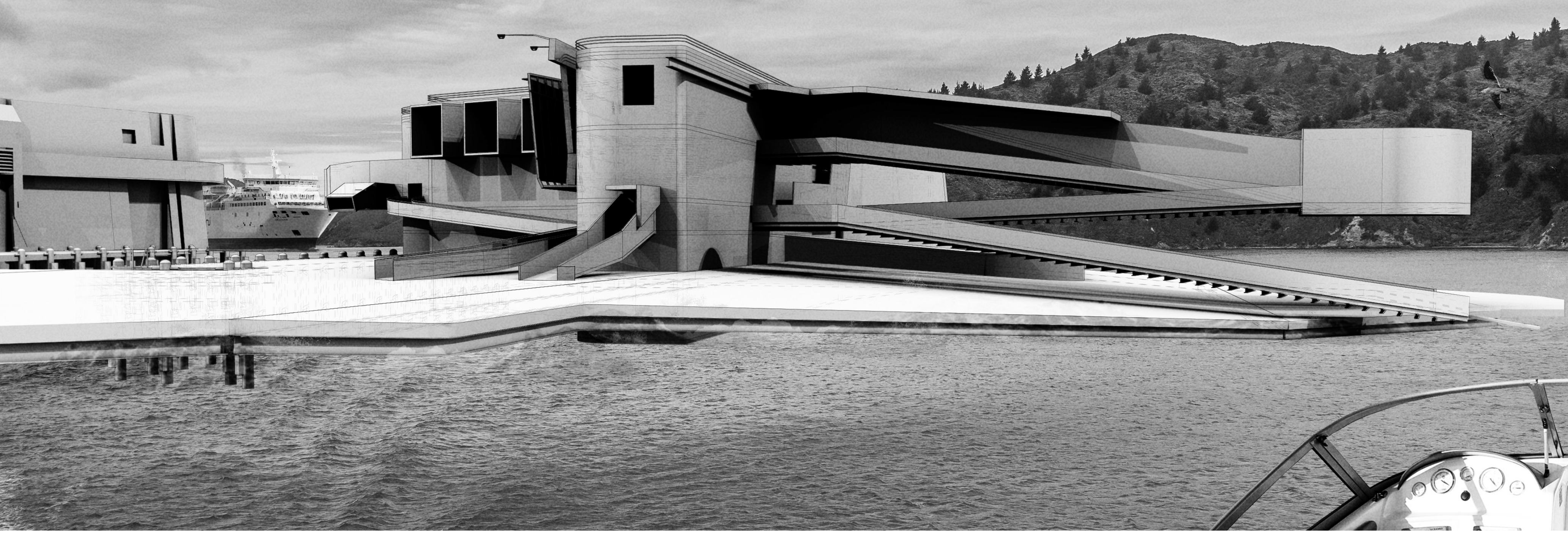

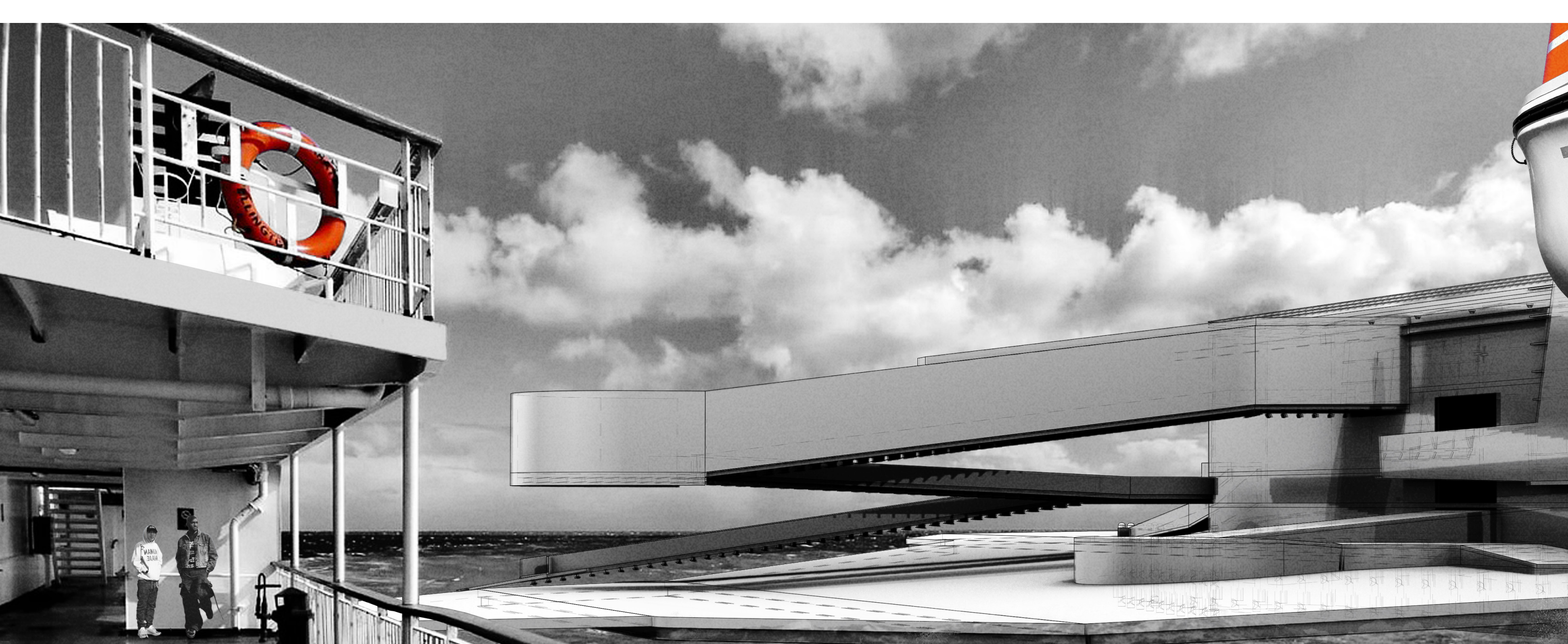

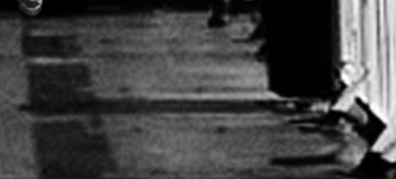
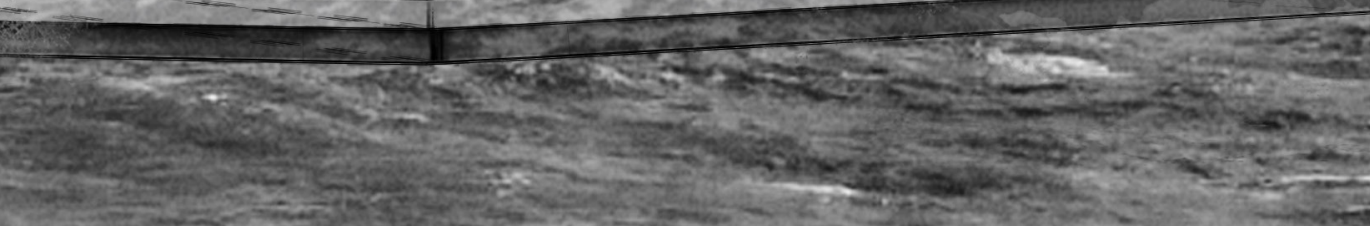


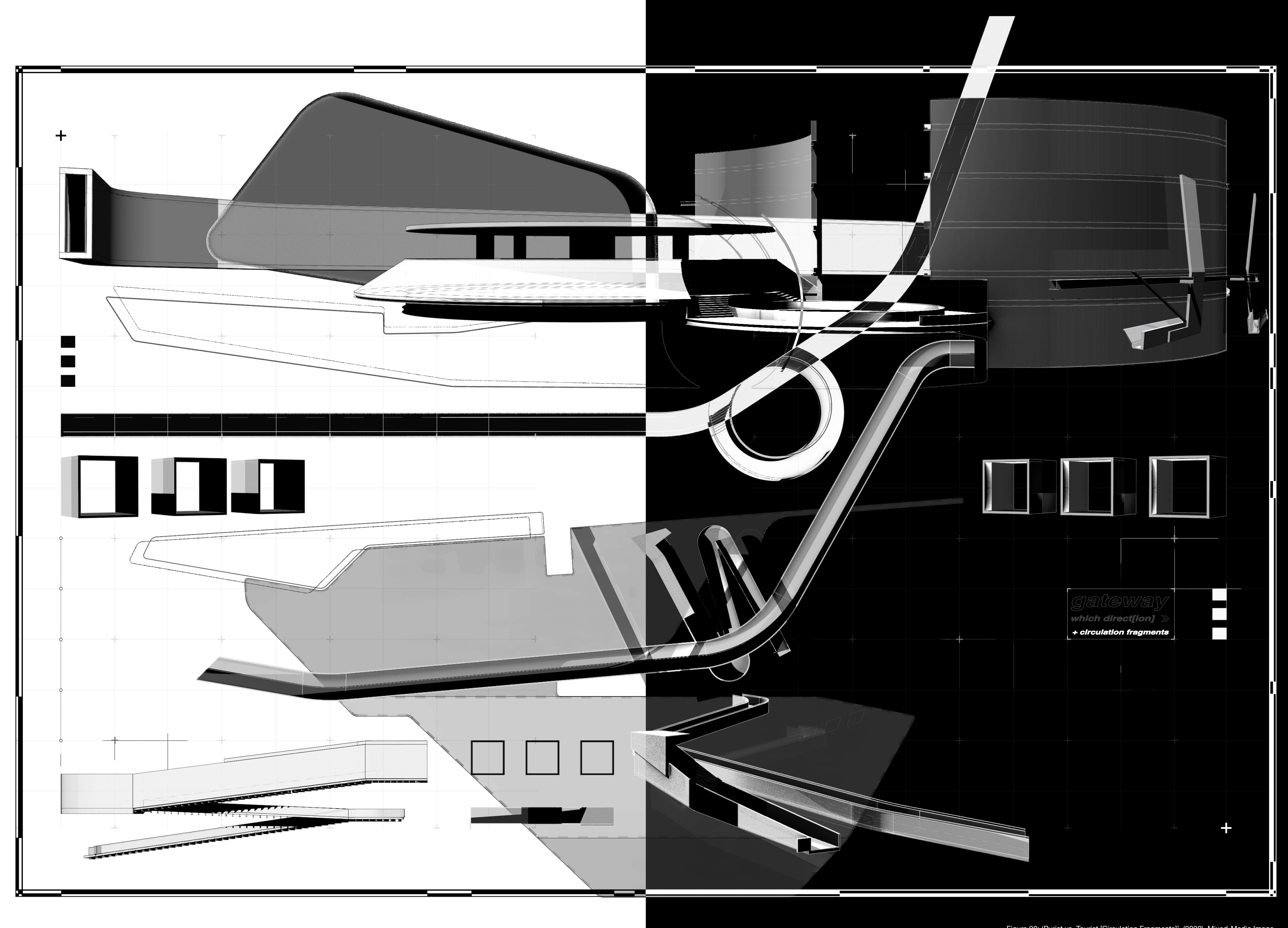




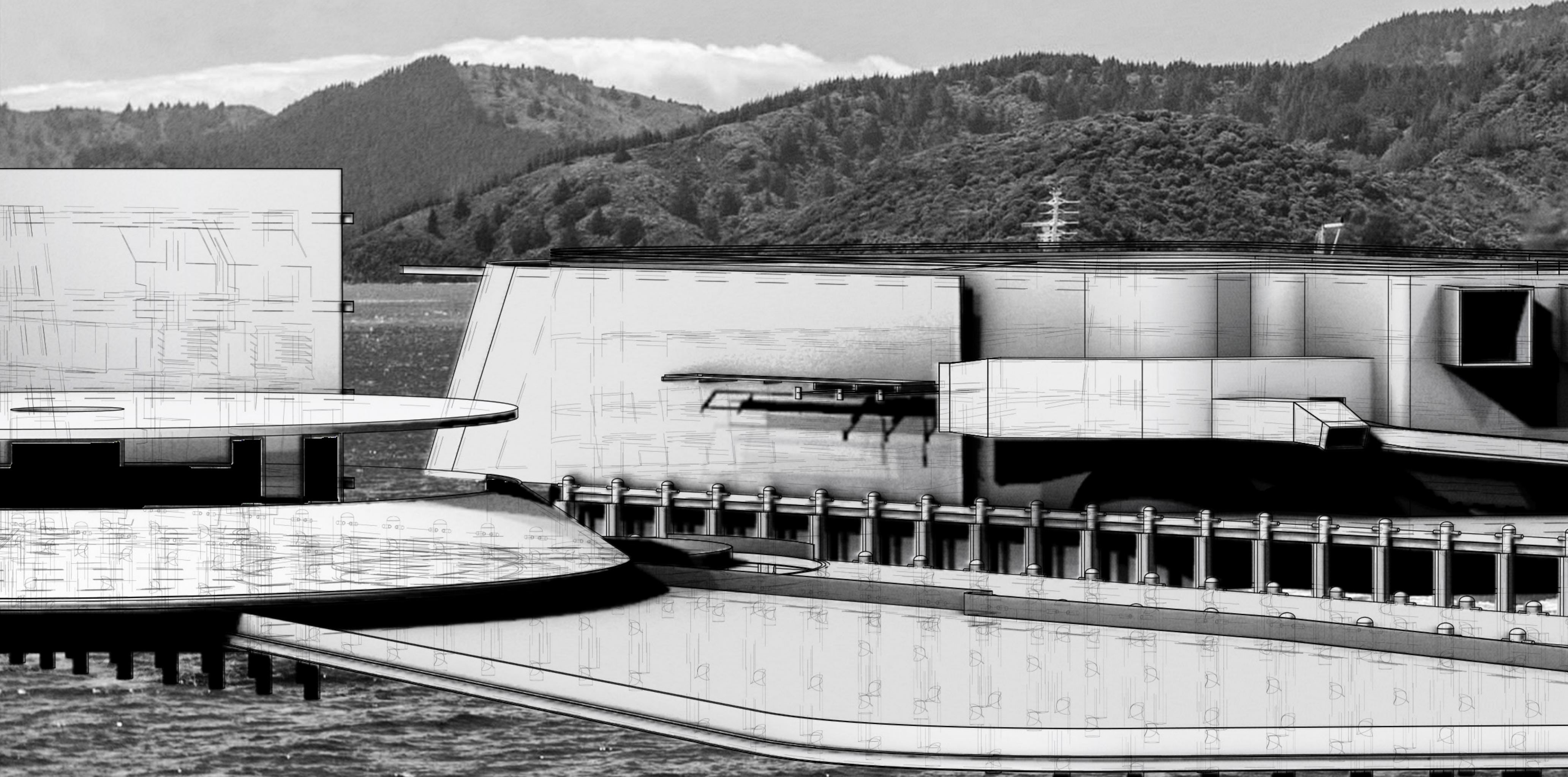

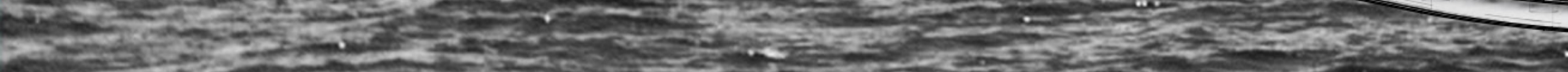




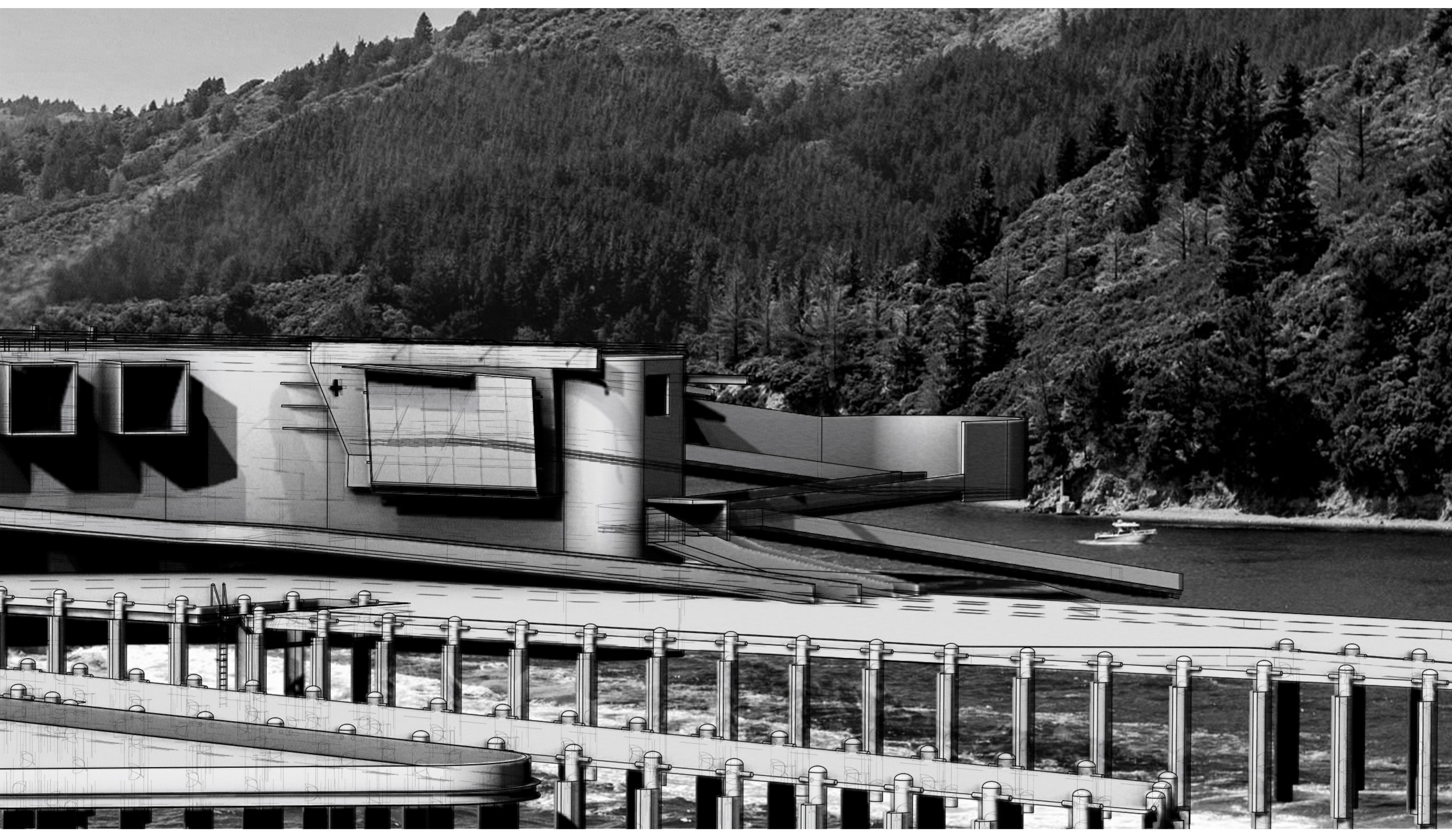




\section{4}

The Gateway

\section{Design Outcome:}

A curiosity into cross-disciplinary design methods informed

key findings for the first intervention design outcome;

the 'Gateway'. The 'Gateway' meets research aims and

objectives - to question how the medium of speculative

architectural drawing through narrative constructs can act

as inquiry tools to actively [re]interpret and interrogate an

erased architectural ruin as a multi-layered repository of

memories. Abstraction and cohesiveness is key in design

language for Abloh, allowing it to be ubiquitous - and

allows the stories to signify the objects. Abloh advocat

for maintaining the curiosity of a tourist without losing the

for maintaining the curiosity of a tourist without losing the

discerning eye of a purist as an important aspect in design -

"it is the person who can be both who can make meaningfu

art" (HighMuseum, 2020). As a gateway, the design works in

a literal sense of binary oppositions, allowing the occupant

to orient themselves as a 'Purist' or 'Tourist' - those

who consume or those in the exalted realm of producing,

respectively. Acting as immersion to the site, and the first

architectural intervention, the 'Gateway' introduces these

opposing characters through the claiming of regular objects

in another figurative sense, which for me as the speculative

in another figurative sense, which for me as the speculative

\begin{abstract}
(HighMuseum, 2020).
\end{abstract}
The final design outcome consists of two ferry docking mechanisms, with large walking platforms and areas of observation and exploration. Through the method of speculative drawing, binary opposites were explored through a yin and yang relationship - testing how seemingly opposite forces may actually be complementary and geometries similar to the detritus scattered at the Perano Station, formulated in a design which allows transportation and exploration to be more efficient, and of pure nature. Given the 'Purist', as an "intelligentsia" knows the history and significance of this example. The Tourist's intervention employs multi-levelled exploration pads and walkways for dizzying inquiry and observation at a multitude of differing angles. The 'Tourist', in their formulation, is an un-jaded enthusiast, wide-eyed about new discoveries and eagr to learn more. This ideology extracted and manipulated from Abloh's understanding, is encapsulated in the unique 'Gateway' design outcome.

\section{Critical Reflections:}

This initial intervention provided an insight into how two opposing characters and mindsets may inhabit a design with a central dualism - unearthing how key character decisions of occupation are made through their subjective learnings and knowledge. This process occurs both through the architecture and the accompanying speculative drawings. architecture and the accompanying speculative drawings. This design also provided an opportunity to bridge the gap between the 'Purist' and 'Tourist', the producer and consumer - through a literal intervention which allows both to exhibit their character[istical] traits. Similarly, key design influence Bryan Cantley advocates for an architecture that favours questions over answers, improvisation over composition, contingency over certainty, and openings over closure. This architecture is operating through a series of sensory intangibles, beginning to examine and attach the threshold been threshold between subjective experience and consuming 'Gateway' enacted a design that started to bridge the gap 
between the 'Purist' and 'Tourist'. Abloh is assiduous on inspiring those who occupy an exhibit to feel welcome in a place that can be unwelcoming for those in the unknown, for the 'Tourists' whom are often deconstructed by the 'Purists'. As Rem Koolhaas notes, participants in the upper echelons of art, design, architecture and fashion grudgingly, if ever,

take the 'tourist' perspective into account, and often put their psyches and their humanity at risk to perform for their fellow purists. Aldo Van Eyck describes this sort of twin phenomena purists. Aldo Van Eyck describes this sort of twin phenomena and that of structure. A zone where two conflicting narm, and that of structure. A zone where two conflicting narratives intersect to act as if they are complimentary - creating a space filled with "multiple meaning in equipoise" (Farhady, 2009, p. 19).

Through this kind of exploratory design, the piecing together of individual mechanical elements derived from the extracted empirical vocabularies was just as important as the final outcome. It allowed a constant feedback loop for design works which followed. Through this immersive act of designing, an in-depth understanding into how a design-led thesis can lead to unexpected processes and happenings was gained. Chance findings and piecing together elements allowed the evocative experience of drawing to produce architectural representations which employ both 'Purist' and 'Tourist' constructs - spatially and poetically.

The communication link between subject and object is an objective function, a bridge cantilevered from either shore but never completing itself in the middle. We 'know' by projecting an analogy of what we do know - ourselves (interior) - onto the other (exterior). (McCarter, 1997, p. 49).
This ideology from Robert McCarter in 'Pamphlet

Architecture no.12: Building Machines' reflects critically on the Gateway intervention. A design that is split literally down the middle, with each respective side to the design the 'Purists' and 'Tourists' terminals, have our knowledge (internal) projected onto the architecture, or the other

(external). This dualism is continually excavated through the explorative drawings and representations - to allow viewers to decide and toggle which side of the spatial construct they wish to occupy. 


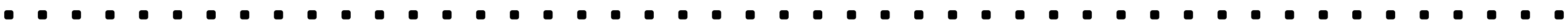

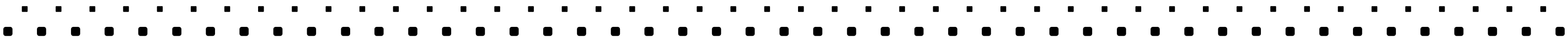

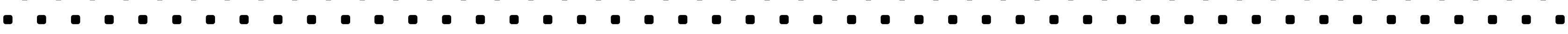

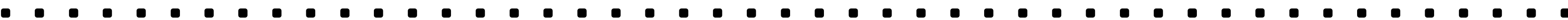

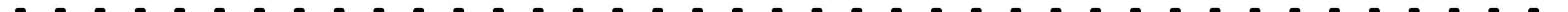

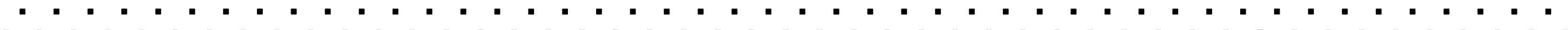

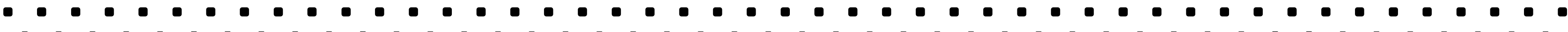

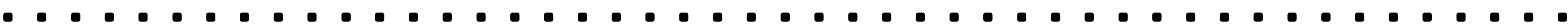

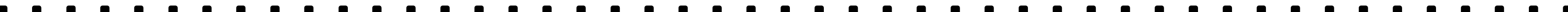

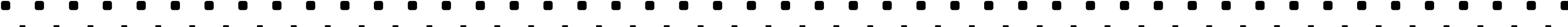

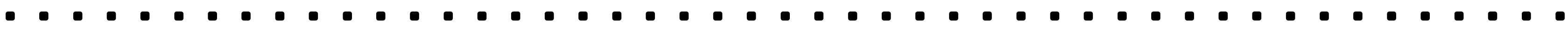

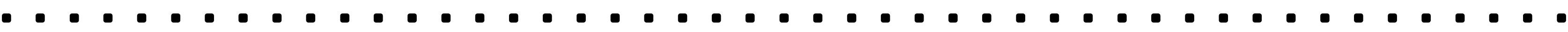

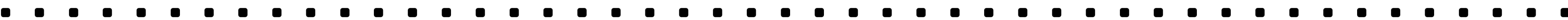

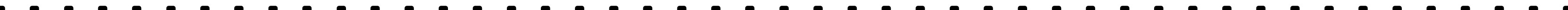

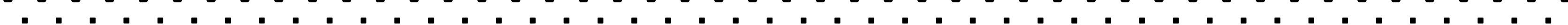

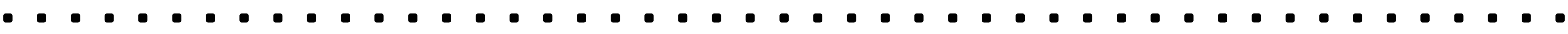

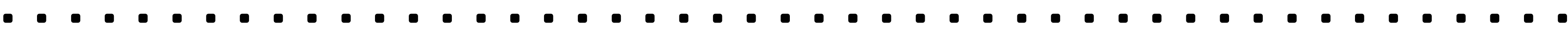

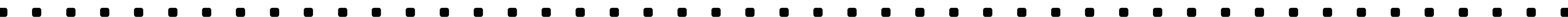
0.00

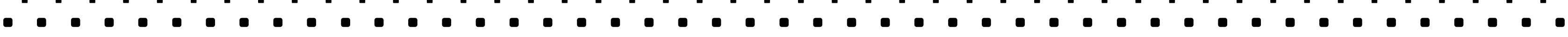
๑

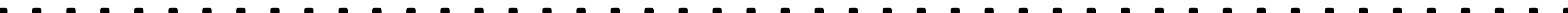

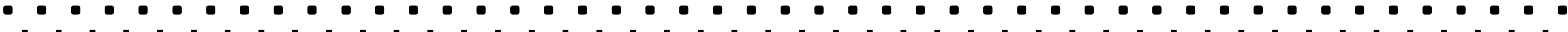

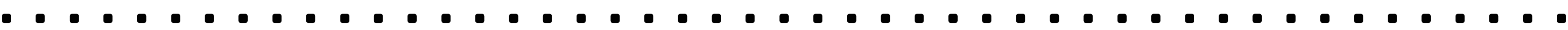

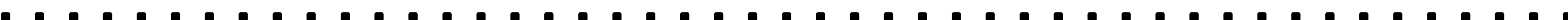

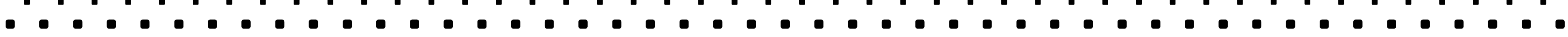


'Ground Zero' - World Trade Centre

Daniel Libeskind (2013)

The case study examined for the second design intervention, the 'Vessel', is "Ground Zero", designed by Daniel Libsekind order to; "present and preserve the history and memories of the events of 9/11, while documenting the impact of the attacks and exploring their enduring significance." The masterplan was designed through a fundamental balance between evoking memory of tragic past happenings, and the need to foster vibrant and functional spaces. In Libeskind's words, the project is a "healing of New York a site of memory, and a space to witness the resilience, a site of mo" (Libesilience and a space to withess the resile

of America" (Libeskind, 2018). Below the plaza is a

subterranean Memorial Museum which serves as an icon of the past towers footprint. It includes historical artefacts as documented exhibited objects. Salvaged structural column and objects of post-trauma are exhibited, and even built upon in some cases. This became important when designing the 'Vessel', and led to an inquiry of how to use existing fragments and structural remnants as architecture to build upon and reawaken in the station's history - not erasing fragments altogether.

Jan Seidler Ramirez, 911 Memorial Museum chief curator, remarks, "objects have kind of a DNA presence about them... They were eyewitnesses to an event." Perhaps the most striking fragment is a 22-foot pillar of torn steel from the original position where Flight 11 crashed into the North Tower. "It is extraordinarily powerful as a tortured witness object," Ramirez (Panero, 2014, p. 51). As the designer, curator and archivist - a lust occurred to ensure the Perano Whaling Station, as a historical and cultural monument, is not fully erased from history books.

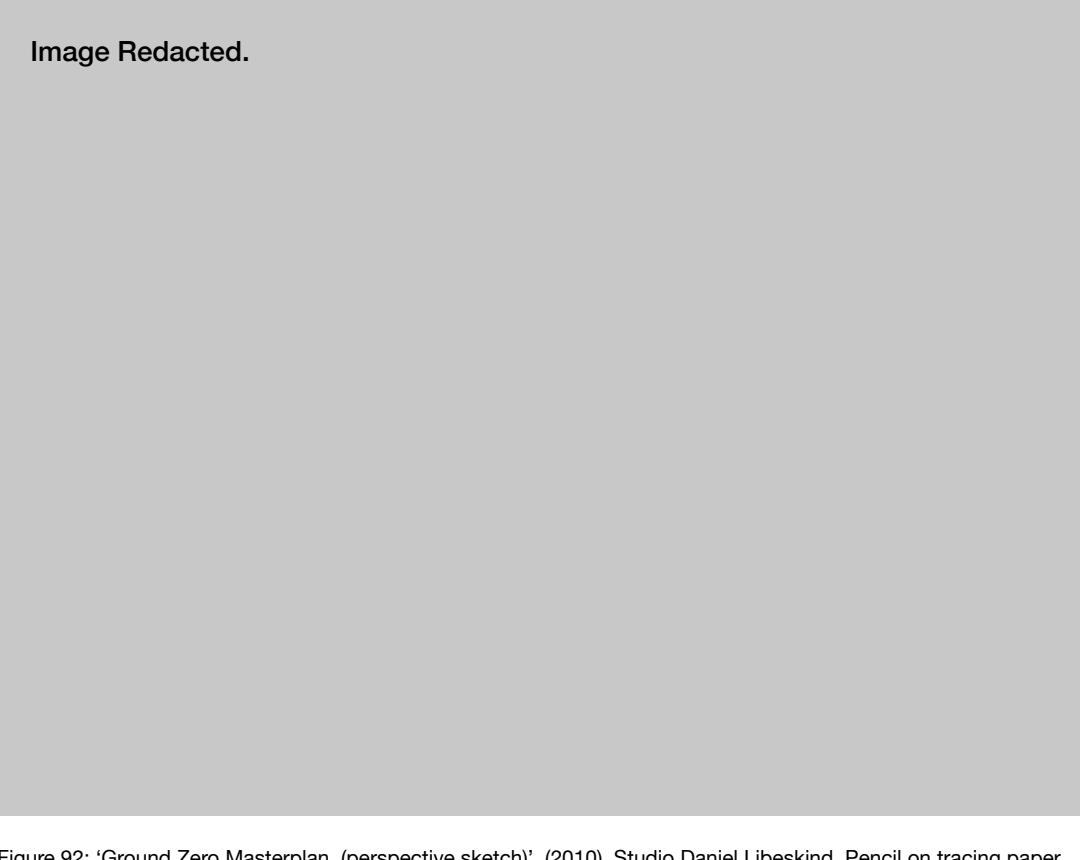

Figure 92: 'Ground Zero Masterplan, (perspective sketch)', (2010). Studio Daniel Libeskind, Pencil on tracing paper

No day shall erase you from the memory of time

Virgil, 1607. 
Figure 93: 'Tridents from the World Trade Center's facade', Photo by Floto + Warner, (2014), Digital Photograph.

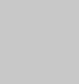


The Vessel [tiramaka]

Aims:

Perano Whaling Station's erased site is a palimpsest

of complex layering involving cultural, social, political,

historical and environmental implications. As an architectural programme, this design experiment represents the traumatic murmurs as stories that remain in the Tory Channel wider context - allegorically reminiscent and [re]presented through figurative geometrical re-purposing. A purist whaler [or 'intelligentsia'] would be a typical figure to represent and design through for this intervention. In her book 'The City of design though for ', Christin ino is re-awakening forgotten memories that have long been

dormant, or because their original function and purpose may dormant, or because their original function and purpose mas traditions and imaginary narrations" (Boyer, 1994, p.19).

Designing with this ideology in mind, the 'Vessel' reinterprets erased fragments scattered on-site as mnemonic devices to 'heal through memory'.

\section{Character: [Purist - Intelligentsia]}

Purist/Intelligentsia would be categorised as someone who:

- aims for a different future from the present, from the past

- is a civilisation... in progress..

- enact[ed] a causation of erasure - a culture of

extraction

hosts knowledge on industry, context, erasure, machinic architecture

- past happenings/knowledge creates less unique

individualistic interpretations

- extraction [action] - [re] action - [re] interaction

\section{Method}

As Rem Koolhaas notes, participants in the upper echelons of architecture grudgingly, if ever, take the tourist perspective into account; often putting their psyches and their humanity at risk to perform for their fellow purists. Abloh resists this pattern, regularly drawing poisonous attention from the purist blogosphere, in order to create more inclusive spaces of creation (Darling, 2020). 'Onto-Cartography: An Ontology of Machines and Media (Speculative Realism)', by Levi Bryant, studies the ontology of maching Real media. In the chapter

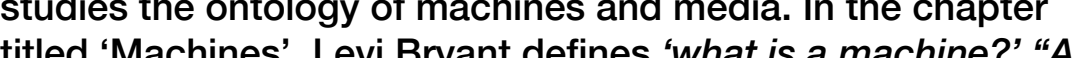
titled 'Machines', Levi Bryant defnes 'What is a machine?' "A machinic conception of objects leads us to think of entities in a very different way. Confronted with a machine, our first thought is not of its properties or qualities, as so much its operations. A machine is something that operates" (Bryant, 2014, p. 147). When a machine superimposes a landscape experiencing trauma, it magnifies existing inputs, and renders mass reflected outputs as a formal therapy.

The third design experiment examines how one might observe a complex multi-layered site of past trauma; acting as a palimpsest of past, present, and future fragments. Through a series of palimpsestuous drawings, testing. into the a senies of palimpsestuous drawings, testing into the ephemeral characteristics of the Perano Station occurred, aiming to create a functional series of empirica geometrical vocabularies. The shielding purists exhibit on tourists became a key design factor moving forward - whilst simultaneously mirroring the 'Purists' 'Gateway' designed for the first intervention. Softwares such as Rhino and V-Ray became critical explorative tools in the process when transitioning from hand to digital - enabling the enhancement of subjective experience. 
Mehemea koe kei te rongo i te tamūtamū i te takiwā, engari kāore koe i te kite tangata, he parangēki tērā, he tiramaka tērā, ko te hunga wairua tērā

$[\cdots]$

If you hear a murmur in the vicinity, but you can't see anyone, that is a sense of foreboding, a portent of a tragic event, and that is the company sense of foreboding, a portent
of spirits [:Wh4 2004:222] +

tirimaka*

ominous omen, sign of foreboding, portent of a tragic (1) nount
sign in the form of sounds or a feeling that gives a sense of foreboding, a portent of a tragic event. 


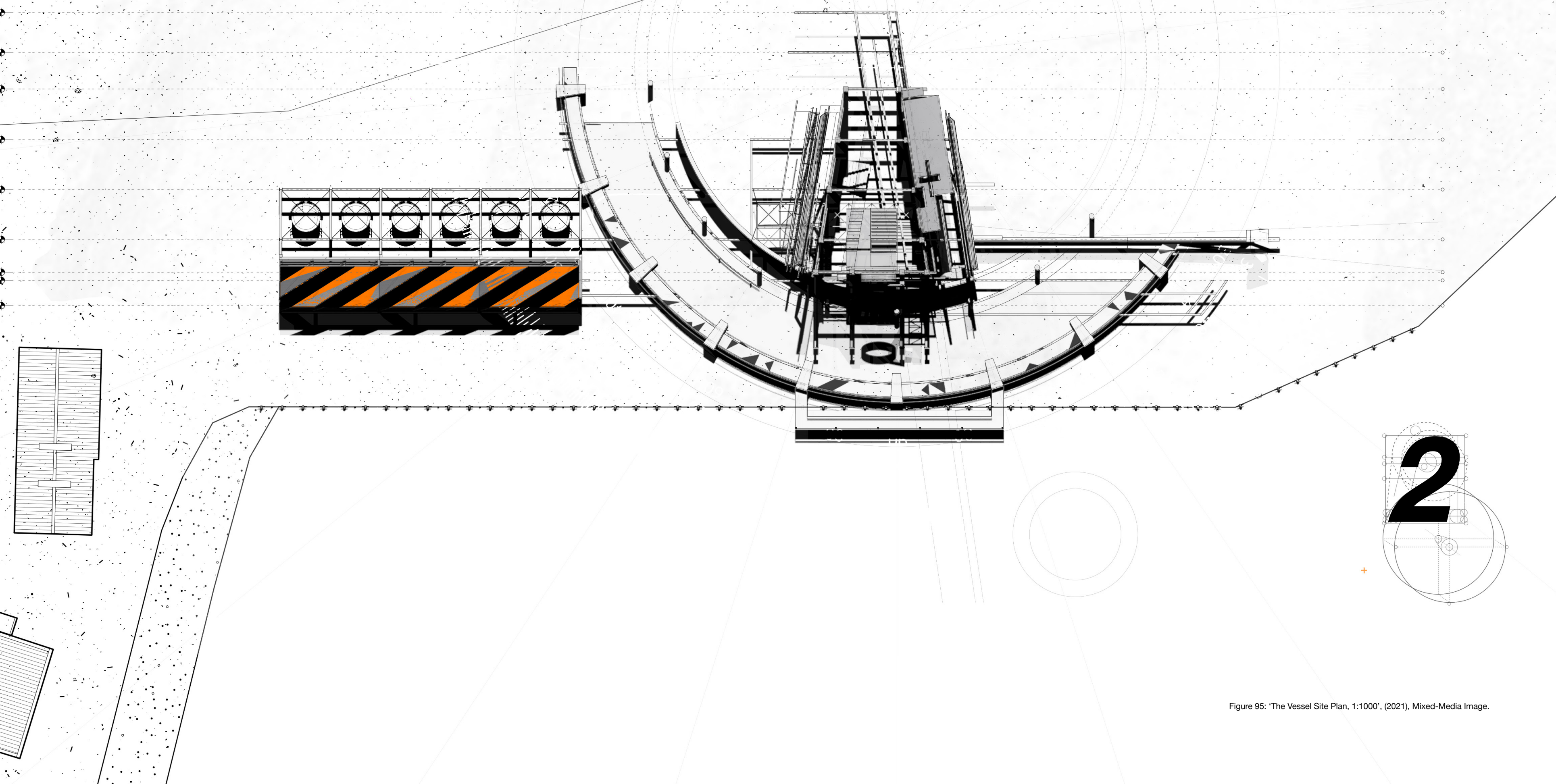




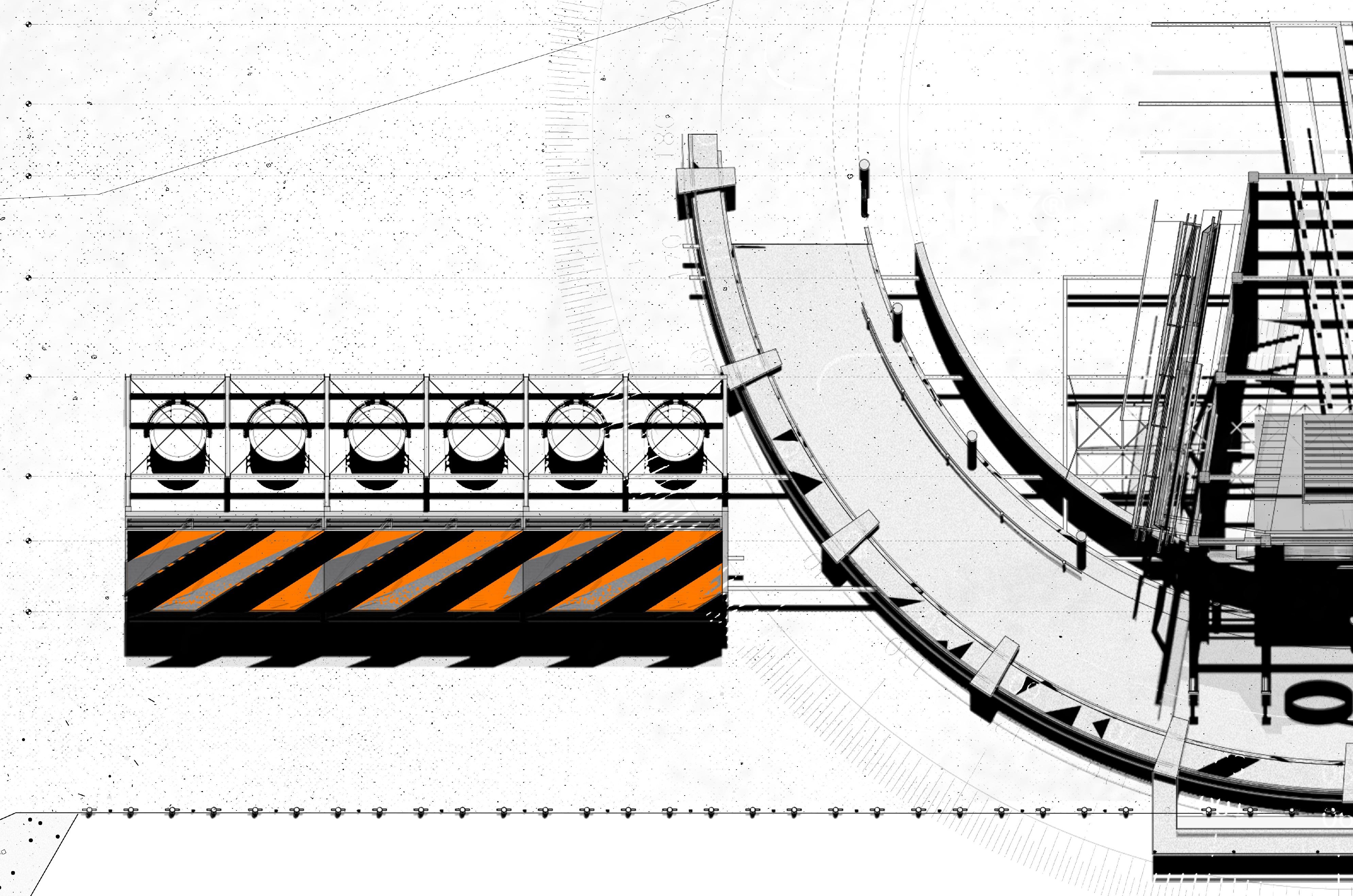




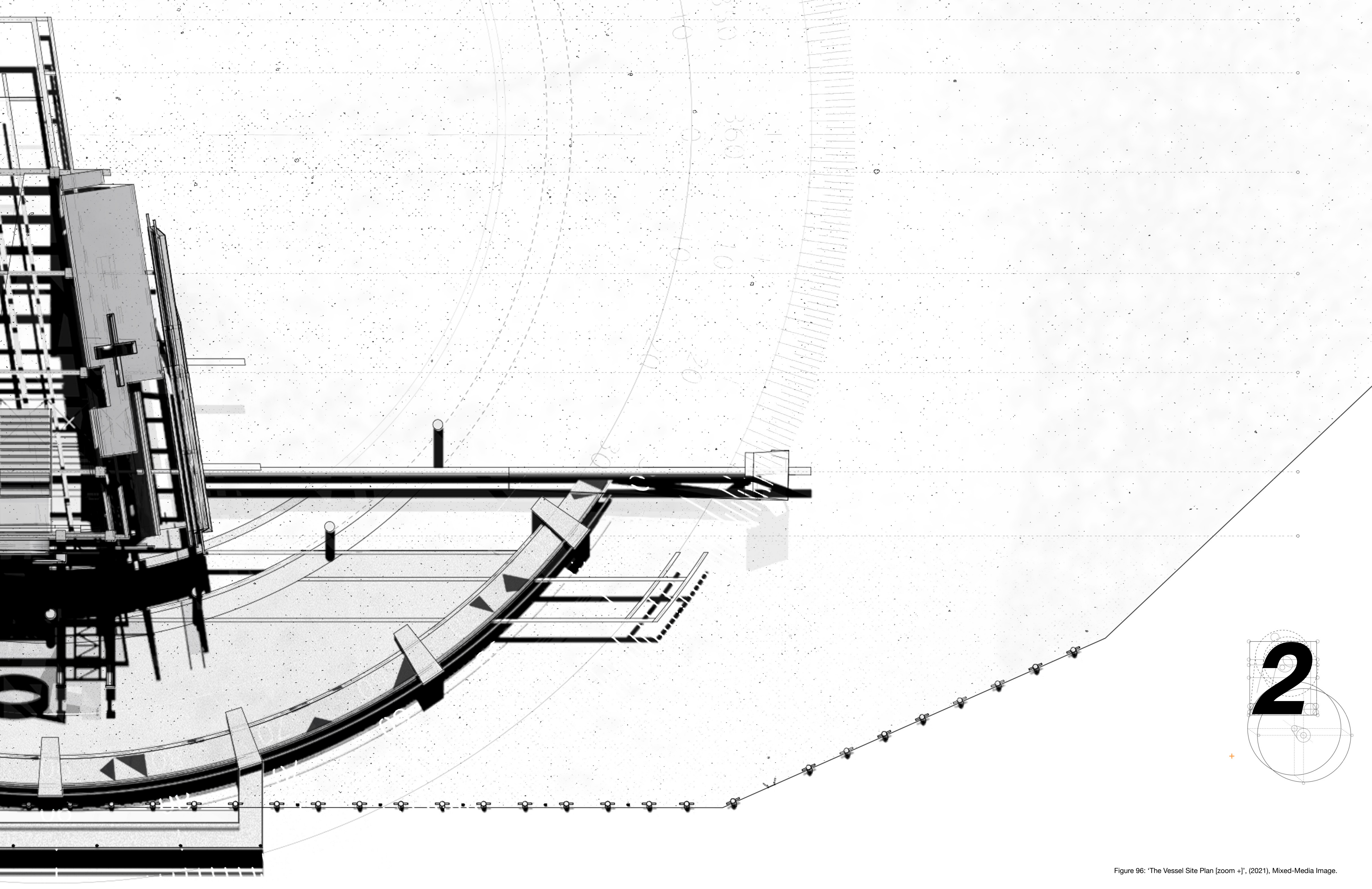




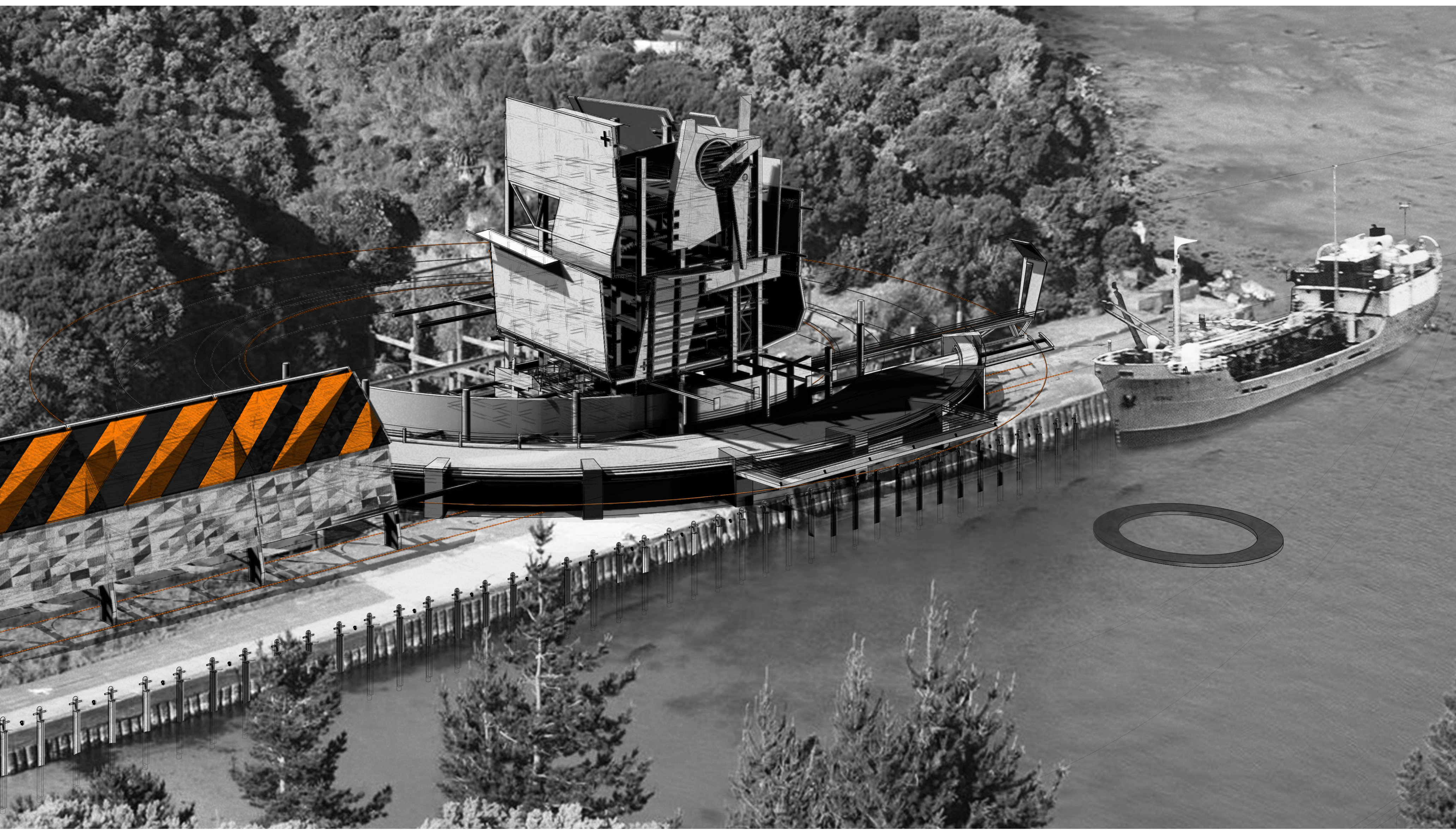




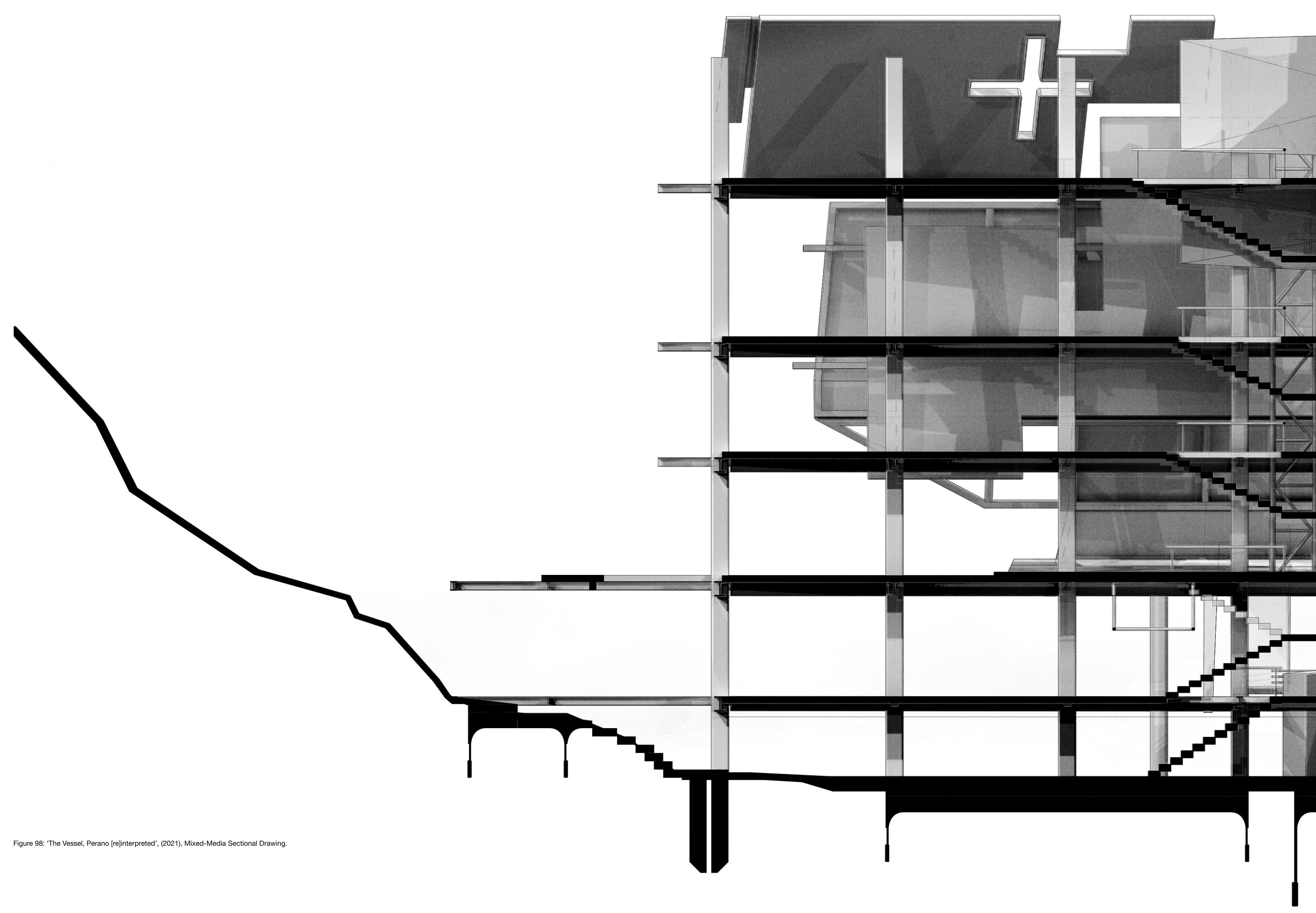




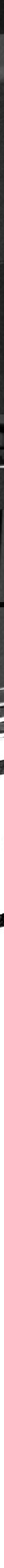




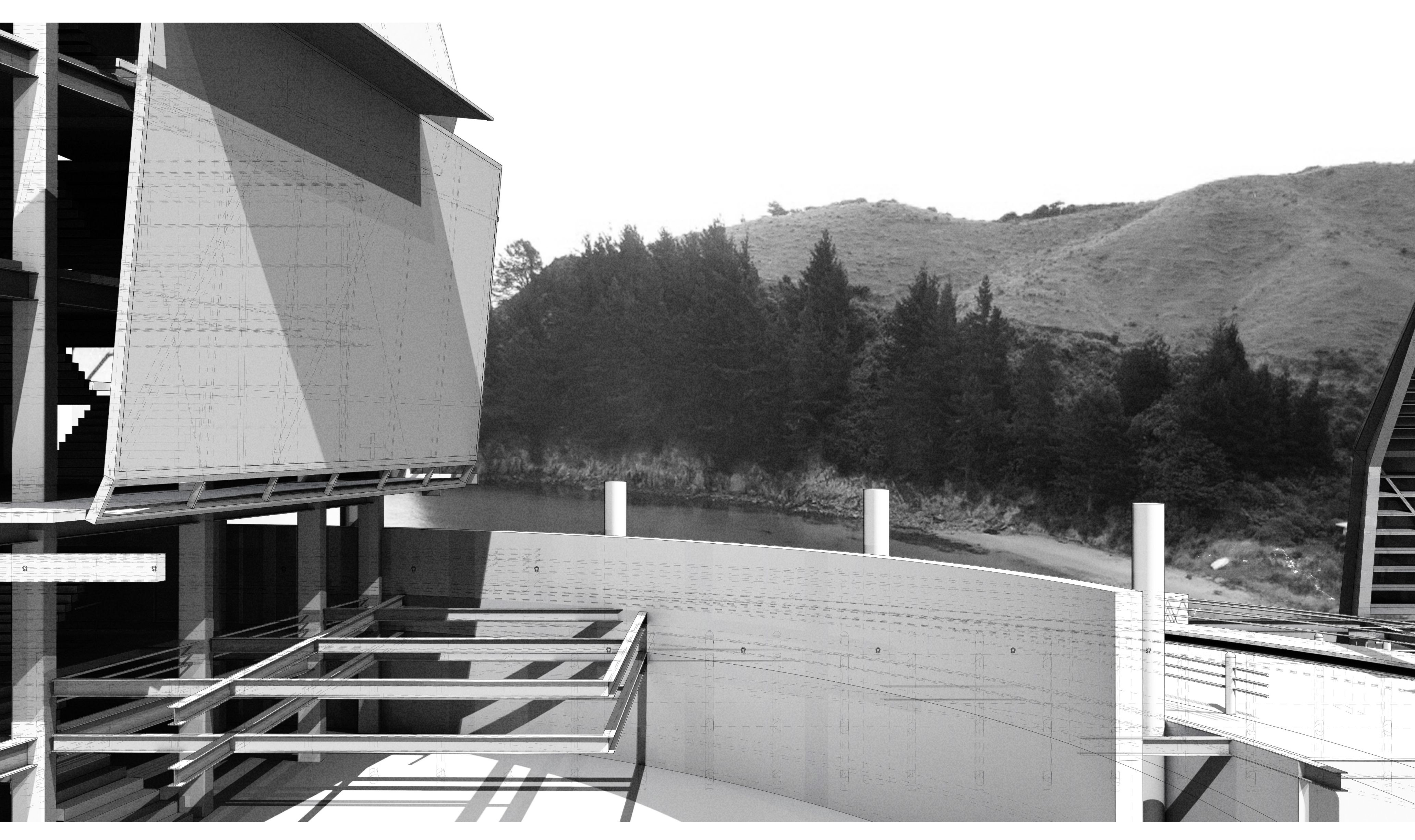




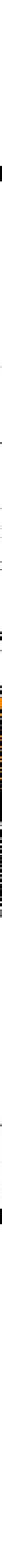




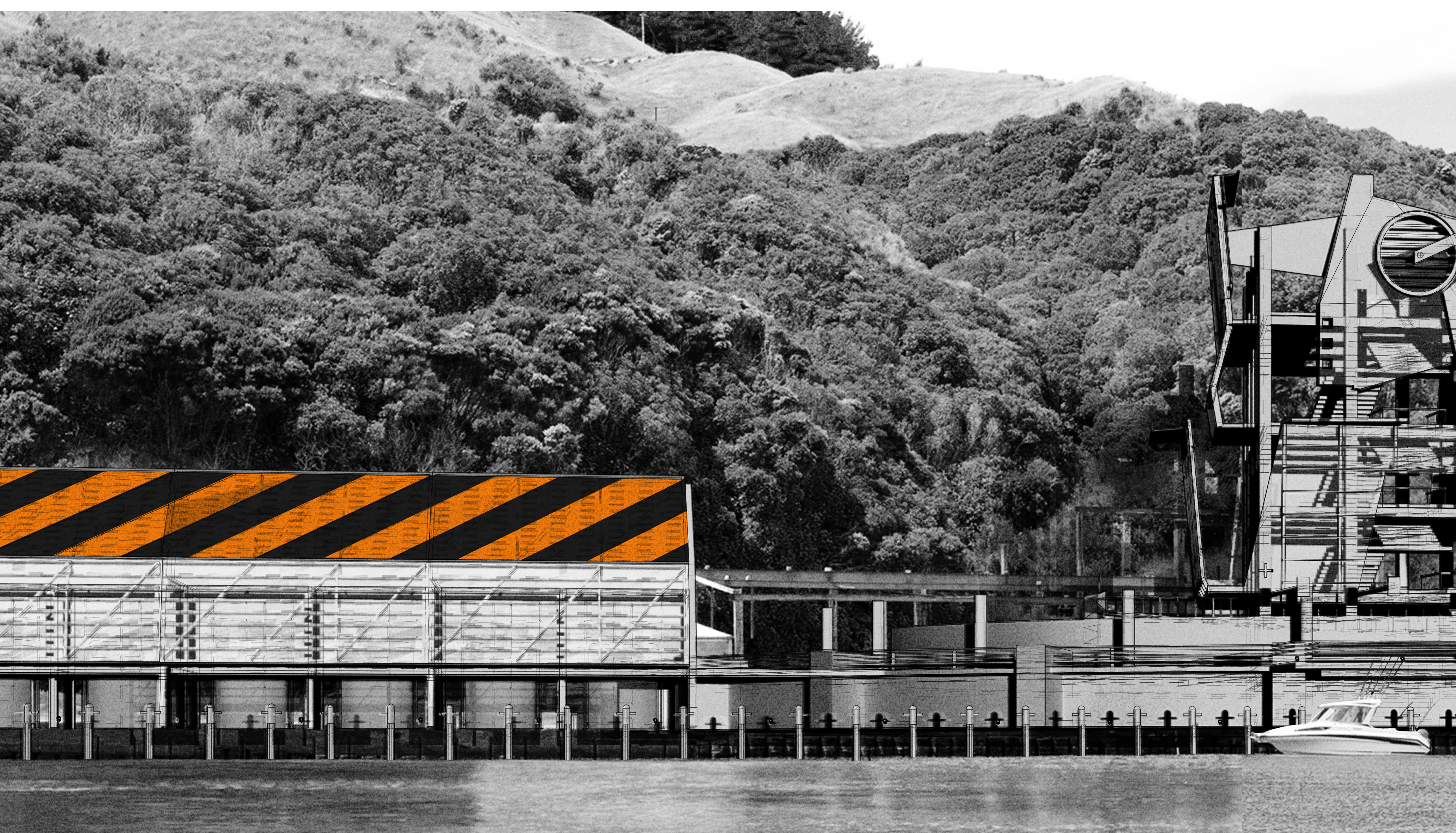




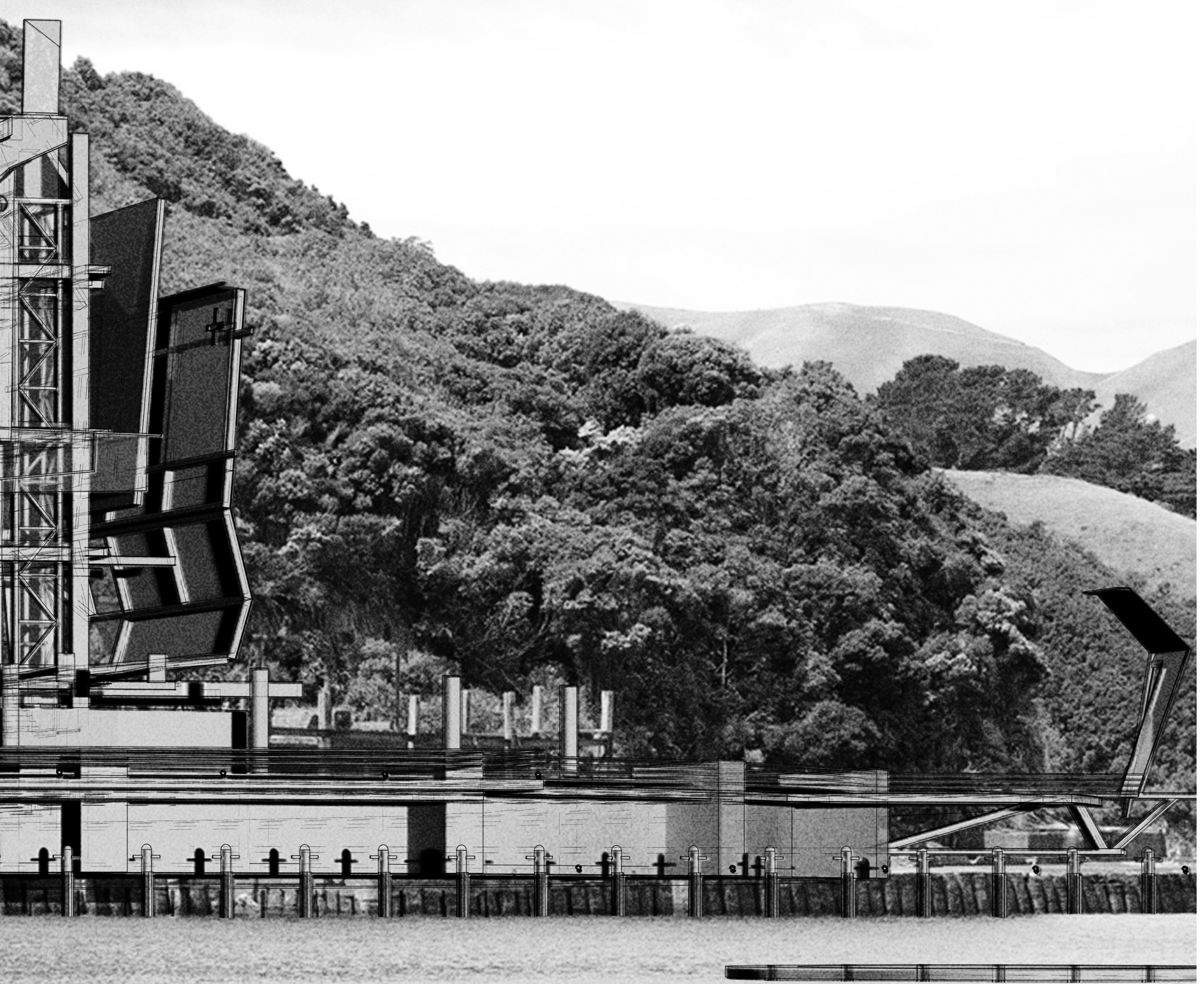




\section{The Vessel [tiramaka]}

"Every place has been touched by a trauma - touched by something - that we are not aware of $[. .$.$] Those voices of the site are not loud, they whisper to$ able - you have to make an effort to listen to the earth" (Libeskind, 2018).

\section{Design Outcome}

The Perano Whaling Station site acted as a palimpsest of historical significance - constructed over a period of 100 years. It provided a rich platform to investigate the damaged landscape caused by the traumatic whaling industry. The final design outcome for the 'Vessel' consists of a carefully inserted [watch]tower proposed on the original footprint and scattered structural remnants left on site from the original station. Accompanying is a large warning display board, with the orange and black construction lines Abloh adopts in his work. This acts as a motif to warn those consuming the happenings. Ruins can therefore install memory permanently, or weaken memory through decay - the occupant is left or weaken memory through decay - the occupant is left
to decide. As Aldo Rossi expressed, "the re-writing of preexisting sites and artefacts fundamentally creates a new locus" (Rossi, 1982, p. 40). The architectural composition is framed to be character and site specific - enclosed by a large circular concrete structure to cut off the tourist character from occupying purists. Purists often disregard tourists when occupying a space.

This design intervention took influence from the cycle of a whale, incorporating the idea of an everlasting [watch]tower to pay homage to those whales tragically extracted and killed once before. The markers of a clock are inscribed in the concrete casing structure, with the everlasting dial mounted to the front of the tower, shifting once every 80 years - the cycle of a whales life. Visual motifs and symbols are curated throughout the design to allow all those whom wish to analyse the design to understand and differentiate between structure, materiality and function.

\section{Critical Reflections:}

This design experiment provided an examination into the capacity for architecture to generate personal association between erased architectural fragments and proposed spatial compositions. It provided a critical insight into how such composed spatial happenings could contribute to our ability to piece together memories through reinterpreted architecture. Peter Zumthor states,

"When I concentrate on a specific site or place for which am going to design a building, when I try to plumb its depths, its form, its history, and its sensuous qualities, images of other places start to invade this process of precise observation: places start to invade this process of precise observation:
images of places that I know and that once impressed me, images of ordinary or special places that I carry with me as inner visions of specific moods and qualities; images of architectural situations which emanate from the world of art, of films, or theatre... When I come across a building that has developed a special presence in connection with the place it stands in, I sometimes feel that it is imbued with an inner tension that refers to something over and above the place itself" (Zumthor, 2013, p. 41).

The second design presented a programme that rendered the scarred site as a palimpsest of infinite possibilities, and allowed a design to be formed from existing scattered fragments translated into an empirical vocabulary in earlier design experiments. The accompanying architectural drawings and images present a body of work that suggests an alternative spatial discourse. Migrating between two distinct, yet 
divided conditions - the experimental architectural drawings

[images] and the machine-like architecture [objects]

are exhibited as conjunctive informants in the process.

Experimental drawings that deconstruct unknown views

which remain unrecognisable act as vehicles to explore

spatial occupation, and [re]connect lost spaces with

imaginary realms to support purist inhabitance. Perano thus

acted as a site for speculation and proposition - through

acted as a sith the fough

both the physical and metaphorical. The kind of drawings

exhibited can be understood as devices for interpretation,

expanding on potential readings and misreadings of the

architecture - the viewer can engage their own distinct

interpretations. This design experiment questioned how

palimpsest-like drawings could aid in the recollection of

memories within the Perano Whaling Station's historical and

cultural context. 


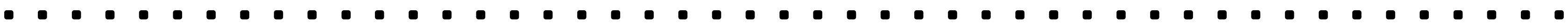

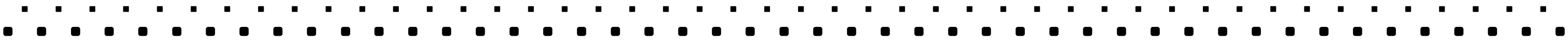

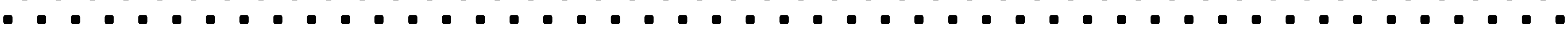

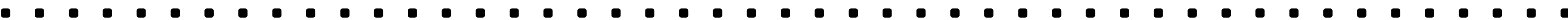
6.

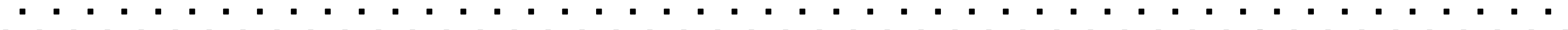

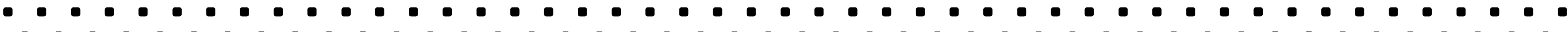

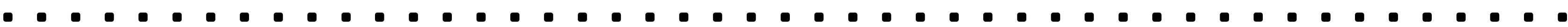

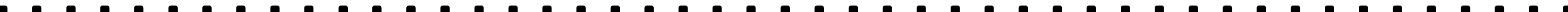
(

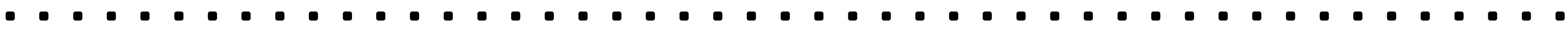

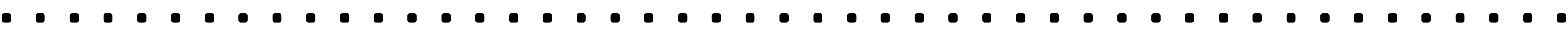

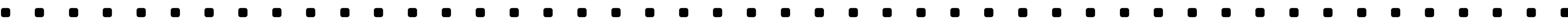

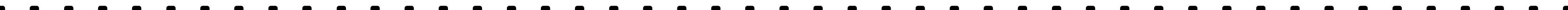

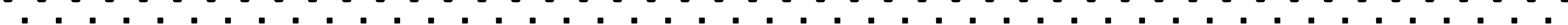

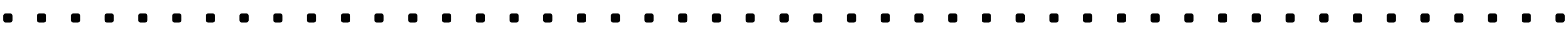

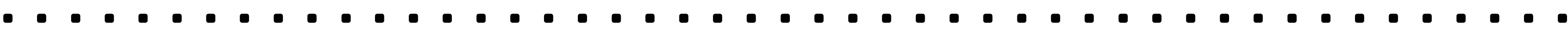

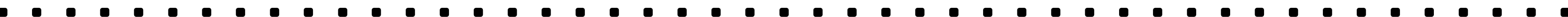
0

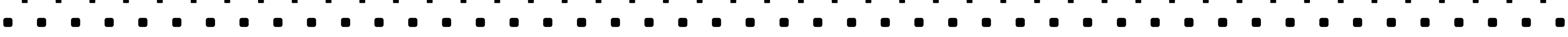
๑

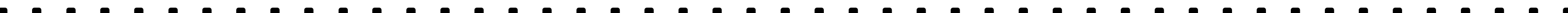

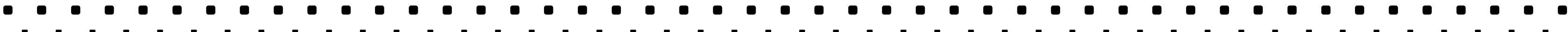

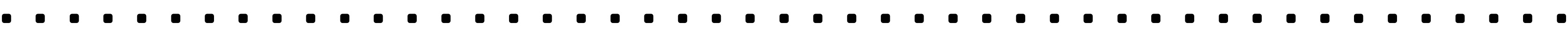

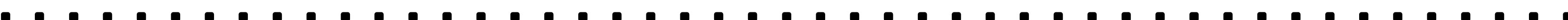

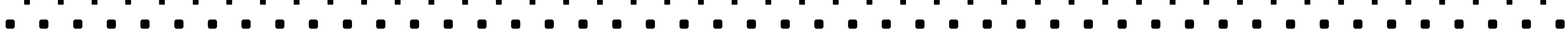




\section{“PAY PER VIEW"}

Virgil Abloh (2018)

"We are all products of our consumption" - Virgil Abloh.

Displayed at Takashi Murakami's 'Kaikai Kiki Gallery' in

Tokyo, Virgil Abloh's "PAY PER VIEW" is an exhibition that touches on the significance of conditioned consumerism; advertising graphic information that has plagued humans' consciousness for generations. Drawing inspiration from Kazimir Severinovich Malevich works, Abloh takes a direct aim at the oldest forms of advertising, repainting logos of billboard companies from predominantly the 90 's, that force fed information for the better half of a century. Abloh creates fed information for the better half of a century. Abloh creates a unique world within this exhibition that captivates his

audience in a multitude of ways - seducing them to reflect on if they are inherently apart of the product of consumption. He also tactically curates his work to enhance the viewer to have personal opinions and provide commentary on current social issues, circumstances, and situations occurring in the world (Murakami, 2018).

Following the premise of Abloh's works, whether it is art, architecture, fashion, music, or furniture, can speak volumes to the 'Tourist' - as well as being easily comprehended by a 'Purist' - an underlying premise for this thesis. This case study allowed the following design, aimed at the 'Tourist', to explore multiple modes of detached observation and graphic display. This formulated a methodology for the viewer to embody a dizzying array of experiences and conclusions through a single object[ive] function. The principal agenda of this exhibition which inherently relates to this design experiment, the 'Sentinel', is to call the viewer to observe in different modes and ways, through a drawing, a view shaft, a series of graphic displays, questioning how information can be tactically arranged to see the cause and effect of a past situation - good or bad. This conceptual spher of a past sitution hidden messages to be uncover

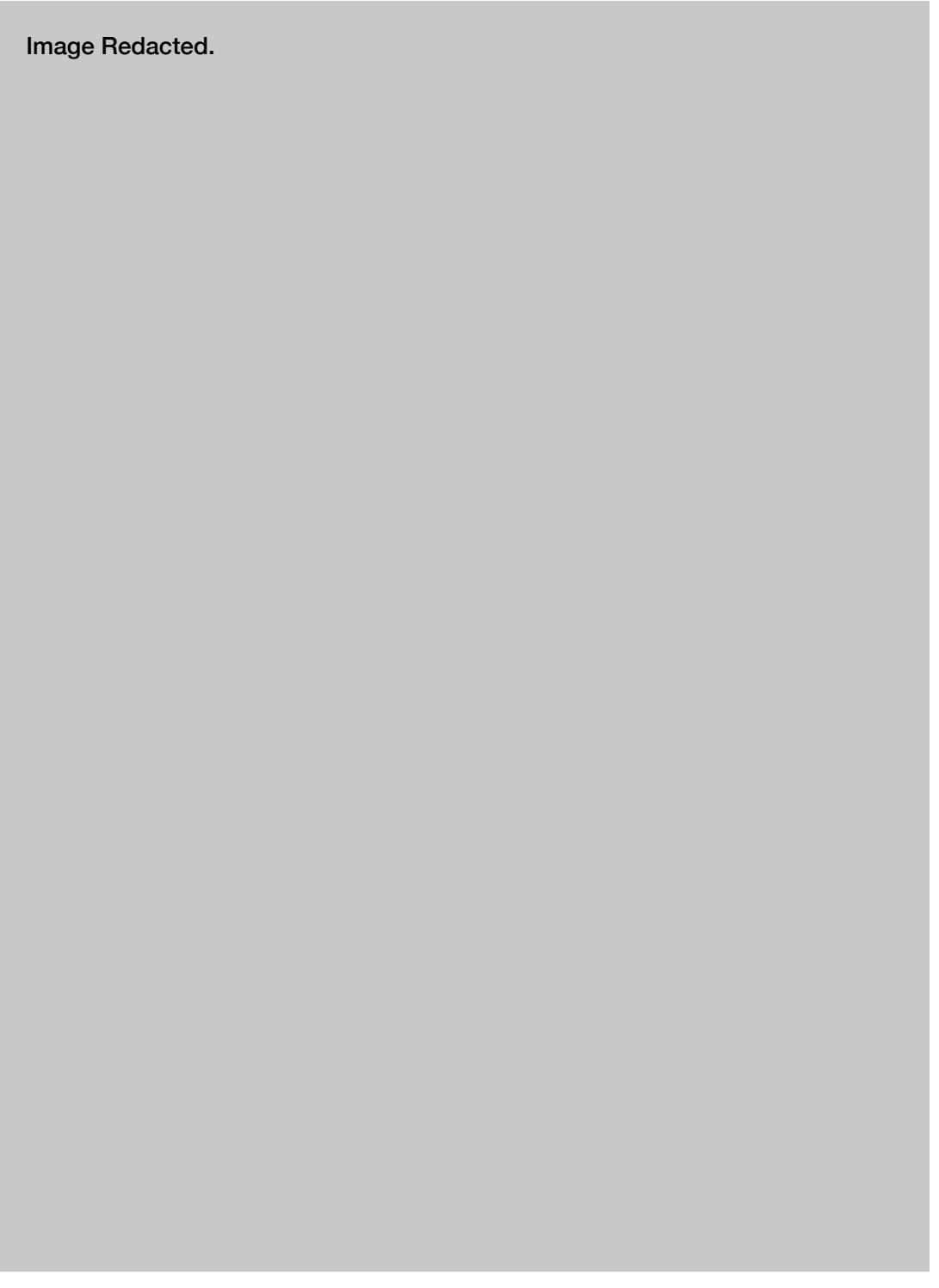

Figure 106: 'PAY PER VEW multi-media installation', Virgil Abloh, (2018), Digital Photograph. 


\section{Image Redacted.}


Aims:

The fourth and final design experiment examines how an

individual, as a 'Tourist', might observe a site experiencing a traumatic past, designed through the evocative experience of drawing and making. How can such speculative architecture, and drawings, designed through a tourist mindset, for a

tourist, aid in situating their memories of a sundered past. As a detached observation sentinel-like tower, this programme cascades West Head Point, enigmatically framing the other two interventions - operating similarly to a photographic two ins of the surrounding context. As the primany desaphic lens of and ch's words to, "maintain the cuiosity of a tourst, with Abloh's words to, "maintain the curiosity of a tourist, without losing the discerning eye of a purist... It's the person who can be both who can make meaningful art" (HighMuseum, 2020). Can such a spatial device assist in the performative process of understanding the roles memories play on our architectural reflections of a space?

\section{Character: [Tourist - Designer/Inhabitant]}

As the designer, viewer, and inhabitant of this intervention, a

tourist exposes the following spatial constructs:

- balance of oppositions - the literal and figurative

reference multiple machines, movements, styles, industries and trends

- construct order from chaos

- [+] converge / [-] diverge from [inter]action

- create unique notations based on past user interfaces

- toggle between both constructs to make meaningful art [open/close doors]
Method:

Dissimilar to past design experiments, the third intervention used speculative drawing and making techniques to create the isolated architectural intervention. Relying on subversive and ironic vocabulary derived from streetwear Virgil Abloh adapts vernacular furniture/objects to

contemporary aesthetics and tastes. Similarly, drawings and empirical object vocabularies follow this same archetypal style within a reputedly elitist milieu - which Abloh advocates for public culture. As well as addressing the context and formal characteristics, this design intervention employs both figurative and literal techniques to portray information to a 'Tourist' character. Through hand and digita information to a 'Tourist' character. Through hand and digita
drawing modes, this experiment met outlined design aims drawing modes, this experiment met outlined design aims and objectives - by recognising and displaying social employed performative techniques through architectonics as formal devices of [re]interpretation.

Through an initial hand-drawn process evaluating West Head Point as a panoramic and photographic lens, rigorous development in the design phase was later undertook in digital environments such as Rhino and V-Ray. This allowed observation to be tested virtually within an immersive and observation to be tested virtually within an immersive and accurately modelled environment that helped analyse tourist's interaction with the sentinel structure. Digita
screens displayed graphic information with 'human compatibility', highlighted throughout the following hybrid drawings. Representation techniques allowed this performative process to continue with a certain graphic warfare between hand and digital - producing architecture that responds to the anamnesis of Perano's wider context.

- "ASK QUESTIONS" 

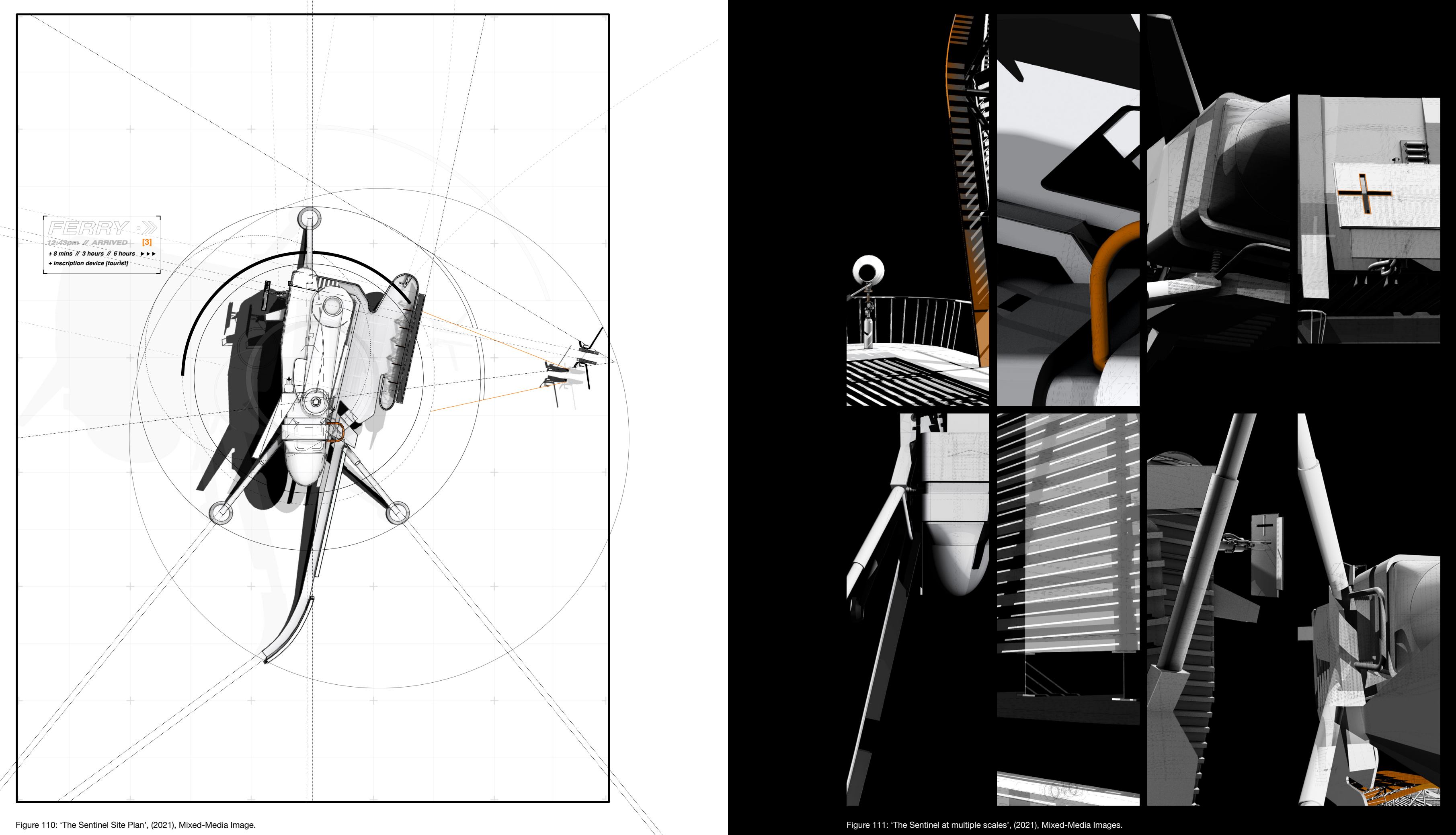

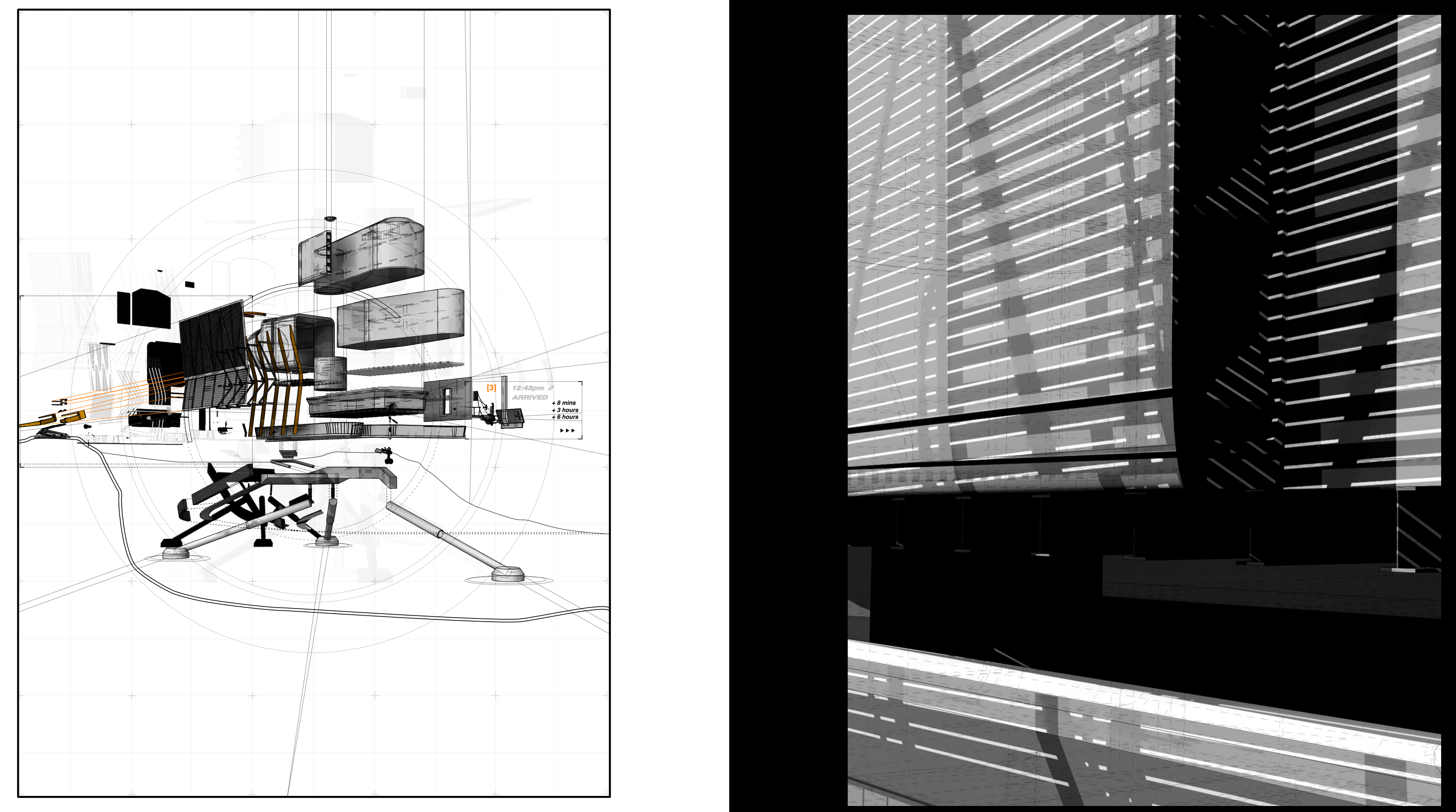

Figure 12: 'The Sentinel, Exploded Axonometric', (2021), Mixed-Media Image.

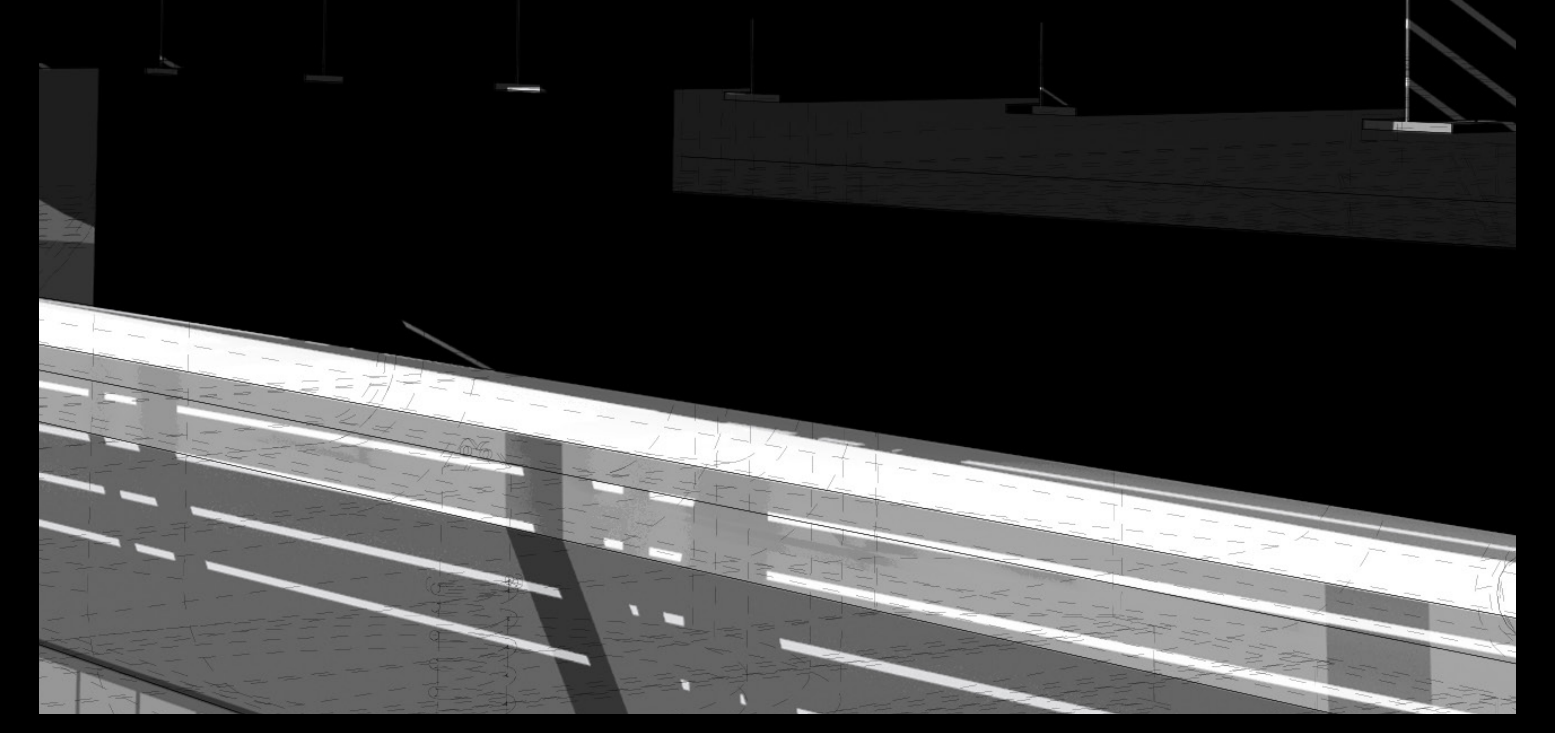




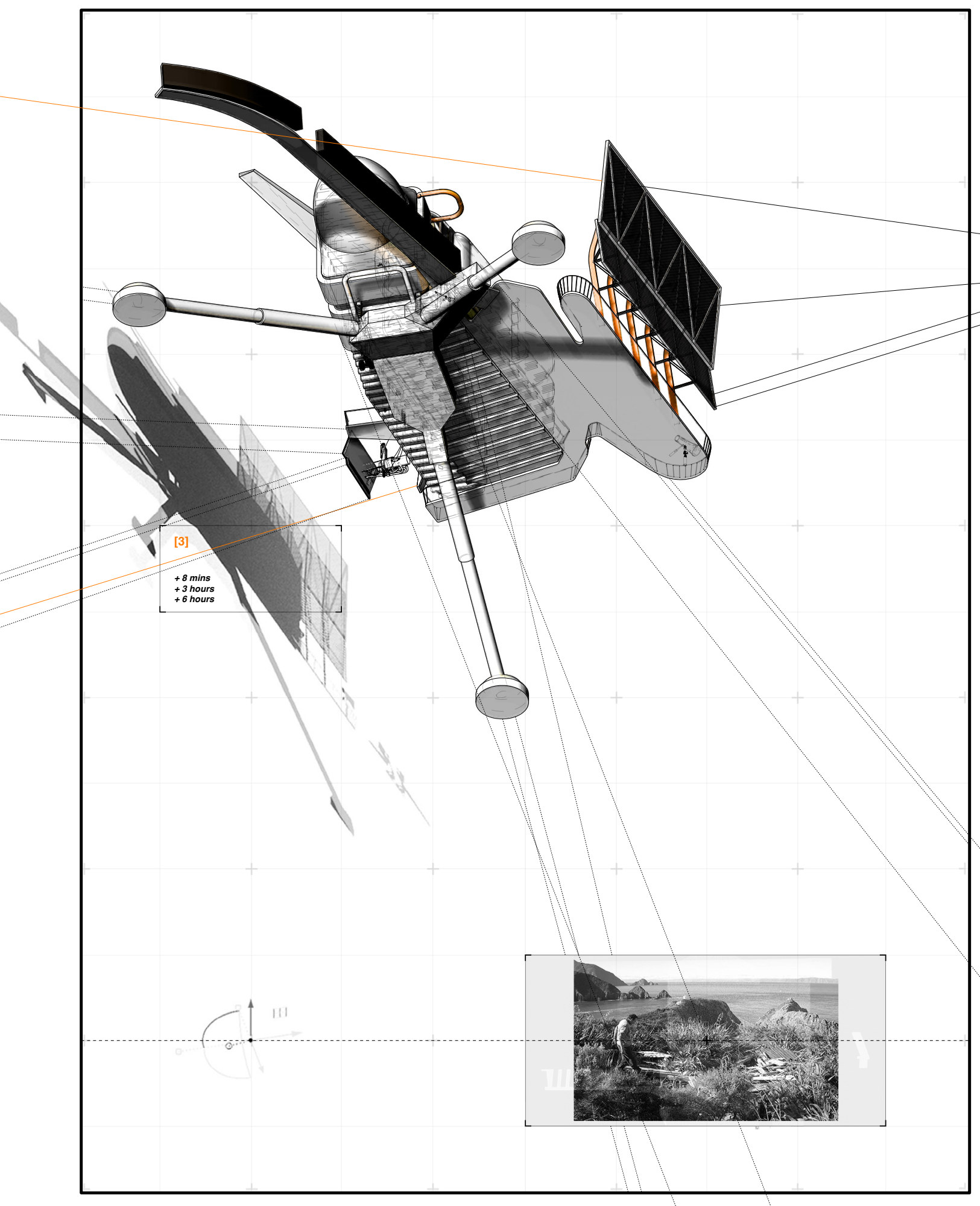

Figure 114: 'The Sentinel [Detached Observation]', (2021), Mixed-Media Worms Eye Isometric.
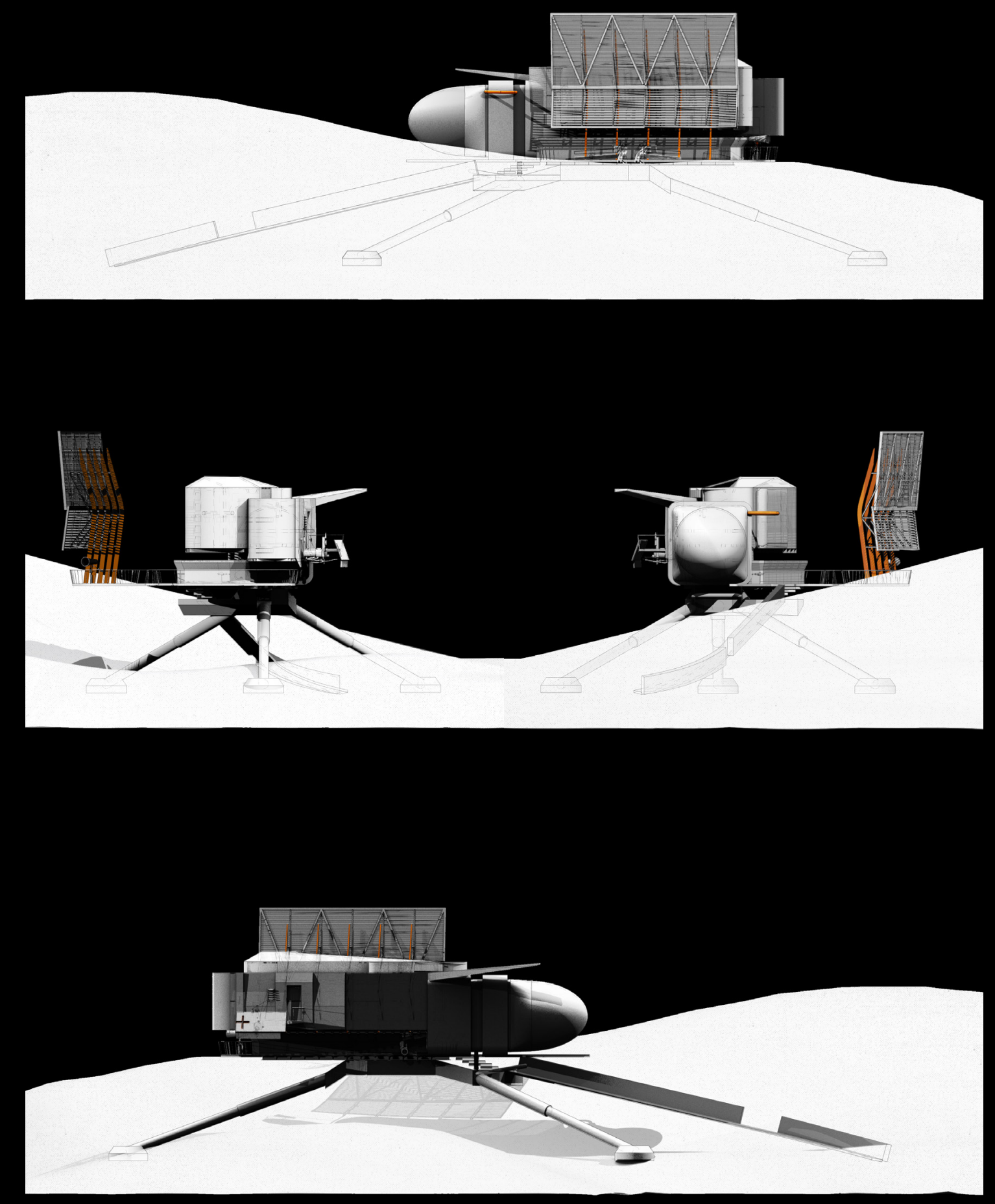

Figure 115: The Sentinel, (2021), Mixed-Media Elevations. 
y.

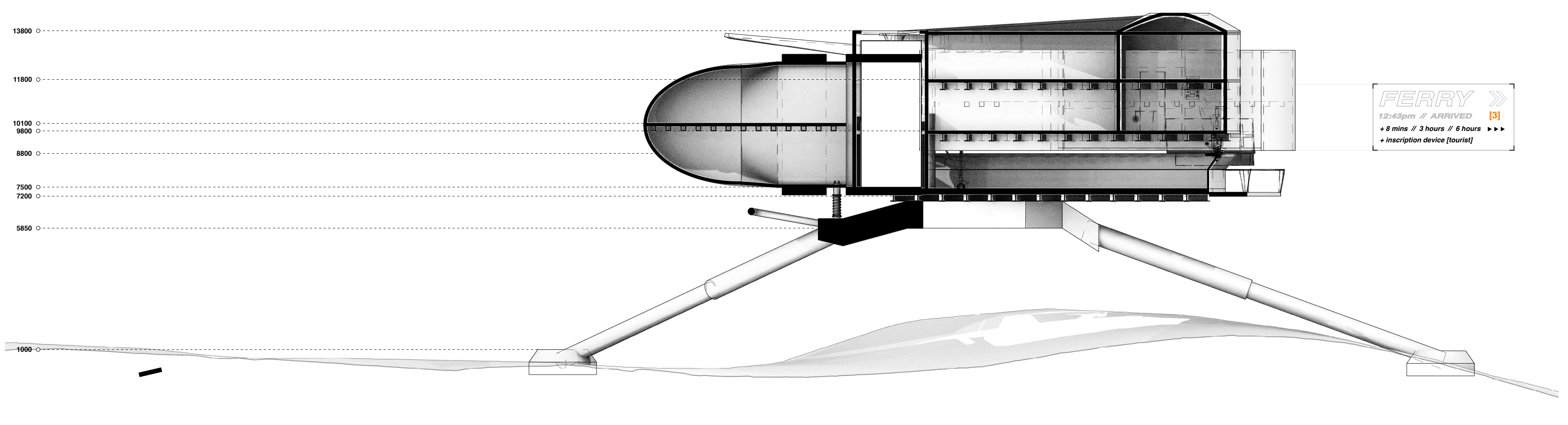




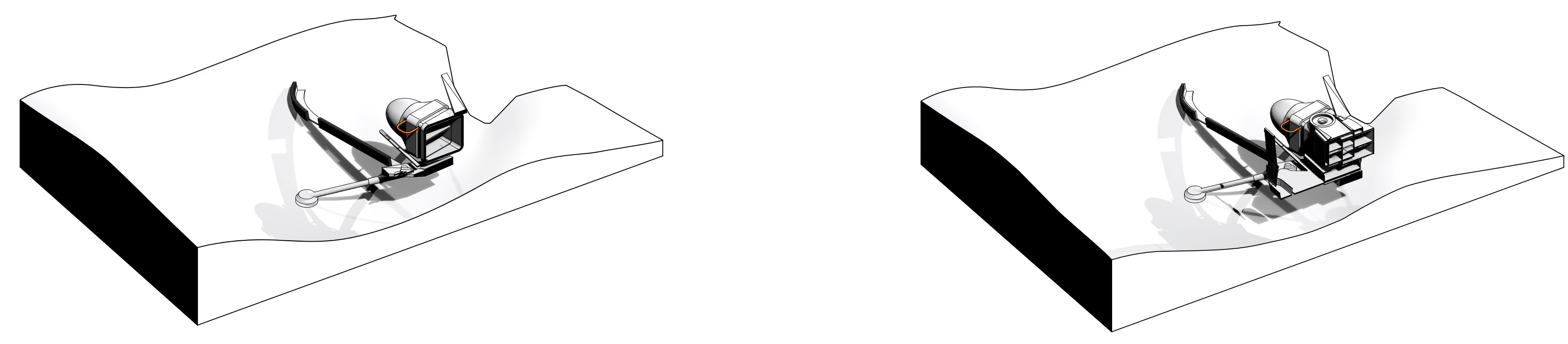


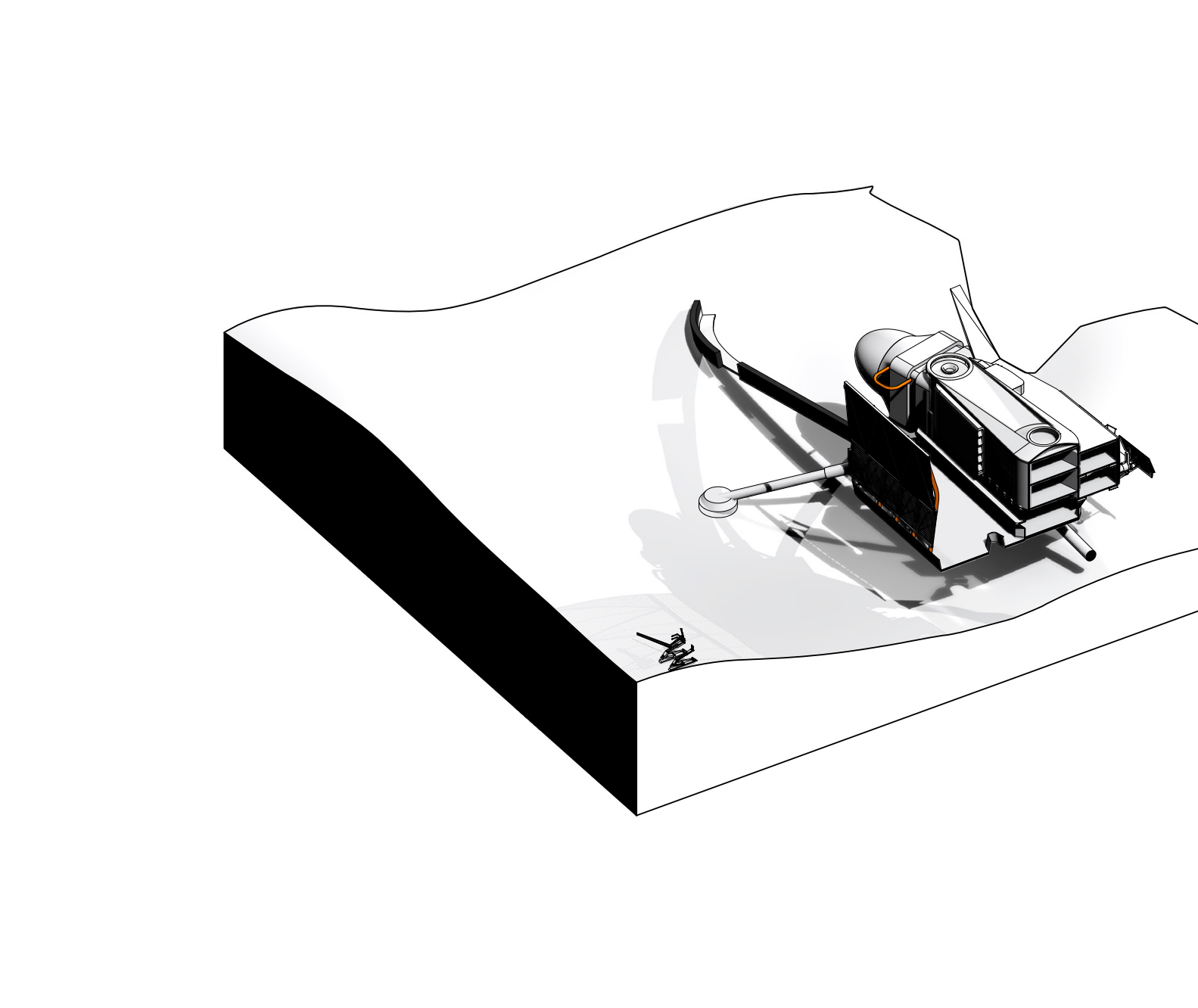



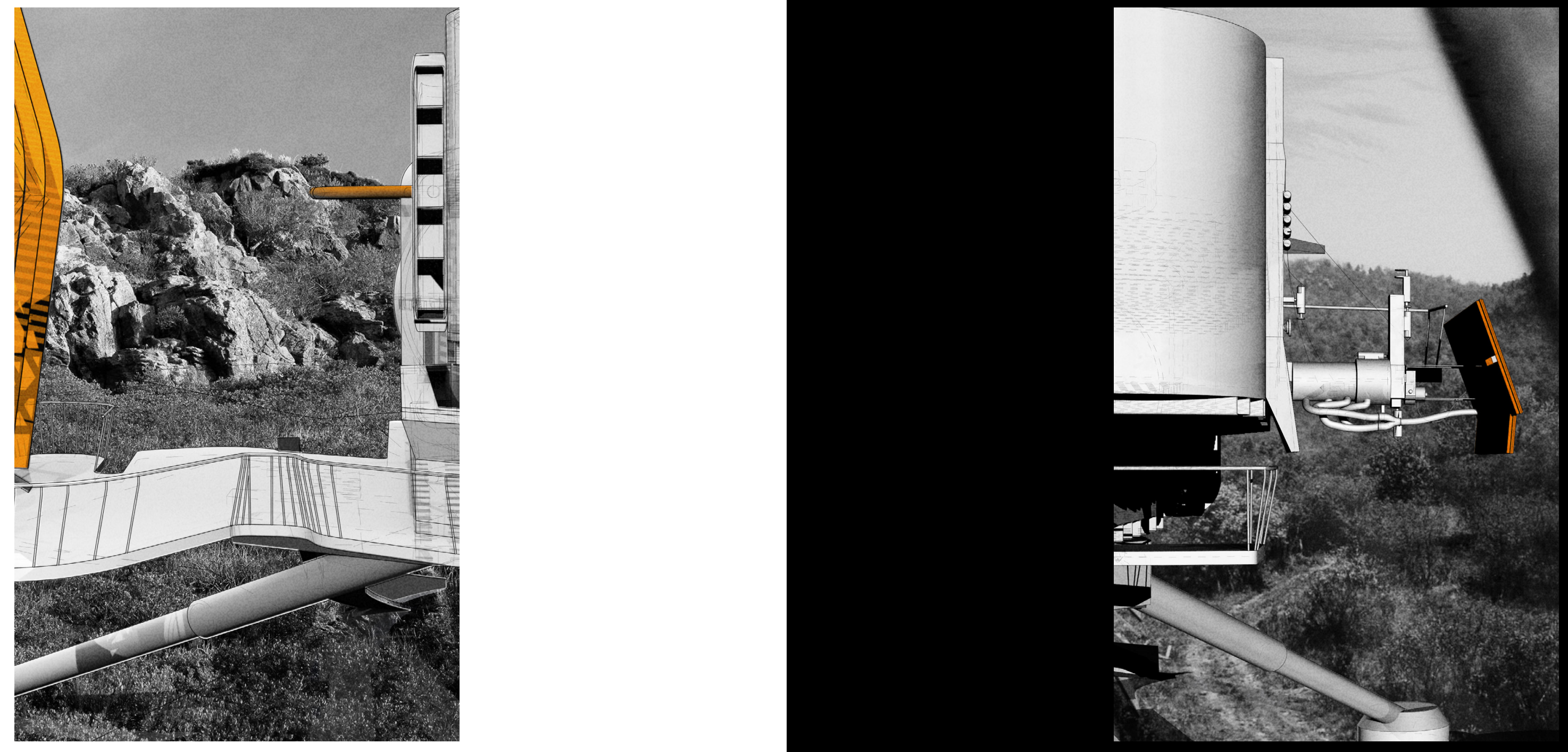



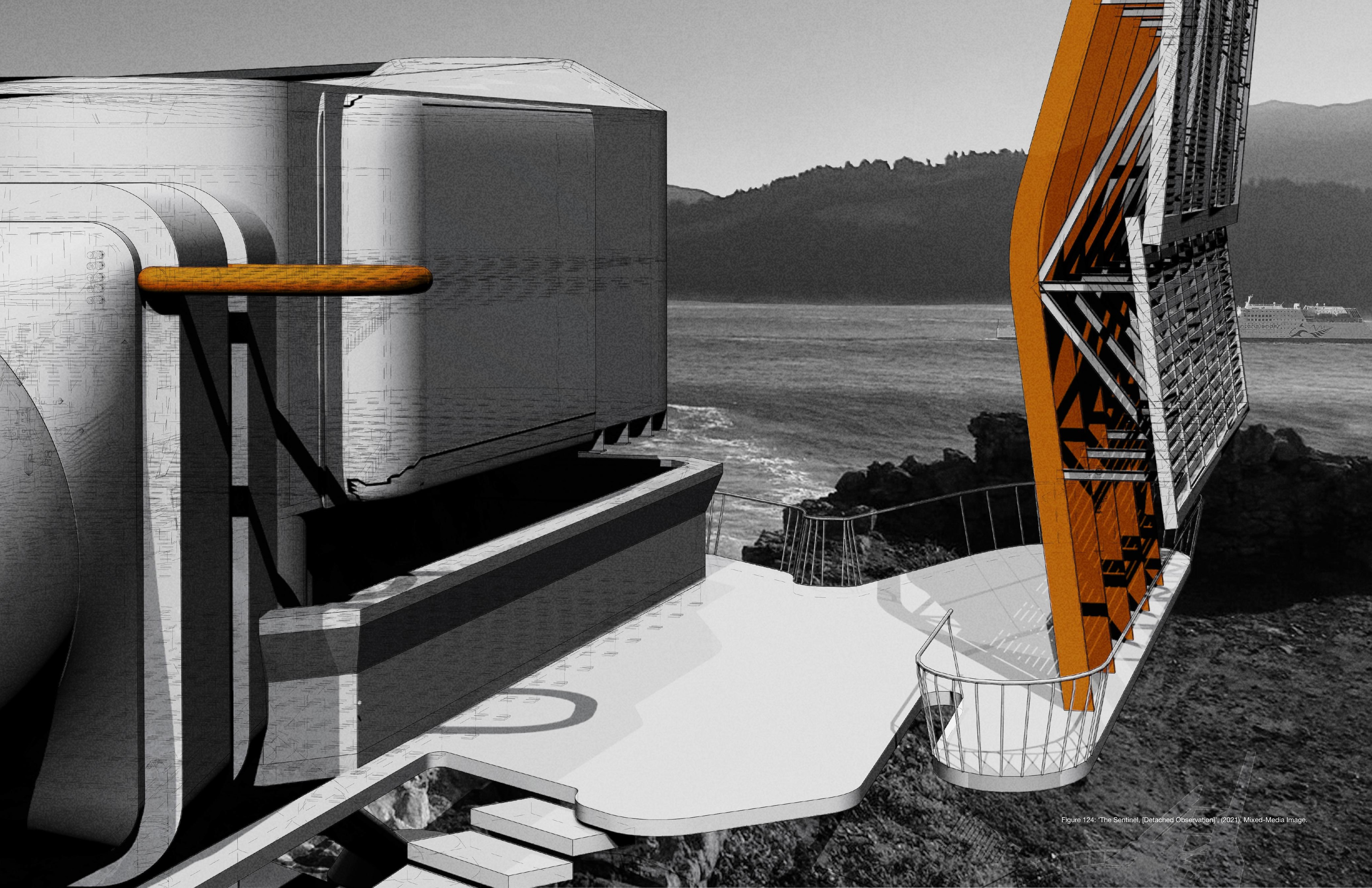




\section{8}

The Sentinel [Detached Observation]

\section{Design Outcome:}

The final design outcome consists of a tripod sentinel

tower, with a large ramped entry branching off the existing track. This tactically delays the 'Tourist' characters entry to the edifice, and allows them to consume all the provided graphic data and [form]al composition of the detached observation tower. The entry ambiguously reaches out to tourists like an extended arm, pulling their psyches in to invite multiple speculations and an array of conclusions. The intersecting circular-like structures in which tourists spatially occupy frame the scarred landscape - and the other two occupy frame the scarred landscape - and the other two interventions in a panoratic sense - where all parts of the design allow observation, including the large platform decking connected to the structure. Boilers, reclaimed water tanks from the past observation hut, mechanical lines, transportation paraphernalia and billboards were unconventional architectural inspirations - extracted from the context and reconnected as an architecture based on machinist geometries.

Collaboration is integral to Abloh's approach. He not only draws inspiration from a staggering array of sources, but draws ins also works and friltates conections among differing personnel. This engagement with the cultural and historical landscape is both generous and generative. Referring back to Cantley's work, he creates from found objects and various other sources, much like Abloh. This toggles back to the aim, designing for a tourist, like a tourist - ensuring not losing the discerning eye of a purist. A premise which Abloh continuously advocates for. By employing inspiration from various geometries and genres, a sentinel structure was created composed from found ready-made objects that suggest an alternative mode of pragmatic operation. This machine-like structure both challenges conventional architectural constructs, and poses a convincing argument for spatial occupation in an alternate historical setting. This evocative process allowed viewers to question - and speculate on an answer - pondering the unconventional future of exhibitive architecture in alternative landscapes.

\section{Critical Reflections:}

This design experiment provided explorative testing into the observation of the 'Gateway' and the 'Vessel' programmes and an overall facilitator of observation of the Tory Channel - a landscape experiencing strict erasure at a larger scale. The programmatic events and generated images enable this architecture to act as a performative intervention. Libeskind elaborates on the tourist character; "Tourists are smart. They learn from the geometry of the building, the space, the light. They learn something that they really want to know. People They learn something that they really want to know. People are interested in profound things... People are thinkers.

People are creatives. Projects thus have to take a risk, to be bold, rather than anaesethize people, they have to shift their perspective" (Libeskind, 2018). Thus, objects inserte into this design are composed in a manner that invites performance, and collaboration between subject and object. The large display boards which plaster graphic information for the 'Tourists' consumption are a key aspect of this. In Abloh's words, "You become a performance art piece just by using the thing" (Yanong, 2019).

While self-referential text is often employed in the field of architecture, either as signage for navigation or as plaques to detail a building's significance, several contemporary artists 
have also regularly applied text to pre-existing buildings to respond to their histories and contexts. American artis Jenny Holzer, whom Abloh has previously collaborated with, has been projecting text onto building façades and electronic signage to gain; "direct access to a large public that might not give 'art' any consideration, while allowing her to undermine forms of power and control that often go unnoticed." In 2008, Holzer projected poetry onto the curved façade of the 'Guggenheim Museum' that touched on sitefaçade of the 'Guggenheim Museum' that touched on sitespecific issues, including the consumption of art and the use of public spaces. This ideology was a key precedent when designing these large digital display boards, and impacted the drawing's excavations as both a process, and final outcome.

In 'Mechudzu' by Bryan Cantley, the first chapter include the essay 'Machinogenesis', written by Wes Jones and Doug Jackson. It explains in critical detail the process of Cantley and why he adopts such a speculative process. They include that "the whole image may be incomprehensible - but - individual moments stand out which engages the viewer's attention" (Cantley, 2011, p. 84). The sentine the viewer's attention" (Cantley, 2011, p. 84). The sentine somewhat employed this phenomenon, where through readymade objects, the tourist's curiosity and engagement with such a dizzying array of objects can begin to allow them to piece together, and understand the architecture as a whole composition, as well as the relative drawings and representations exhibited. The architecture is a drawing, and the drawing is the architecture. The 'Sentinel' as a concluding design experiment expanded on the role architecture has in contributing to a viewer's understanding of an erased historical context, and how it can be pieced

of an erased historical context, and how it can 


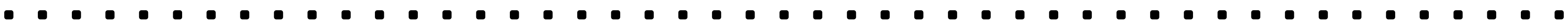

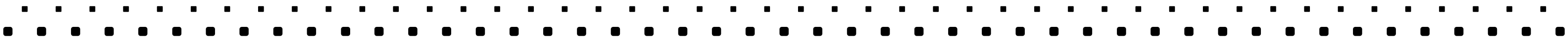

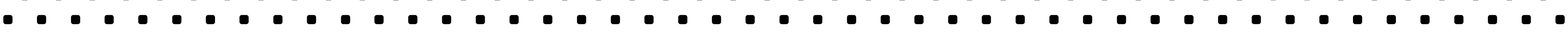

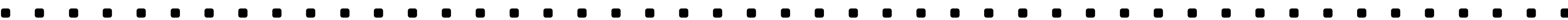
6.

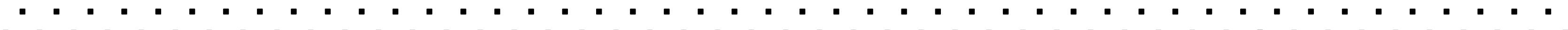

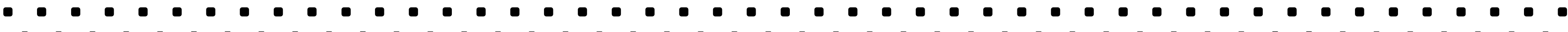
•

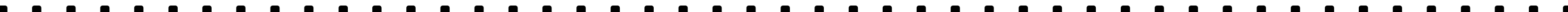

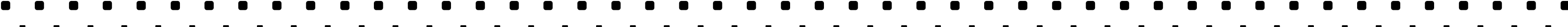

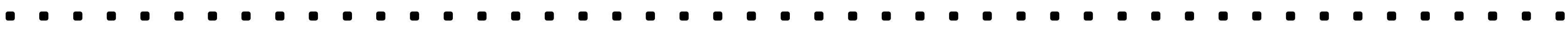

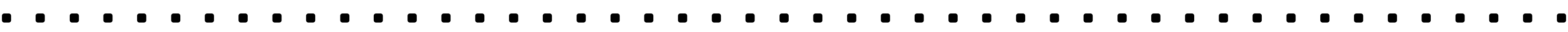

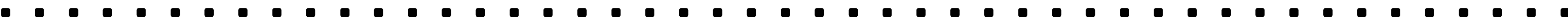

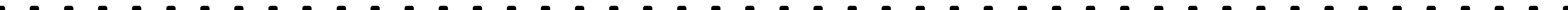

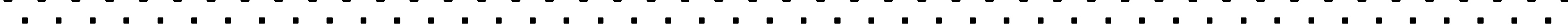

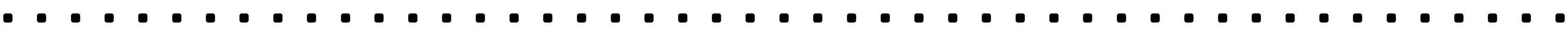

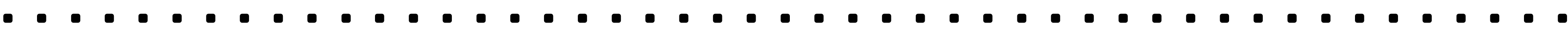

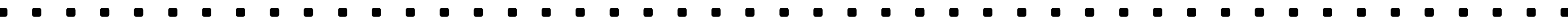
0.00

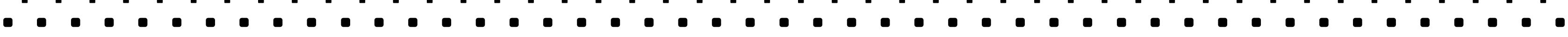
๑

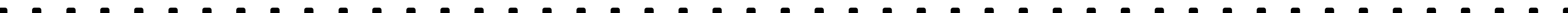

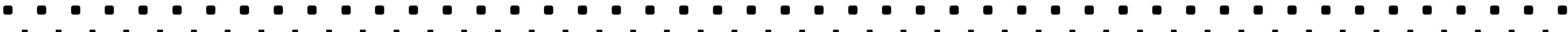

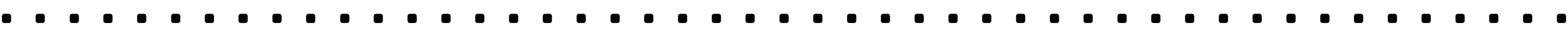

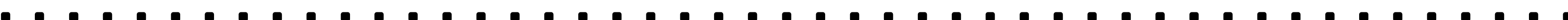

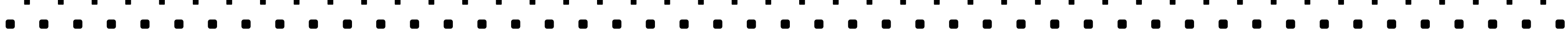




\section{Conclusions and Critical Reflections}

"A drawing should be an investigative device, a voyage of discovery, a series of glances into the future" (Cook, 2013, p. 80

This design-led thesis excavated a complex and multilayered problem within not only the architectural discourse, but, creative disciplines as a whole. Valuable discourse regarding the architectural discipline have been explored and ultimately propelled - ultimately leading to questions and some limitations speculative drawing has in [re] interpreting and [re]creating a landscape experiencing on-going historical, cultural and environmental erasure. This thesis posed the following question in response to This thesis posed the following question in response to the research problem, in an attempt to re-examine the role speculative architecture has in the discipline; how the medium of speculative architectural drawing, can be used as an inquiry tool for interrogating and reinterpreting, an erased architectural ruin as a repository of memories?

Three seminal theorists, Virgil Abloh, Tim Edensor, and Andreas Hussyen, along with key related literature reviews and case studies contributed to this thesis' body of research which ultimately led to an initial design experiment, and three developed design outcomes. The developed outcomes were three meticulously related interventions that synchronousy three merk together as a vincle to explore the historical and work together as a whole to explore the historical and cultural story of Perano Whaling Station - and the wider Tory Channel context. Consistently throughout the design process, there was a deep desire to arrive at a destination that toggled between landscape and architecture; exploring how these interrelate. Throughout this body of research, several specific conclusions have been reached that relate directly to the research aim of this exploration. Conclusions propose architectural drawings can investigate and reassemble Tory Channel, and other derelict sites, through the polemical act of superimposing drawings and designs to a polemical act of superimposing drawings and designs to a andscape.
Unexpected findings within the drawing process explored abstracted perspectives that challenged the narrative through extrapolation of pre-constructed assemblies. Layering, 2D, 3D modelling, drawing and [re]drawing as collaged compositions acted as a palimpsestuous process of recordings - achieving unconventional architecture that provoked a curiosity and deeper inquisition of viewing architecture in an alternative spatial discourse.

Whilst this thesis undertook a multi-disciplinary approach could not approach all aspects of the conventional design process. It does not engage with financial restraints, resource management or consent - simply put, due to them residing outside of the defined scope. If this thesis were to progress past the defined scope, further exploration and connection of interior spaces could have enhanced the narrative, and interlinked the three design interventions relationships even more. Whilst this research investigated a site-specific landscape along New Zealand's shoreline, further opportunities arise to investigate other forms of further opportunites arese to nivestigate of er forms of historical identity. This design-led thesis concludes as historical identity. This design-led thesis concludes as an ongoing process of exploration, but, created a framework
for future design experimentations to continue the re-

for future design experimentations to continue the re-
examination speculative architecture and drawing has within the architectural discourse - and imagines how we can create architecture in the future. 


\section{Cited Works}

Abloh, V. (2017). Core Studio Public Lecture: Virgil Abloh, "Insert Complicated Title Here". Harvard University Graduate School of Design.

Allen, L., \& Pearson, L. C. (2016). Drawing Futures: Speculations in Contemporary Drawing for Art and Architecture. UCL Press. https://doi.org/10.2307/j.ctt1ht4ws

Allen, L., \& Smout, M. (2008). Out of the Phase: Making an Approach to Architecture. Architectural Design. Vol. 78, (No. 4). John Wiley \& Sons Ltd. p. 80-85

Bartlett School of Architecture. (2017). Bryan Cantley: International Lecture Series.

Berger, M. (2013). Difficult Memories: Reconciling Meaning. Birkhauser. Vol. 4.

Bishop, C. (2005). Installation Art: A Critical History. (Issue 3). London: Tate Publishing \& Enterprises.

Bryant, L. (2014). Onto-Cartography: An Ontology of Machines and Media (Speculative Realism). (First Edition). Edinburgh University Press.

Cantley, B. (2011). Mechudzu: New Rhetorics for Architecture. Springer, Vienna. (First Edition). Paperback.

Cantley, B. (2013). Two Sides of the Page: The Antifact and the Artefact. AD Drawing Architecture. London. Artmedia, Vol. 83, (Issue 5). p. 36-44.

Cook, P. (2013). Looking and Drawing. AD Drawing Architecture. London. Artmedia, Vol. 83, (Issue 5). p. 80-87.
Corner, J. (2014). The Landscape Imagination: Collected essays of James Corner, 1990-2010. (First Edition). Princeton Architectural Press.

Darling, M. (2020). How Virgil Abloh is shaking up the design scene. Article featured in Numéro News.

Darling, M. (Editor), Koolhaas, R. (2019). Virgil Abloh: Figures of Speech [Special Edition]. Prestel. Hardcover.

DeSilvey, C., \& Edensor, T. (2012). Reckoning with Ruins. Vol. 37, (Issue 4). p. 410-485.

Diderot, D. (2011). Te Salon of 1767. In: Dillon, B. Ruins. London: Whitechapel Gallery. p. 22.

Dodds, G. (1992). On the Place of Architectural Speculation Journal of Architectural Education. Vol. 46, (No. 2), p. 76-86. Published by: Taylor \& Francis, Ltd. doi:10.2307/1425201

Downtown, P. (2003). Design Research. Melbourne. RMIT University Press Publishing.

Dunne, A. (2005). Hertzian Tales: Electronic Products, Aesthetic Experience, Critical Design. Cambridge, Mass.; London: MIT Press. p. 84-98.

Edensor, T. (2005). Industrial Ruins: Spaces, Aesthetics and Materiality. (First Edition). Oxford: Berg Publishers. p. 140.

Edensor, T. (2005). Waste Matter: The Debris of Industrial Ruins and the Disordering of the Material World. Journal of Material Culture. Vol. 10(3). p. 311-332. 
Farhady, M. (2009). Comparison of In-between Concepts by Aldo Van Eyck and Kisho Kurokawa. Vol. 8. (Issue. 1). Journa of Asian Architecture and Engineering.

Grady, D. (1982). The Perano whalers of Cook Strait - 19111964. Reed, Wellington [N.Z]

Hejduk, J. (1985). Mask of Medusa - Works 1947-1983. (First Edition). Rizzoli International Publications.

\section{High Museum of Art. (2020). Conversations with}

Contemporary Artists: Virgil Abloh. Virgil Abloh and Kevin

Tucker, the High's Chief Curator.

Huyssen, A. (2010). Authentic Ruins. In: Hell, J., \& Schonle, A.

Ruins of Modernity. Durham: Duke University Press. p. 17-27.

Kulper, P. (2013). A world below. Architectural Design, Vol. 83, (No. 5), p. 56-63. doi.org/10.1002/ad.1663

Laudanno, C. (2009). Iberê Camargo Foundation. ArtNexus. Vol. 8, (No. 74).

McCarter, R. (1997). Pamphlet Architecture No. 12;

Building Machines. (Second Edition). Paperback. Princeton

Architectural Press. New York.

Murakami, T. (2018). Virgil Abloh's "PAY PER VIEW", featured in Kaikai Kiki Gallery.

O'Hagan, S. (2012). Renzo Piano: The Shard Is My Dream Building. The Independent. Independent Digital News and Media.
Panero, J. (2014). Ground Zero. The New Criterion. Vol. 33, (Number 1). p. 51.

Phillips, J. Whaling - Modern whaling and whale watching. Te Ara - the Encyclopedia of New Zealand, http://www.TeAra. govt.nz/en/video/6282/whaling-in-cook-strait (accessed 26 April 2020)

Picon, A. (2000). Anxious Landscapes: From the Ruin to Rust. Translated Bates, K. Grey Room 01. (6), p. 64-83. doi:10.1162/152638100750173065.

Prickett, N. (2002). The Archeology of New Zealand Shore Whaling. Wellington: Department of Conservation. ISBN 0-47S-2220S-4. p. 73-78.

Reiter, W. (1999). Vessels and Fields. (First Edition). Princeton Architectural Press. New York.

Rossi, A. (1982). The Architecture of the City. Cambridge: MIT Press.

Schonle, A. (2010). Ruins of Modernity. Vol. 48, (Issue 1). Durham: Duke University Press (Politics, History and Culture).

Spiller, N. (2018). Celebrating the Marvellous: Surrealism in Architecture. (Architectural Design). (First Edition) Paperback. Academy Press.

Spiller, N. (2011). "SPILLERS WORLD." Lebbeus Woods Wordpress. Accessed 20 March, 2020 https://lebbeuswoods. wordpress.com/2011/03/19/spillers-world/ 
Benjamin, W. (1977). The Origin of German Tragic Drama

(Radical Thinkers). Paperback. New York and London: Verso.

p. 177-180

Yanong, L. (2019). Virgil Abloh: "Figures of Speech". Featured in The Fashion Map.

Yarwood, V. (2002). Thar she blows - A grisly trade in bone

and oil. (Issue 60). NZ Geographic. Accessible at: https://

www.nzgeo.com/stories/thar-she-blows-a-grisly-trade-in-

bone-and-oil/

Zumthor, P. (2010). Thinking Architecture. (3rd, expanded ed). Basel: Birkhauser. Print. 


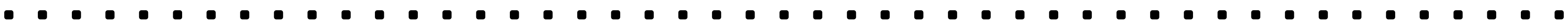

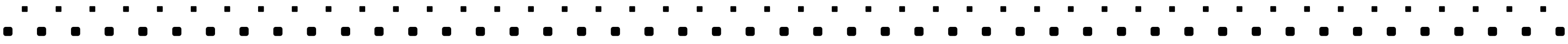

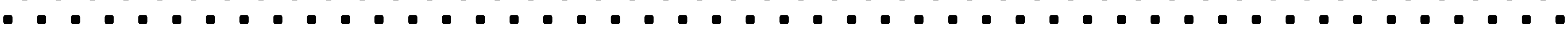

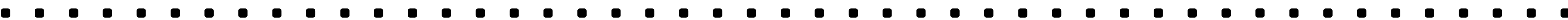

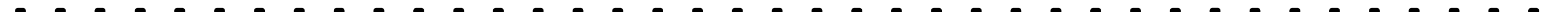

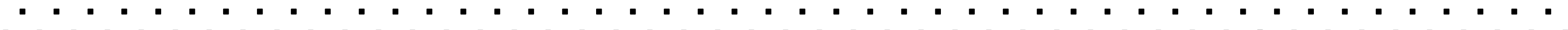

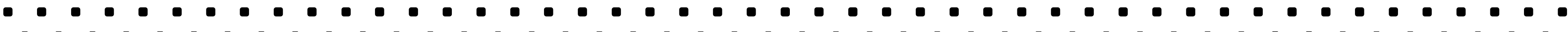

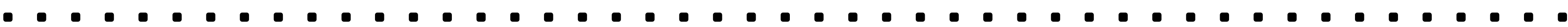

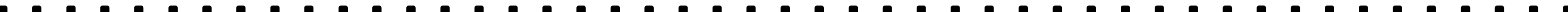

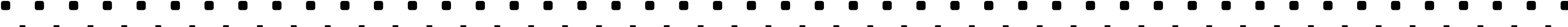

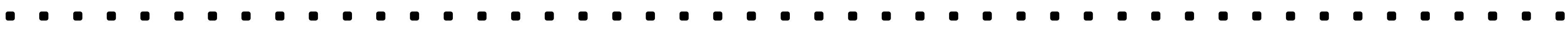

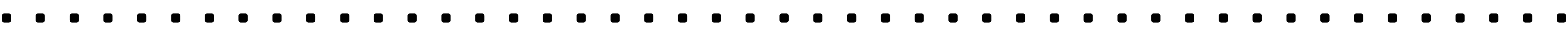

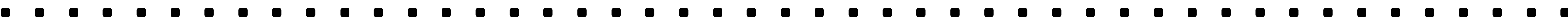

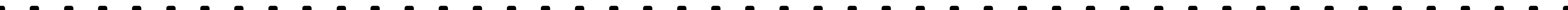

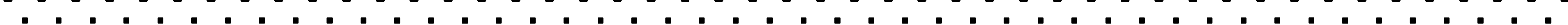

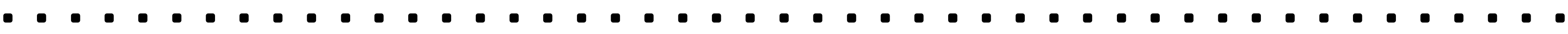

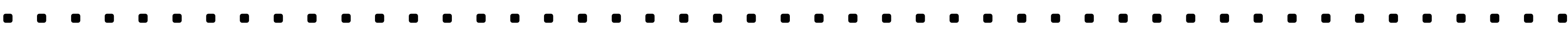

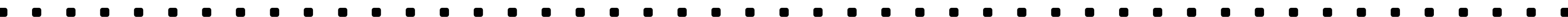
0.00

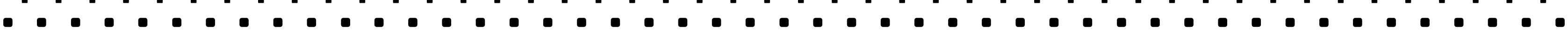
๑

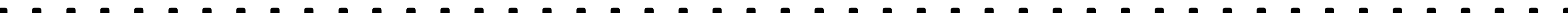

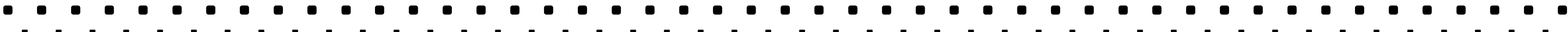

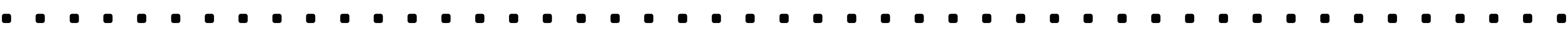

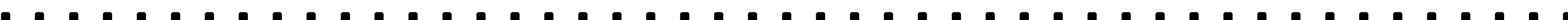

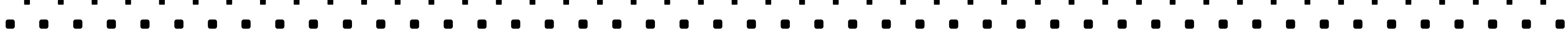


List of Figures
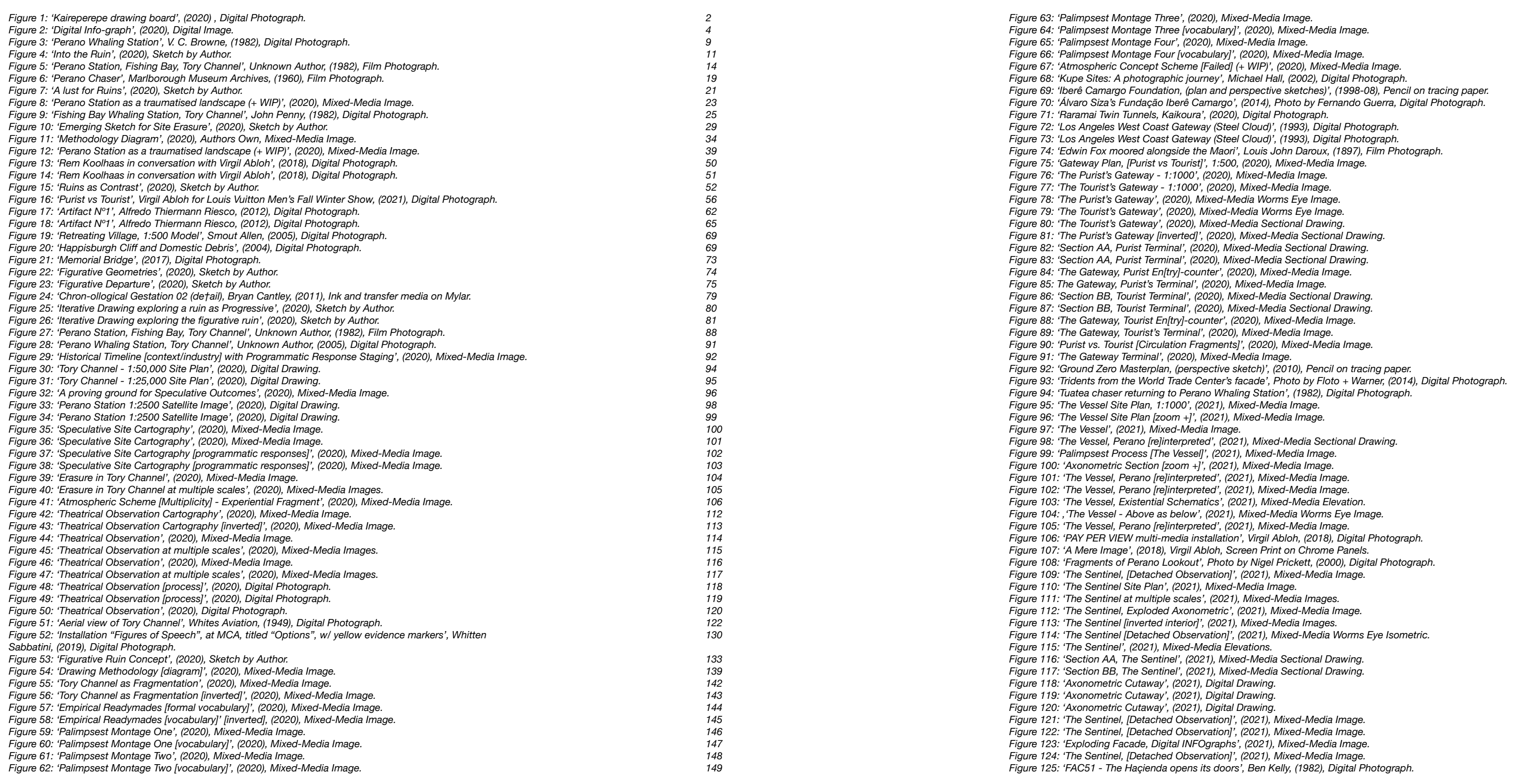
$t+t$ 